Article

\title{
Human Peripheral Blood Gamma Delta T Cells: Report on a Series of Healthy Caucasian Portuguese Adults and Comprehensive Review of the Literature
}

\author{
Sónia Fonseca ${ }^{1,+}$, Vanessa Pereira ${ }^{2,+}$, Catarina Lau ${ }^{1, \ddagger}$, Maria dos Anjos Teixeira ${ }^{1, \ddagger}$, \\ Marika Bini-Antunes ${ }^{3}$ and Margarida Lima ${ }^{1, *}$ \\ 1 Laboratory of Cytometry, Unit for Hematology Diagnosis, Department of Hematology, Hospital de Santo \\ António (HSA), Centro Hospitalar Universitário do Porto (CHUP), Unidade Multidisciplinar de Investigação \\ Biomédica, Instituto de Ciências Biomédicas Abel Salazar, Universidade do Porto (UMIB/ICBAS/UP), \\ 4099-001 Porto Porto, Portugal; soniafonseca.hematologiaclinica@chporto.min-saude.pt (S.F.); \\ catarinalau.hematologiaclinica@chporto.min-saude.pt (C.L.); \\ mariateixeira.hematologiaclinica@chporto.min-saude.pt (M.d.A.T.) \\ 2 Department of Clinical Pathology, Centro Hospitalar de Vila Nova de Gaia/Espinho (CHVNG/E), \\ 4434-502 Vila Nova de Gaia, Portugal; v_lpereira@hotmail.com \\ 3 Laboratory of Immunohematology and Blood Donors Unit, Department of Hematology, Hospital de Santo \\ António (HSA), Centro Hospitalar Universitário do Porto (CHUP), Unidade Multidisciplinar de \\ Investigação Biomédica, Instituto de Ciências Biomédicas Abel Salazar, Universidade do \\ Porto (UMIB/ICBAS/UP), 4099-001Porto, Portugal; u08095@chporto.min-saude.pt \\ * Correspondence: margaridalima@chporto.min-saude.pt; Tel.: + 351-22-20-77-500 \\ + These authors contributed equally to this work. \\ $\ddagger$ These authors contributed equally to this work.
}

Received: 10 February 2020; Accepted: 13 March 2020; Published: 16 March 2020

\begin{abstract}
Gamma delta T cells (Tc) are divided according to the type of $\mathrm{V} \delta$ and $\mathrm{V} \gamma$ chains they express, with two major $\gamma \delta$ Tc subsets being recognized in humans: $V \delta 2 V \gamma 9$ and $V \delta 1$. Despite many studies in pathological conditions, only a few have quantified the $\gamma \delta$ Tc subsets in healthy adults, and a comprehensive review of the factors influencing its representation in the blood is missing. Here we quantified the total $\gamma \delta$ Tc and the V $\delta 2 / V \gamma 9$ and $V \delta 1$ Tc subsets in the blood from 30 healthy, Caucasian, Portuguese adults, we characterized their immunophenotype by 8-color flow cytometry, focusing in a few relevant Tc markers (CD3/TCR- $\gamma \delta, C D 5, C D 8)$, and costimulatory (CD28), cytotoxic (CD16) and adhesion (CD56) molecules, and we examined the impacts of age and gender. Additionally, we reviewed the literature on the influences of race/ethnicity, age, gender, special periods of life, past infections, diet, medications and concomitant diseases on $\gamma \delta$ Tc and their subsets. Given the multitude of factors influencing the $\gamma \delta$ Tc repertoire and immunophenotype and the high variation observed, caution should be taken in interpreting "abnormal" $\gamma \delta$ Tc values and repertoire deviations, and the clinical significance of small populations of "phenotypically abnormal" $\gamma \delta$ Tc in the blood.
\end{abstract}

Keywords: gamma delta T cells; gamma delta $\mathrm{T}$ cell repertoire; Vdelta1; Vdelta2; Vgamma9; normal reference values; human herpes viruses; human cytomegalovirus; immune response

\section{Introduction}

Gamma delta T cells $(\gamma \delta \mathrm{Tc})$ are a minor Tc population in the peripheral blood (PB) from human adults [1-3]. They are usually divided according the type of $\mathrm{V} \delta$ chain they express at the $\mathrm{T}$ cell receptor (TCR), with two major $\gamma \delta$ Tc subsets being relatively well characterized in humans in terms of tissue distribution, antigen $(\mathrm{Ag})$ recognition patterns and functional properties: $\mathrm{V} \delta 2$ and $V \delta 1 \mathrm{Tc}$. V $\delta 2$ chain 
associates with $\mathrm{V} \gamma 9$ in most cases, defining a $\mathrm{V} \gamma 9 \mathrm{~V} \delta 2$ Tc population that is unique to humans and other primates, whereas $\mathrm{V} \delta 1 \mathrm{Tc}$ use diverse $\mathrm{V} \gamma$ regions [4-6].

Gamma delta Tc is involved in the immune response to viruses, intracellular bacteria, and parasitic protozoa [7-14]; is involved in immune surveillance against hematological neoplasms and solid tumors [15-17] and the pathogenesis of autoimmune diseases [18,19]; and abnormal percentages and/or absolute numbers of $\gamma \delta$ Tc involving different $\gamma \delta$ Tc subsets have been reported in the PB and in different organs from patients with various pathological conditions. V $\delta 2$ Tc respond mainly to intracellular bacteria and solid tumors, while V $\delta 1 \mathrm{Tc}$, resident mainly in tissues, is used mostly in the defense against viruses and malignancies, although this dichotomy is not absolute. In addition, $\gamma \delta$ T-cells are being explored in cell-based immunotherapy [20-22].

In parallel to the low frequency of $\gamma \delta$ Tc, lymphoproliferative disorders (LPD) of $\gamma \delta$ Tc are rare disease conditions. These comprise $\gamma \delta$ Tc large granular lymphocyte (LGL) proliferations, including $\gamma \delta$ Tc LGL leukemia, defined as clonal expansions of cytotoxic $\gamma \delta$ Tc, which have an indolent clinical course and often coexist with cytopenias and other pathologies [23,24], and hepatosplenic and other $\gamma \delta$ Tc lymphomas, which usually have an aggressive clinical course, poor response to chemotherapy and short survival [25-28].

Gamma delta Tc expressing V $\gamma 9 \mathrm{~V} \delta 2$ are known to identify microbe-derived (e.g., (E)-4-hydroxy-3methyl-but-2-enyl pyrophosphate, HMB-PP) and host-derived (e.g., isopentenyl pyrophosphate, IPP) phosphorylated metabolites ("phosphoantigens") originating from the isoprenoid metabolic mevalonate and non-mevalonate pathways, through association with butyrophilin 3A1 (B3A1) [29,30]. V 81 Tc are mainly located in the epithelia, where they interact with cells expressing stress-induced ligands through interaction with natural killer group 2 member D (NKG2D) activating receptors [31,32]. The former includes major histocompatibility complex (MHC) class I polypeptide-related chains (MIC) $A$ and $B$, and UL16 binding proteins (ULBP), also termed retinoic acid early transcripts (RAET1) [31,32]. Although being first described for V $\delta 1$ Tc, interactions of the ULBP and MIC-A/B molecules with

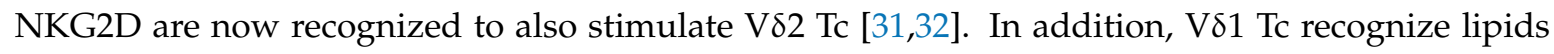
and glycolipids presented by CD1d molecules [33-35]. Finally, both $\gamma \delta$ Tc subsets, V $\delta 1$ and V $\delta 2$, are activated by heat shock proteins (HSP) [36,37], which are upregulated in stressed, infected and malignant cells [4-6].

In humans, the size of the circulating pool of $\gamma \delta \mathrm{Tc}$ is small at birth, and it expands during the first decade of life, from less than $2 \%$ of cord blood (CB) Tc to around $5 \%$ of PB Tc in adults [38]. V $\delta 1$ Tc, which is the dominant $\gamma \delta$ Tc subset at birth, becomes progressively less represented, and the initially small $\mathrm{V} \gamma 9 \mathrm{~V} \delta 2$ subset already predominates by 10 years of age [38]. In the PB from human adults, most $\gamma \delta$ Tc expresses $\mathrm{V} \delta 2$, usually paired with $\mathrm{V} \gamma 9$, the remainder being mostly $\mathrm{V} \delta 1$, and some $\mathrm{V} \delta 3$ or $\mathrm{V} \delta 5$, all paired with different $\mathrm{V} \gamma$ chains [38].

Analysis of PB lymphocyte subsets by flow cytometry (FCM) has become an essential tool in the investigation of different pathological conditions. As such, evaluation of the TCR V $\beta, V \gamma$ and V $\delta$ repertoires, using monoclonal antibodies (mAbs) specific for distinct families of the TCR V regions, has been used to study the $\alpha \beta$ and $\gamma \delta$ Tc compartments in inflammatory, infectious, autoimmune and neoplastic diseases [23,39-47]. Additionally, different types of $\gamma \delta$ Tc neoplasms have been demonstrated to originate preferentially from distinct $\mathrm{V} \gamma / \mathrm{V} \delta$ Tc subsets $[23,40,48]$. In accordance, for appropriate diagnosis and follow-up of patients, correct interpretation of the laboratory results from normal reference intervals is required, and more information is needed about the correspondent $\mathrm{V}$ usage in healthy individuals. For TCR-V $\beta$, there have already been a large number of studies performed in normal PB samples $[41,49,50]$. For TCR-V $\gamma$ and $V \delta$, however, fewer studies have been published so far, and several focused on only one $\gamma \delta$ Tc subset [51-56].

We report on the percentages and absolute numbers of $\gamma \delta$ Tc and $V \delta 1$ and $V \delta 2 / V \gamma 9$ Tc subsets in the PB from a series of 30 Caucasian, Portuguese healthy adults, and the main phenotypic characteristics of these cells, concerning the expression of CD3, TCR, CD5, CD8, CD16, CD28 and CD56 molecules. Additionally, we review the literature on the subject, focusing on the influences of race/ethnicity, 
age, gender, special periods of life, past immunological experiences, diet, medications and past and concomitant diseases on $\gamma \delta$ Tc and their subsets. We emphasize the role of $\gamma \delta$ Tc in mediating the immune response in viral infections, and the abilities of different types of viruses, mainly herpesviruses, to activate $\gamma \delta$ Tc and modulate $\gamma \delta$ Tc repertoires. Finally, using "take-home-messages," we highlight some key points about $\gamma \delta$ Tc we want the reader to remember.

\section{Materials and Methods}

\subsection{Study Population}

A cross-sectional study was conducted with 30 Caucasian Portuguese healthy adults (blood donors, excluding those who were giving blood for the first time), 18 males and 12 females, with a median age of 47 years, ranging from 26 to 66 years (mean \pm standard deviation of $48 \pm 14$ years). All gave informed consent to participate, and the procedures followed the Helsinki Declaration.

\subsubsection{Clinical Criteria for Blood Donation}

Before blood donation, blood donors were required to fill out an informed consent form and a self-assessment/self-exclusion standardized questionnaire, to ensure that they were in good health, and free of infections and other diseases potentially transmissible by blood; they were also interviewed by a clinician, being submitted to a brief clinical assessment and physical evaluation which included height, blood pressure and capillary hemoglobin levels. Criteria for blood donation followed the Guidelines on Assessing Donor Suitability for Blood Donation recommended by the World Health Organization (WHO), and the Portuguese legislation.

\subsubsection{Screening of Blood Transmitted Diseases and Other Blood Tests}

As part of routine blood donation procedures, blood donors were tested for human immunodeficiency viruses (HIV) type 1 and 2 (HIV-1 and 2), human T cell lymphoma/leukemia viruses type I and II (HTLV-I and II) and hepatitis B (HBV) and C (HCV) viruses; and for Treponema Pallidum, using serological studies. In addition, nucleic acid tests were performed for HIV, HCV and HIV. Alanine aminotransferase serum levels were also determined.

\subsection{Blood Samples}

Peripheral blood samples obtained by venipuncture were collected in BD Vacutainer tubes (Becton Dickinson-BD, San Jose, CA, USA) containing tri-potassium ethylenediaminetetraacetic acid (K3-EDTA) and processed within $6 \mathrm{~h}$ of collection.

\subsection{Blood Cell Counts}

Blood cell counts were obtained using a Coulter LH750 automated hematology analyzer (Beckman Coulter-BC, Miami, FL, USA).

\subsection{Flow Cytometry}

\subsubsection{Monoclonal Antibodies and Cell Staining}

Whole blood was analyzed by ten-parameter eight-color FCM using the following mouse anti-human mAbs from BC/Immunotech (IOT), BD or Endogen: anti-V 11 (clone TS8.2; Endogen), anti-V 22 (clone Immu389; BC/IOT) or anti-V $\gamma 9$ (clone Immu360; BC/IOT), conjugated with fluorescein isothiocyanate (FITC); anti-CD56, conjugated with phycoerythrin (PE) (clone NCAM16.2; BD); anti-TCR $-\gamma \delta$ conjugated with PE-Cyanine 5.5 (PC5.5) (clone Immu510; BC/IOT); anti-CD28, conjugated with PE-Cyanine 7 (PC7) (clone CD28.2; BC/IOT); anti-CD5, conjugated with allophycocyanin (APC) (clone L17F12; BD); anti-CD3, conjugated with allophycocyanin cyanine 7 (APC-H7) (clone SK7; BD); anti-CD16, conjugated with violet 450 (V450) (clone 3G8; BD); and anti-CD8, conjugated with krome 
orange $(\mathrm{KO})$ (clone B9.11; BC/IOT). These mAbs were combined in three distinct tubes, in order to quantify and characterize $\gamma \delta$ Tc and their subsets: $\mathrm{V} \delta 1$ or $\mathrm{V} \delta 2$ or $\mathrm{V} \gamma 1 / \mathrm{CD} 56 / \mathrm{TCR}-\gamma \delta / \mathrm{CD} 28 / \mathrm{CD} 5 / \mathrm{CD} 3 /$ CD16/CD8. According to the manufacturer, the "pan" anti-TCR- $\gamma \delta$ mAb used (clone IMMU510) recognizes all $\gamma \delta \mathrm{Tc}$, regardless of the variable genes or junction regions they express.

Briefly, $100 \mu \mathrm{L}$ of PB was incubated for $15 \mathrm{~min}$ at room temperature with the appropriated $\mathrm{mAbs}$, subjected to red blood cell lysis and leukocyte fixation using the BD FACS ${ }^{\mathrm{TM}}$ lysing solution, washed once, suspended in phosphate buffered saline and then acquired in the flow cytometer.

\subsubsection{Flow Cytometer and Sample Acquisition}

Sample acquisition was performed in a BD FACSCanto II $^{\mathrm{TM}}$ flow cytometer calibrated according to the EuroFlow Standard Operating Procedures [57]. External quality control assessment was achieved by participating in the EuroFlow Quality Assurance program [58]. A median number of 443,388 events was recorded per tube and stored as FCM standard (.fcs) 3.0 files, for subsequent analysis.

\subsubsection{Data Analysis}

Flow cytometry data files were analyzed using the Infinicyt ${ }^{\mathrm{TM}}$ software (Cytognos, Salamanca, Spain). The following percentages were calculated: lymphocytes (among white blood cells, WBC); Tc (among lymphocytes and among WBC); $\gamma \delta$ Tc (among total Tc and among WBC); V $\delta 1, V \delta 2$ and $\mathrm{V} \gamma 9 \mathrm{Tc}$ (among $\gamma \delta \mathrm{Tc}$ and among WBC); CD5+, CD8+, CD16+, CD28+ and CD56+ Tc (among $\gamma \delta \mathrm{Tc}$, and among $\mathrm{V} \delta 1, \mathrm{~V} \delta 2$ and $\mathrm{V} \gamma 9 \mathrm{Tc}$ ). In addition, the median fluorescence intensities (MedFI) of CD3, TCR- $\gamma \delta, C D 5, C D 8, C D 16, C D 28$ and CD56 expression were evaluated in each cell population: $\gamma \delta$ Tc and $\alpha \beta$ Tc (i.e., TCR- $\gamma \delta$ negative Tc), and $V \delta 1, \mathrm{~V} \delta 2$ and $\mathrm{V} \gamma 9 \mathrm{Tc}$.

The strategy used for cell gating and analysis is depicted in Figure 1.

Absolute counts of total Tc, $\gamma \delta \mathrm{Tc}$ and V $\delta 1 ; \mathrm{V} \delta 2$; and $\mathrm{V} \gamma 9 \mathrm{Tc}$, expressed as numbers of cells $/ \mu \mathrm{L}$, were calculated using a dual platform method, in which total WBC counts were obtained from the hematology analyzer.

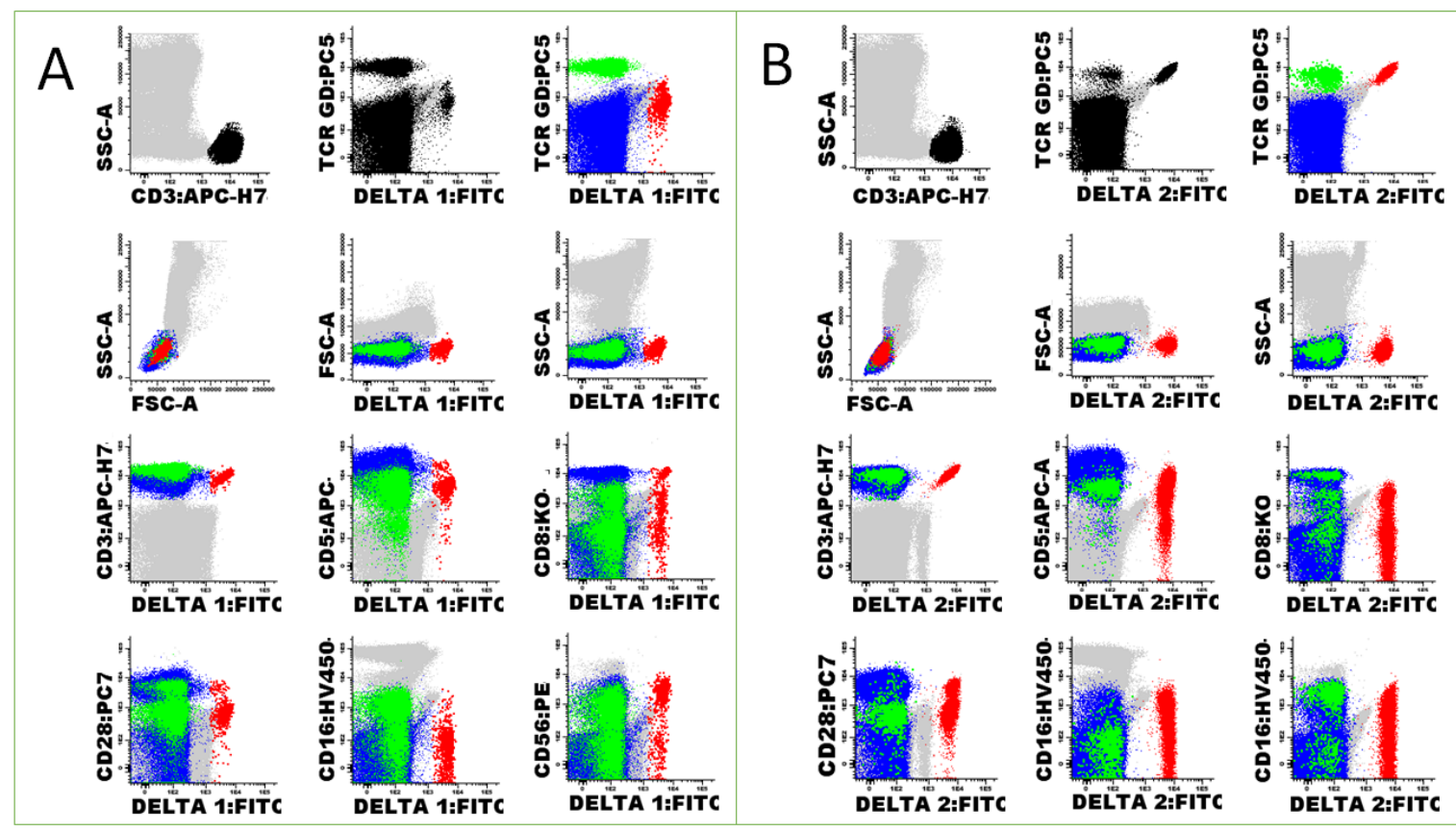

Figure 1. Dot plots obtained from the peripheral blood of a healthy adult stained with an eight-color panel of mAbs, which includes a pan anti-TCR- $\gamma \delta \mathrm{mAb}$, anti-V $\delta 1$ (A) or an anti-V $\delta 2(\mathbf{B}) \mathrm{mAbs}$, and mAbs against CD3, CD5, CD8, CD28, CD16 and CD56. V $81 \mathrm{Tc}$ (A, red dots) represented 5.6\% of $\gamma \delta \mathrm{Tc}$, $0.9 \%$ of Tc and $0.2 \%$ of WBC, whereas V $\delta 2$ Tc (B, red dots) were $94.4 \%$ of $\gamma \delta$ Tc, $14.5 \%$ of Tc and $2.7 \%$ of WBC. Strategy used for $\gamma \delta$ Tc gating and analysis: After removing debris and cell aggregates using the 
SSC-A/FSC-A and the FSC-H/FSC-A dot plots, Tc were identified based on the expression of CD3 (first dot plot in the first row of each panel, black dots), and observed for the staining with anti-TCR $\gamma \delta$ and the $\mathrm{mAb}$ specific for each of the $\mathrm{V} \gamma$ or $\mathrm{V} \delta$ regions (second dot plot in the first row of each panel, black dots). Afterwards, $\gamma \delta$ Tc expressing the putative $V$ chain were painted in red; other $\gamma \delta$ Tc were painted in green; and TCR- $\gamma \delta$ negative Tc (i.e., $\alpha \beta$ Tc) were painted in blue (third dot plot in the first row of each panel). Finally, $\gamma \delta$ Tc were analyzed for their FSC and SSC (second row of each panel) and for the expression of cell surface molecules (third and fourth rows of each panel).

\subsection{Statistics}

\subsubsection{Statistic Software}

Data were entered first into an Excel table and then exported to MedCalc Statistical Software version 16.4.3 (MedCalc Software, Ostend, Belgium) for analysis.

\subsubsection{Descriptive Statistics}

Descriptive statistics included the absolute and relative frequencies for the qualitative variables, and medians, minimum and maximum values for the quantitative continuous variables. Although several parameters did not have normal distributions (please see below), the mean and standard deviation (SD) values were also calculated in order to facilitate comparisons with other studies.

\subsubsection{Statistic Tests}

The normality of distributions was assessed using the D'Agostino-Pearson (D'A-PT) and the Kolmogorov-Smirnov (KST) tests. Of the variables tested, the hypothesis of normal distribution was accepted for all the hematological parameters, including the WBC and platelet counts; the hemoglobin levels; and the percentages and absolute numbers of neutrophils and monocytes (Table S1 in Supplementary Materials). Concerning the immunological parameters, a normal distribution was accepted for the percentages of Tc (among lymphocytes) and Tc counts, and for the percentages of $\mathrm{V} \delta 1, \mathrm{~V} \delta 2$ and $\mathrm{V} \gamma 9 \mathrm{Tc}$ (among $\gamma \delta \mathrm{Tc}$ ). It was rejected for the absolute numbers and percentages of $\gamma \delta$ Tc (among Tc); the ratios between V $\delta 2$ and V $\delta 1$ Tc; and the absolute numbers of $\gamma \delta$ Tc, including the $\mathrm{V} \delta 1, \mathrm{~V} \delta 2$ and V $\gamma 9$ Tc subsets (Table S1). As several of the studied variables did not present a normal distribution and given the small size of the sample, non-parametric tests were used for statistics. The coefficients of skewness and kurtosis were used as measures for the degree of symmetry and for the degree of tailedness in the variable distribution.

The Mann-Whitney U test (MWUT) and the Wilcoxon signed rank test (WSRT) were used to compare continuous variables of two independent and two related samples, respectively. The F-test (FT) was applied to compare the variances. The Spearman rank correlation test (SRCT) was used to evaluate the association between two variables. In addition, linear regression analysis was performed. The Tukey test (TT) was used to check for outliers, which were subsequently excluded when indicated. $p$ values less than 0.05 were considered statistically significant.

\subsubsection{Normal Reference Intervals}

The National Committee for Clinical Laboratory Standards (NCCLS), and the Clinical and Laboratory Standards Institute (CLSI) guidelines C28-A2 [59] and EP28-A3C [60], were followed for estimating percentiles and their $90 \%$ confidence intervals; percentiles were calculated as the observations corresponding to rank $\mathrm{r}=p^{*}(n+1)$ and confidence intervals were calculated using integer ranks. The 95th reference interval (reference range) was calculated using three methods [60]: (a) as 97.5th percentile of the ordering data, assuming a normal distribution; (b) using a non-parametrical percentile method, recommended by CLSI for large samples ( $n \geq 120)$; and (c) using a "robust method" 
in which the confidence intervals for the two limits are calculated using the percentile bootstrap method (percentile interval method) recommended by the CLSI for small samples $(n<120)$.

\subsubsection{Graphics}

Graphics are displayed as box-and-whisker plots in which the central box represents the values from the lower to upper quartile (25th-75th percentile), the middle line represents the median and the horizontal line extends from the minimum to the maximum value, excluding "outliers" which are displayed as separate squares. The outliers were defined as values that were smaller than the lower quartile minus 1.5 times the interquartile range, or larger than the upper quartile plus 1.5 times the interquartile range.

\subsection{Literature Review}

A literature review of the studies published was conducted in the PubMed, to locate potentially relevant, peer-reviewed original and review manuscripts indexed in the MEDLINE database.

\section{Results}

\subsection{Hematological Counts, Lymphocyte Populations and Gamma Delta T Cells}

The median, minimum and maximum; the mean \pm SD of the hematological counts and percentages; and the absolute numbers of the PB cell populations analyzed are shown in Table 1. The median percentage of $\gamma \delta$ Tc among Tc was of $4.3 \%$, ranging from $1.2 \%$ to $15.4 \%$, and the median absolute number of $\gamma \delta$ Tc was 63/ $\mu \mathrm{L}$, ranging from 9 to 253 cells/ $\mu \mathrm{L}$ (Table 1 ).

Table 1. Hematological counts and percentages and absolute numbers of total peripheral blood $\gamma \delta$ Tc in the study population of healthy adults.

\begin{tabular}{|c|c|c|c|}
\hline Method (Equipment) & Parameter & Median (Min -Max) & Mean \pm SD \\
\hline \multirow{7}{*}{$\begin{array}{l}\text { Automated hematology } \\
\text { analyzer (Coulter LH750) }\end{array}$} & Hemoglobin (g/dl) & $14.4(11.8-16.9)$ & $14.2 \pm 1.3$ \\
\hline & Platelets $\left(\times 10^{9} / \mathrm{L}\right)$ & $207(133-332)$ & $225 \pm 56$ \\
\hline & WBC (cells $/ \mu \mathrm{L})$ & $6700(4800-9800)$ & $6927 \pm 1362$ \\
\hline & Neutrophils (\% WBC) & $58.1(44.1-78.8)$ & $58.7 \pm 7.7$ \\
\hline & Neutrophils (cells/ $\mu \mathrm{L}$ ) & 4034 (2506-7092) & $4097 \pm 1121$ \\
\hline & Lymphocytes (\% WBC) & $30.8(18.3-47.8)$ & $30.6 \pm 7.2$ \\
\hline & Lymphocytes (cells $/ \mu \mathrm{L}$ ) & 2087 (1122-3704) & $2102 \pm 601$ \\
\hline \multirow{6}{*}{$\begin{array}{l}\text { Flow cytometry (BD FACS } \\
\text { Canto II) }\end{array}$} & Tc (\% Lymphocytes) & $72.8(57.4-85.6)$ & $72.8 \pm 6.9$ \\
\hline & $\gamma \delta \mathrm{Tc}(\% \mathrm{Tc})$ & $4.3(1.2-15.4)$ & $5.0 \pm 3.6$ \\
\hline & $\mathrm{V} \delta 1 \mathrm{Tc}(\% \gamma \delta \mathrm{Tc})$ & $24.6(3.5-65.7)$ & $27.4 \pm 16.1$ \\
\hline & $\mathrm{V} \delta 2 \mathrm{Tc}(\% \gamma \delta \mathrm{Tc})$ & $66.4(15.7-96.0)$ & $60.0 \pm 22.5$ \\
\hline & $\mathrm{V} \gamma 9 \mathrm{Tc}(\% \gamma \delta \mathrm{Tc})$ & $69.1(25.7-96.5)$ & $66.3 \pm 20.5$ \\
\hline & $\mathrm{V} \delta 2 / \mathrm{V} \delta 1$ ratio & $2.7(0.3-27.7)$ & $4.1 \pm 5.4$ \\
\hline \multirow{5}{*}{ Dual platform } & Tc $($ cells $/ \mu \mathrm{L})$ & 1547 (782-2356) & $1533 \pm 454$ \\
\hline & $\gamma \delta \mathrm{Tc}(\mathrm{cells} / \mu \mathrm{L})$ & $63(9-253)$ & $78 \pm 60$ \\
\hline & 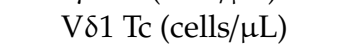 & $16(2-75)$ & $23 \pm 19$ \\
\hline & 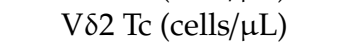 & $39(6-243)$ & $63 \pm 62$ \\
\hline & V $\gamma 9$ Tc $($ cells $/ \mu \mathrm{L})$ & $40(7-247)$ & $68 \pm 62$ \\
\hline
\end{tabular}

Abbreviations: Tc, T cells. See Table S1 for information concerning testing for normal distribution and identification of outliers.

\subsection{Gamma Delta T cell Immunophenotype}

Overall, $\gamma \delta$ Tc exhibited higher CD3, CD16 and CD56 levels, and they had lower levels of CD5 and CD28 expression than $\alpha \beta$ Tc, as evaluated by the MedFI of each marker in the correspondent Tc population; additionally, the levels of CD8 expression were significantly lower than those observed on CD8 + high $\alpha \beta$ Tc (MWUT and WSRT: $p<0.001$ in all cases) (Figure 2A). 
An appreciable fraction of $\gamma \delta$ Tc were terminal effector cytotoxic Tc (i.e., LGL), as defined by absence of CD28 expression (58.4\%; 19.4-91.0\%), concomitantly to the expression of CD16 and/or CD56 in a variable fraction of cells $(45.3 \% ; 12.3-77.3 \%$ ) (Figure 2B and Table S2); in some cases, $\gamma \delta$ Tc had high levels of CD16 and/or CD56 expression, suggesting a fully differentiated cytotoxic phenotype, whereas in other cases, low levels of these molecules were observed. CD5 and CD8 were also expressed in a variable fraction of $\gamma \delta \mathrm{Tc}$, with median and range values of $93.2 \%(57.1-98.9 \%)$ and $28.6 \%(11.5-66.9 \%)$, respectively (Figure 2B and Table S2).

A

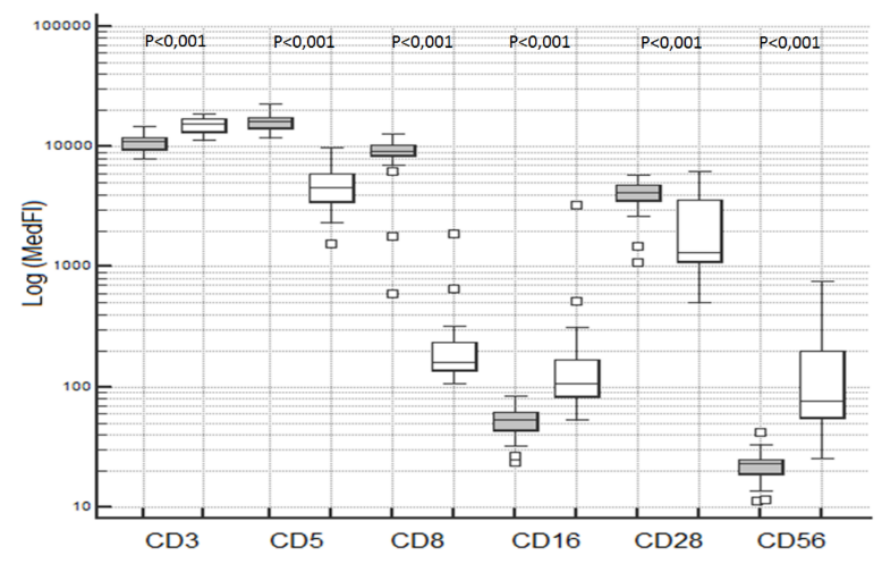

B

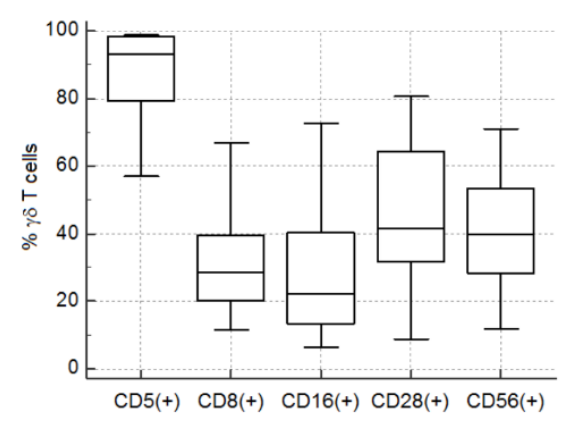

Figure 2. Median fluorescence intensities observed for CD3, CD5, CD8, CD16, CD28 and CD56 molecules on blood $\alpha \beta$ (gray boxes) and $\gamma \delta$ Tc (white boxes) (A), and percentages of CD5+, CD8+, $\mathrm{CD} 16+, \mathrm{CD} 28+$ and CD56+ cells among peripheral blood $\gamma \delta \mathrm{Tc}(\mathbf{B})$ in the study population of healthy adults. $p$ values (Mann-Whitney $\mathrm{U}$ test) are indicated inside the graphic.

The percentage of CD28- cells among $\gamma \delta$ Tc (median: 58.4\%; range: 19.4-91.1\%) was significantly higher than that observed in the $\alpha \beta$ Tc compartment (median: $14.0 \%$; range: $1.6-52.4 \%$ ) (MWUT: $p<0.001$ ), and correlated positively with the percentages of CD5- (SRCT: $p=0.001 ; \mathrm{r}=0.554$ ), CD8+ (SRCT: $p=0.018 ; \mathrm{r}=0.430), \mathrm{CD} 16+($ SRCT: $p<0.001 ; \mathrm{r}=0.665)$ and CD56+ (SRCT: $p=0.026 ; \mathrm{r}=0.406)$ $\gamma \delta$ Tc (Figure 3).

\subsection{Gamma Delta T Cell Subsets}

As expected, most peripheral blood $\gamma \delta$ Tc were $\mathrm{V} \delta 2+$ and $\mathrm{V} \gamma 9+$ (median values: $66.4 \%$ and $69.1 \%$, respectively), and most of the remaining $\gamma \delta$ Tc were $\mathrm{V} \delta 1+$ (median value: $24.6 \%$ ) (Table 1 and Figure $4 \mathrm{~A}$ ). However, the percentages of $\mathrm{V} \delta 1, \mathrm{~V} \delta 2$ and $\mathrm{V} \gamma 9 \mathrm{Tc}$ were highly variable, varying from 3.5 to $65.7 \%, 15.7$ to $96.0 \%$ and 25.7 to $96.5 \%$, respectively. In one-third of the individuals, the $\mathrm{V} \gamma 9 \mathrm{~V} \delta 2$ subset accounted for $<50 \%$ of the circulating $\gamma \delta$ Tc (Figure $4 \mathrm{~B}$ ).

The median fraction of $\gamma \delta$ Tc that were negative for $\mathrm{V} \delta 1$ and $\mathrm{V} \delta 2$ was $9.2 \%$, ranging from $0.0 \%$ to $52.2 \%$, corresponding to cells expressing V $\delta$ chains that were not tested, such as V $\delta 3$ and V $\delta 5$, because the $\mathrm{mAbs}$ with these specificities are no longer available in the market (Figure 4). Similarly, the median fraction of $V \gamma 9$ negative $\gamma \delta$ Tc was $30.9 \%$, ranging from $5.5 \%$ to $72.8 \%$, probably corresponding to 
cells expressing other $\mathrm{V} \gamma$ regions (e.g., $\mathrm{V} \gamma 2, \mathrm{~V} \gamma 3, \mathrm{~V} \gamma 4, \mathrm{~V} \gamma 5$, and $\mathrm{V} \gamma 8$ ) that were not tested for the same reasons.
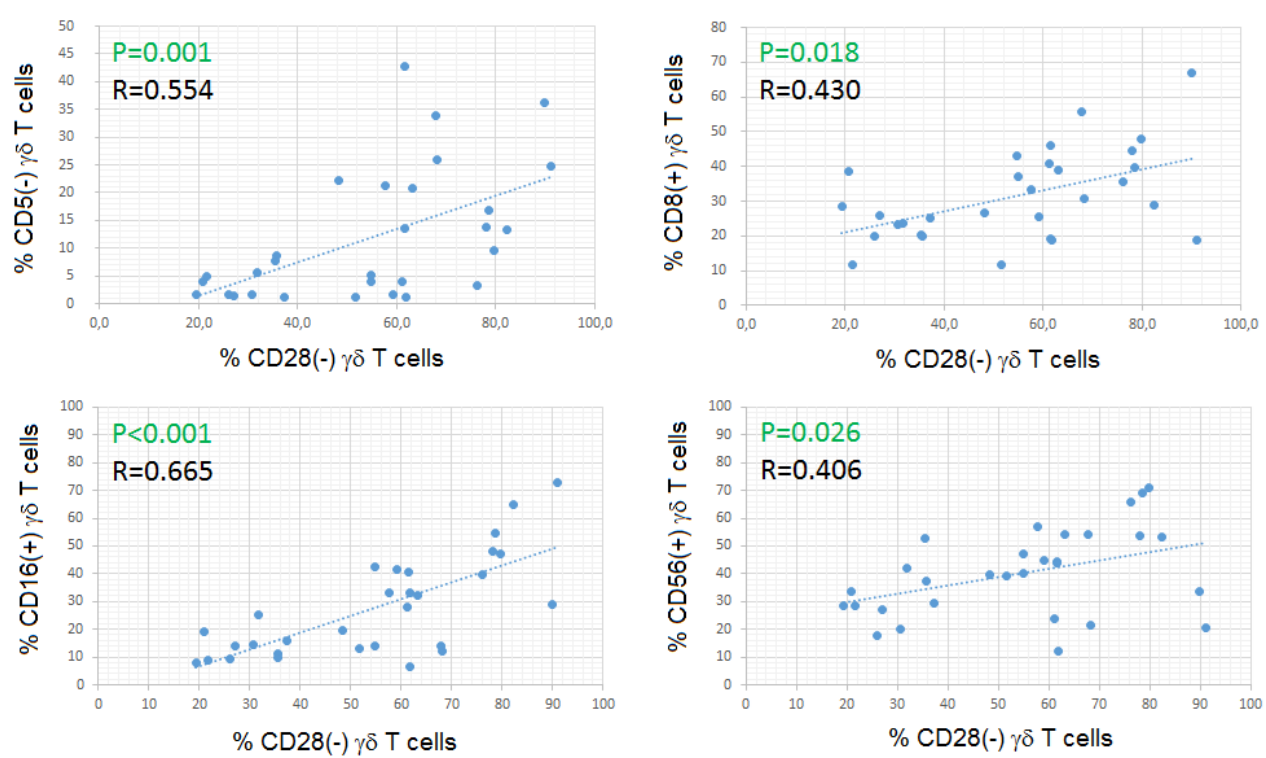

Figure 3. Correlations between the percentages of CD5-, CD8+, CD16+ and CD56+ cells, and the percentages of CD28- $\gamma \delta$ Tc in in the study population of healthy adults. The Spearman's rank correlation coefficients and $p$ values are indicated inside the graphics.

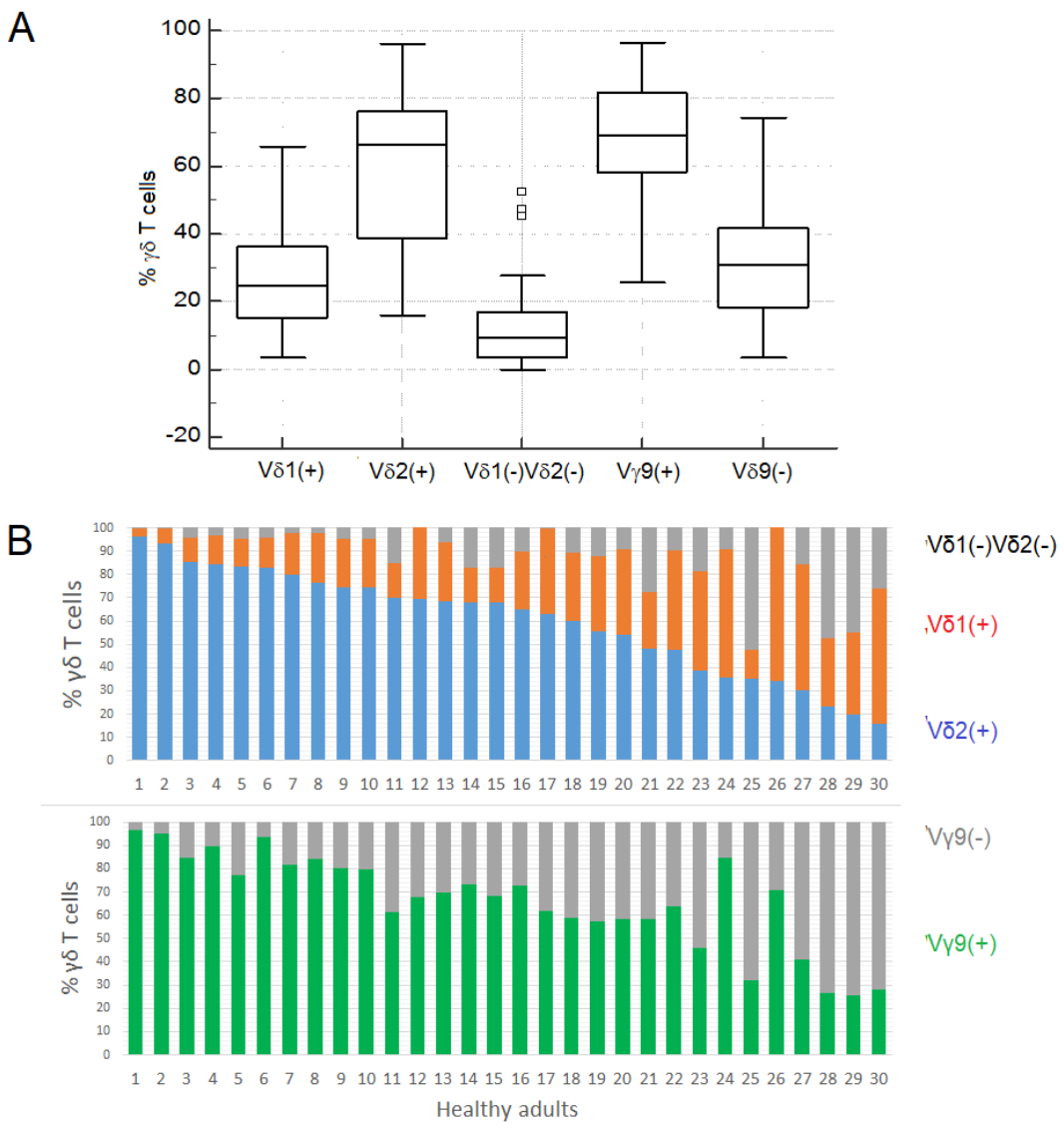

Figure 4. Percentages of $\mathrm{V} \delta 1+, \mathrm{V} \delta 2+, \mathrm{V} \delta 1-\mathrm{V} \delta 2-, \mathrm{V} \gamma 9+$ and $\mathrm{V} \gamma 9$ - Tc among peripheral blood $\gamma \delta \mathrm{Tc}$ in the whole study population (A) and in each of the healthy adults studied, numbered by order of decreasing percentage of $\mathrm{V} \delta 2+\mathrm{Tc}$, followed by order of decreasing percentage of $\mathrm{V} \delta 1+\mathrm{Tc}(\mathbf{B})$. 
Compared to V $\delta 2$ Tc, V $\delta 1$ Tc had lower levels of CD3, TCR- $\gamma \delta, C D 5$ and CD28, and higher levels of CD8 expression, as evaluated by the MedFI (MWUT and WSRT: $p<0.001$ in all cases); no significant differences were observed for the MedFI of CD16 and CD56 expression in total V $\delta 1$ and V $\delta 2$ Tc (MWUT and WSRT: $p>0.05$ in both cases) (Figure 5A).

V81 Tc also had a higher fraction of CD5- and CD28- cells, compared to V82 Tc (MWUT and WSRT: $p<0.001$ in both cases), and no significant differences were observed for the percentages of CD16+ and CD56+ cells (MWUT and WSRT: $p>0.05$ in both cases) (Figure 5B and Table S2). Moreover, in 13 cases (43\%), part of the V $\delta 1$, but not of V $\delta 2 \mathrm{Tc}$, had high and homogeneous CD8 expression, at levels that approximated those observed in CD8+high $\alpha \beta$ Tc.
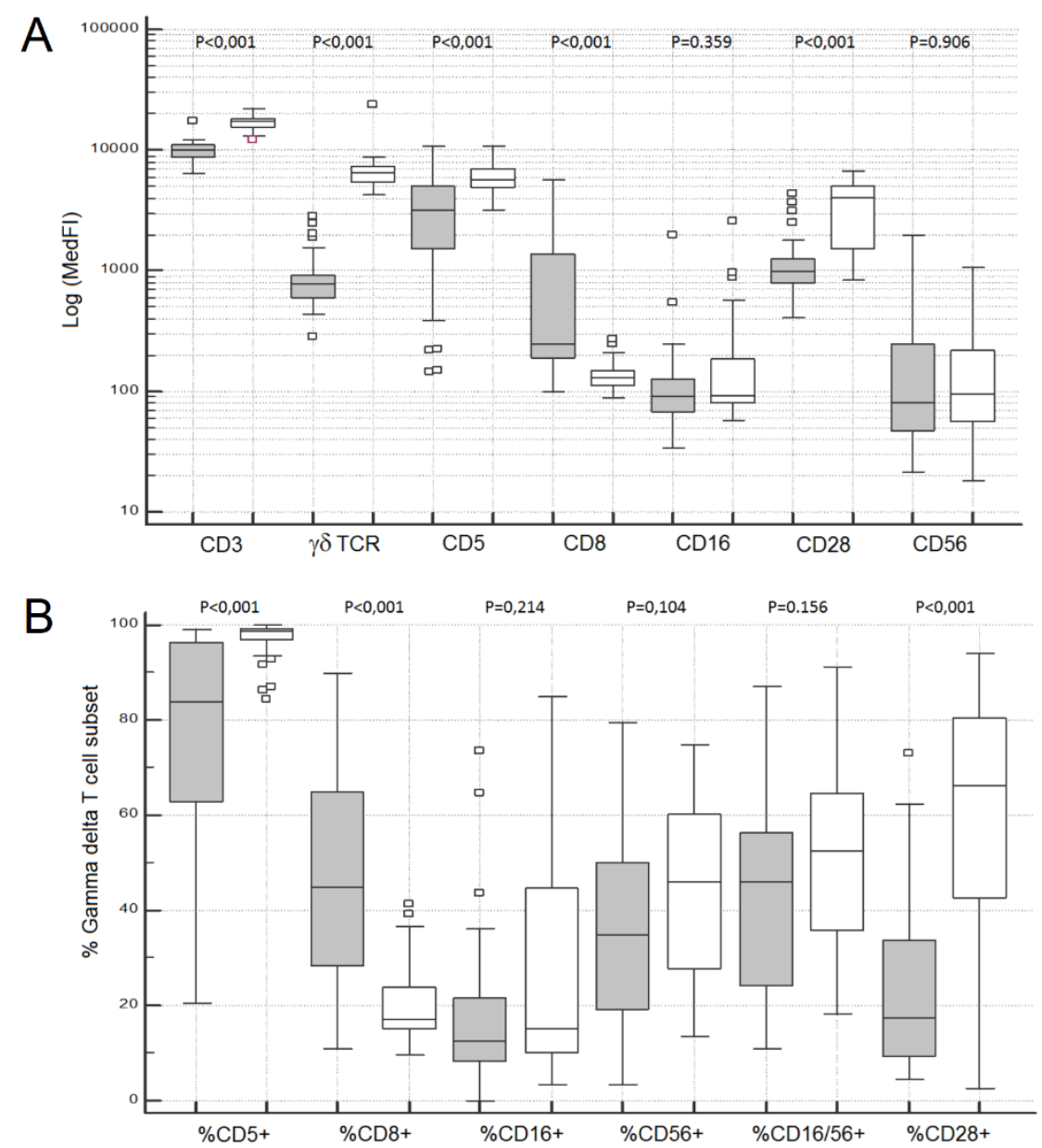

Figure 5. Median fluorescence intensity (A) and percentages of positive cells (B) observed for CD3, TCR- $\gamma \delta$, CD5, CD8, CD16, CD28 and CD56 molecules in the peripheral blood V $\delta 1$ (gray boxes) and $\mathrm{V} \delta 2$ (white boxes) Tc from the study population of healthy adults.

\subsection{Age Based Analysis}

Both the percentages and absolute numbers of $\gamma \delta$ Tc had a modest negative correlation with age (Figure 6).

In agreement with what has been said above, healthy adults 46 to 70 years old had lower percentages and lower absolute numbers of $\gamma \delta$ Tc, compared to those 20 to 45 years old (MWUT: $p=0.010$ and 0.014 , respectively) (Figure 7 and Table S3). In addition, the absolute numbers of all the $\gamma \delta$ Tc subsets were lower in older subjects, although reaching significance only for $\mathrm{V} \gamma 9 \mathrm{~V} \delta 2 \mathrm{Tc}$ (MWUT: $p=0.008$ for $\mathrm{V} \gamma 9$ and $p=0.035$ for V $\delta 2$ ) (Figure 7 and Table S3). The percentages of V $\delta 1, \mathrm{~V} \delta 2$ and $V \gamma 9$ Tc among $\gamma \delta$ Tc did not differ significantly between the mentioned age groups (Figure 7 and Table S3). 

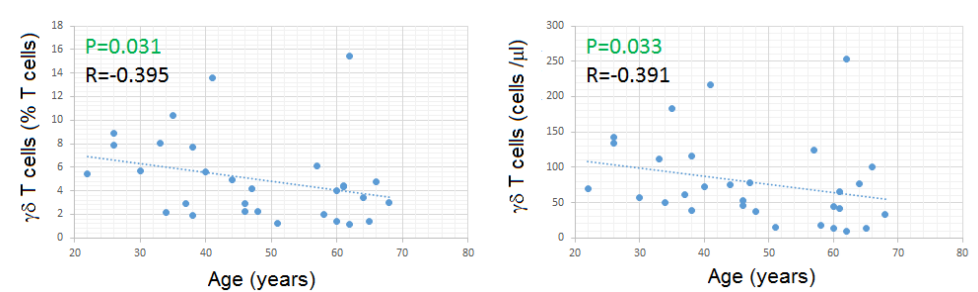

Figure 6. Correlations between age and the percentages and absolute numbers of $\gamma \delta$ Tc in the study population of healthy adults. The Spearman's rank correlation coefficients and $p$ values are indicated inside the graphics.
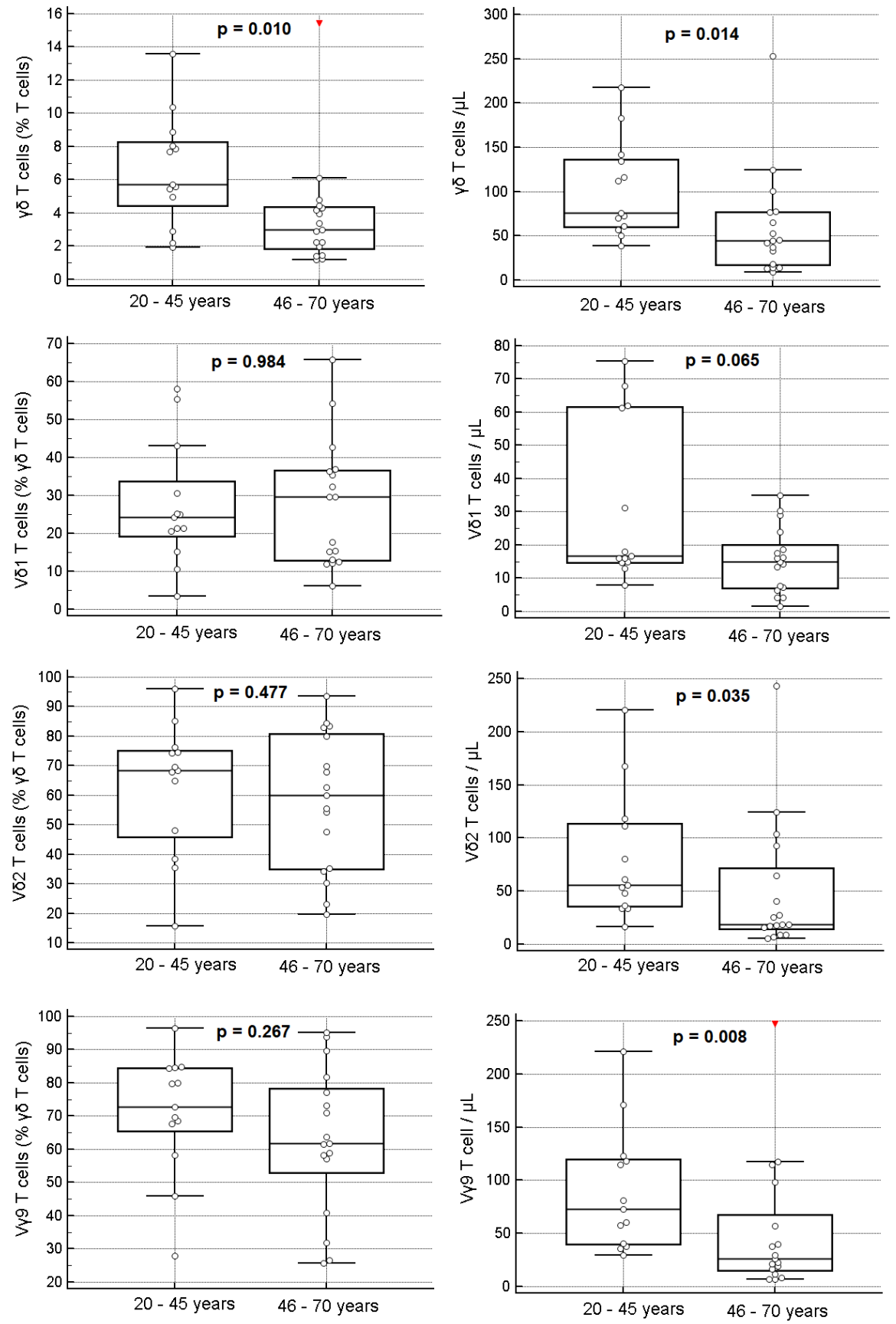

Figure 7. Percentages and absolute numbers of total $\gamma \delta \mathrm{T}$ cells and $\gamma \delta \mathrm{T}$ cells expressing V $\delta 1, \mathrm{~V} \delta 2$, and $\mathrm{V} \gamma 9$, in the peripheral blood from healthy adult individuals 20-45 years old, compared to those 46-70 years old. $p$ values (Mann-Whitney $U$ test) are indicated inside the graphics. 
Contrarily to what happened with CD28- $\alpha \beta$ Tc, and especially CD8+high CD28- $\alpha \beta$ Tc, both of which increased with aging, we found no significant correlation between the fraction of CD28- $\gamma \delta$ Tc and age, nor between CD16 $+\gamma \delta \mathrm{Tc}$, and age (Figure 8); unexpectedly, the fraction of CD56+ $\gamma \delta \mathrm{Tc}$ correlated inversely with age (SRCT: $p=0.018 ; \mathrm{R}=-0.427$ ) (Figure 8 ), this correlation being specific for V82Tc (SRCT: $p=0.025 ; \mathrm{R}=-0.408$ ).
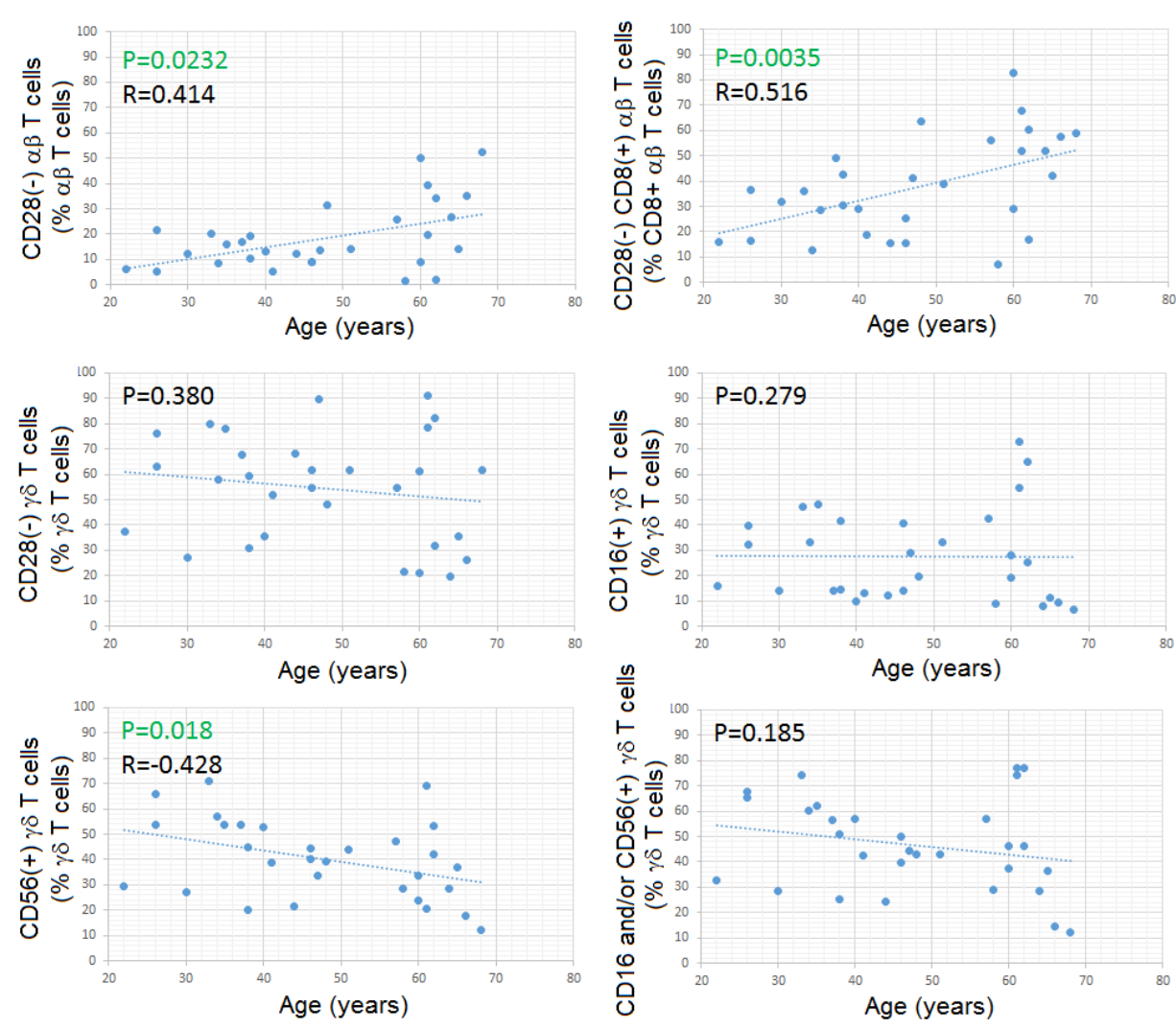

Figure 8. Correlations between age and the percentages and absolute numbers of CD28- $\alpha \beta$ Tc, CD8+CD28- $\alpha \beta$ Tc, CD28- $\gamma \delta$ Tc, CD16+ $\gamma \delta$ Tc, CD56+ $\gamma \delta$ Tc and CD16/CD56+ $\gamma \delta$ Tc in the study population of healthy adults. The Spearman's rank correlation coefficients and $p$ values are indicated inside the graphics.

\subsection{Gender-Based Analysis}

The percentages and absolute numbers of $\gamma \delta$ Tc and V $\delta 1, \mathrm{~V} \delta 2$ and $\mathrm{V} \gamma 9$ Tc subsets showed no significant gender differences when the overall study population was considered (Figure 9 and Table S4) (MWUT: $p>0.05$ in all cases), although the median values of $\gamma \delta$ Tc and V $\delta 2 \mathrm{~V} \gamma 9$ Tc were lower in males than in females. We also noticed that the percentages of $\gamma \delta$ Tc were more variable in males than in females (FT: $p<0.001$ ), as were their absolute numbers (FT: $p=0.003$ ), due mainly to variations in the V $\delta 2 \mathrm{~V} \gamma 9$ Tc subset (Figure 9 and Table S4). 

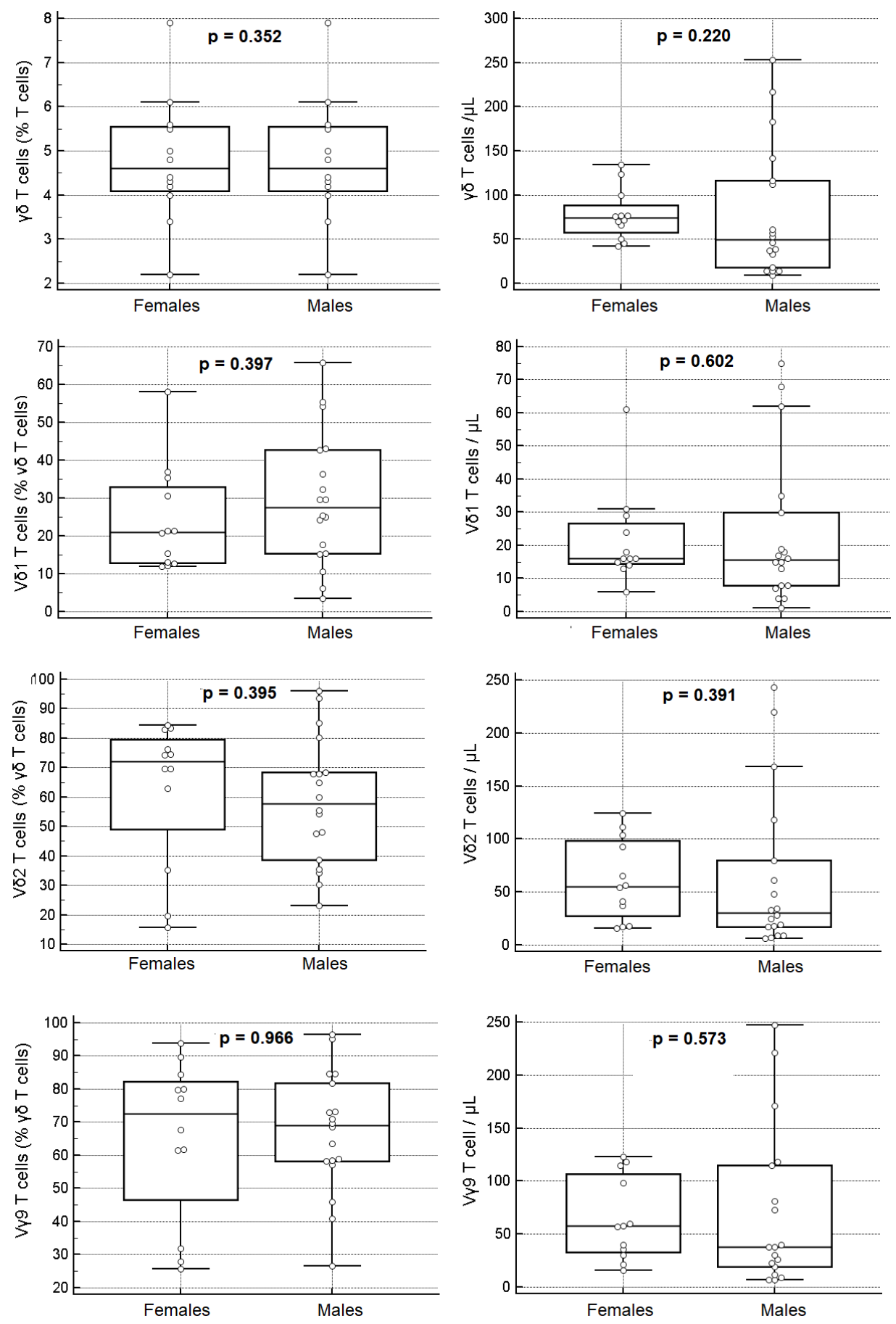

Figure 9. Percentages and absolute numbers of total $\gamma \delta \mathrm{T}$ cells and $\gamma \delta \mathrm{T}$ cells expressing V $\delta 1$, V $\delta 2$ and $\mathrm{V} \gamma 9$, in the peripheral blood of healthy adult females, compared to healthy adult males. $p$ values (Mann-Whitney $\mathrm{U}$ test) are indicated inside the graphics.

\subsection{Combined Analysis for Age and Gender}

When age and gender were considered together, we found significant differences between males and females concerning the relation between various immunological parameters and aging, despite the low number of individuals in each group. Indeed, a negative correlation was found for both the percentages and absolute numbers of $\gamma \delta$ Tc and age in males (SRCT: $p=0.046$ and $p=0.007$, respectively), but not in females (SRCT: $p>0.05$ in both cases), and similar observations were done for the absolute numbers of V $\delta 1, \mathrm{~V} \delta 2$ and V $\gamma 9$ Tc (SRCT males: $p=0.016, p=0.012$, and $p=0.018$, 
respectively; SRCT females: $p>0.05$ in all cases) (Figure 10, Table S5 and Figure S1). In contrast, the percentages of $\mathrm{V} \delta 1, \mathrm{~V} \delta 2$ and $\mathrm{V} \gamma 9 \mathrm{Tc}$ subsets among total $\gamma \delta$ Tc and the ratio between $\mathrm{V} \delta 2$ and $\mathrm{V} \delta 1 \mathrm{Tc}$ did not correlate with age, neither in females nor in males (SRCT: $p>0.05$ ) (Figure 10, Table S5 and Figure S1).

A
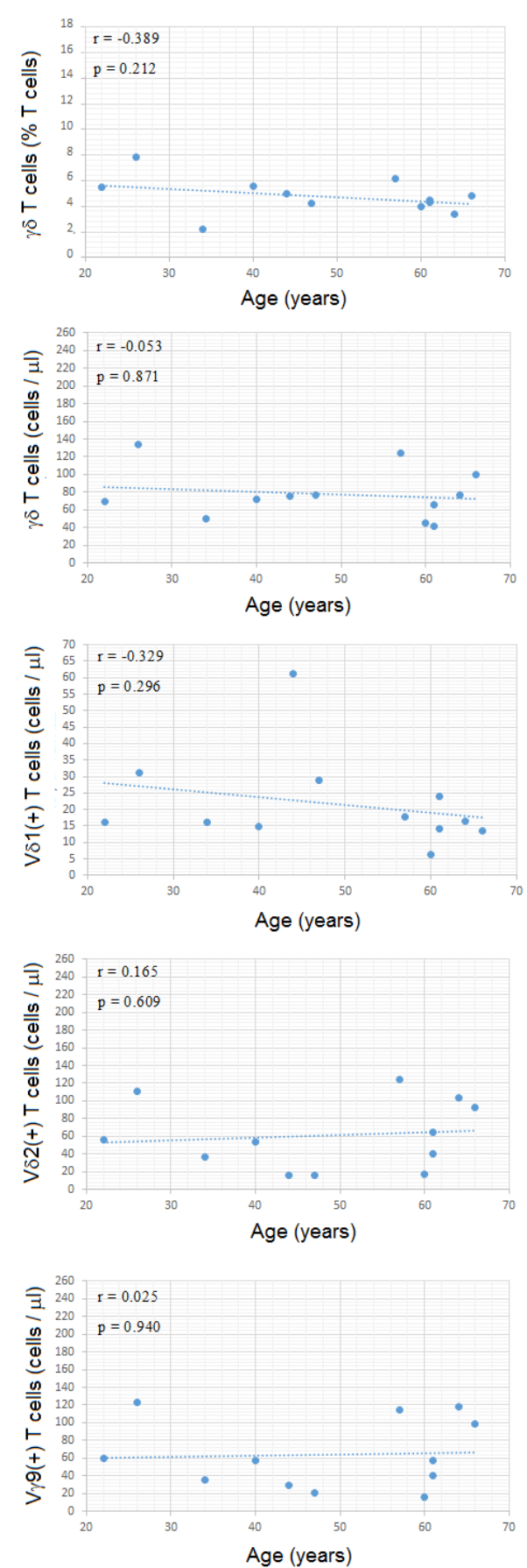

B
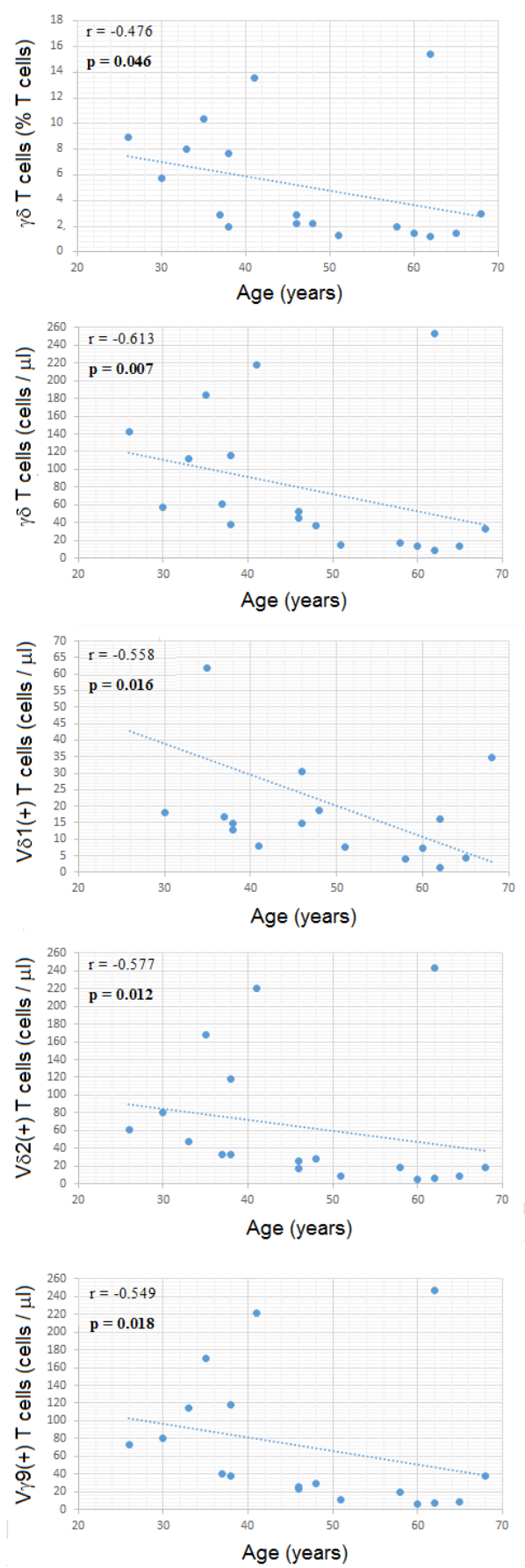

Figure 10. Relations between age and the percentages and absolute numbers of $\gamma \delta \mathrm{Tc}$, and the absolute numbers of the $\gamma \delta$ Tc subsets in the study population of healthy adult females (A) and males (B). The Spearman's rank correlation coefficients and $p$ values are indicated inside the graphics.

Linear regression analysis revealed that circulating $\gamma \delta$ Tc drop less strikingly in women than in men, as demonstrated by the slope of the regression equations obtained in females and males 
(Table S6). Curiously, considering the age groups mentioned above (20-45 and $46-70$ years old), there were significant differences between females and males in older but not in younger individuals, with older males having significantly lower percentages and lower counts of $\gamma \delta$ Tc (MWUT: $p=0.006$ and $p=0.019$, respectively) (Table S7). Older males also had a tendency for having lower counts of V $\delta 2$ and $\mathrm{V} \gamma 9 \mathrm{Tc}$, when compared to older females (MWUT: $p=0.064$ in both cases) (Table S7). The percentages of $V \delta 1, V \delta 2$ and $V \gamma 9$ Tc among total $\gamma \delta$ Tc and the $V \delta 1$ Tc counts did not differ significantly between the younger and older healthy subjects, either in males or in females (MWUT: $p>0.05$ in all cases) (Table S7).

\subsection{Normal Reference Intervals}

In an attempt to obtain the normal reference interval for the parameters analyzed, we calculated the 95th ranges using three different methods: 97.5th percentile of the ordering data, assuming a normal distribution; non-parametrical percentile method; and "robust method" also known as percentile bootstrap method, recommended by the CLSI for small samples [60]. Due to the high variation observed, and possibly also because of the small study sample, the lower limits of many parameters had negative values regardless of the method used, and, in some cases, the upper limits of percentage values exceeded $100 \%$, which is also not biologically possible (Table S8).

\section{Discussion and Literature Review}

Despite the enormous progress made over the last decade, the development of $\gamma \delta$ Tc is still puzzling, as are their immunophenotypic and functional properties. Biological characteristics such as race, age, gender and past immunological experiences have been shown to affect the relative and absolute numbers of the $\gamma \delta$ Tc and their subsets in the $\mathrm{PB}$, and their immunophenotype and function. However, only a few studies were performed in healthy subjects, and it is hardly difficult to compare the results obtained, not only due to the variations in the study populations (e.g., race, age, and gender) but also because of missing data and differences in reporting of the results obtained. The latter comprises graphic representation vs. tabulated data; percentages vs. absolute numbers; and different types of summary statistics, including diverse measures of central tendency (e.g., median and mean) and spread (e.g., standard deviation, range and quartiles). Thus, further comprehensive studies of $\gamma \delta$ Tc from healthy persons are needed to better understand the normal immune system and to interpret the data obtained from patients.

Contrasting with the high number of studies investigating the $\mathrm{V} \gamma / \mathrm{V} \delta$ usage in pathological conditions, normal reference intervals for $\mathrm{V} \delta 1, \mathrm{~V} \delta 2$ and $\mathrm{V} \gamma 9 \mathrm{Tc}$ are not available, and only a few studies aimed to quantify the $\gamma \delta$ Tc subsets in healthy adults were performed to date. To the best of our knowledge, our study is one that provides more information about the population evaluated and the variables analyzed, despite the small sample size.

\subsection{Total $\gamma \delta T$ Cells in the $P B$}

There is controversy about expressing the PB lymphocyte populations using relative (\%) or absolute cell counts (cells $/ \mu \mathrm{L}$ ). For instance, absolute CD4+ Tc counts are an important measure of the immune status and are preferred over the percentage of CD4+ Tc in predicting the risk of acquired immunodeficiency syndrome (AIDS)-related illnesses in HIV+ individuals [61]. Absolute cell counts are also considered for the diagnostic criteria of many LPD, as defined by the WHO Classification of Tumors of Hematopoietic and Lymphoid Tissues [62]. However, only a few studies on $\gamma \delta$ Tc have expressed the results as absolute cell counts.

The absolute numbers of $\gamma \delta$ Tc obtained in our study (median values of $63 \gamma \delta \mathrm{Tc} / \mu \mathrm{L}$, ranging from 9 to $253 ; 78 \pm 60 \gamma \delta \mathrm{Tc} / \mu \mathrm{L})$, and their percentages among total Tc $(4.3 \%$, ranging from $1.2 \%$ to $15.4 \%$; $5.0 \pm 3.6$ ), were similar to those obtained in a series of 157 Spanish healthy adults (78 males median age of 57 years), who had a median percentage of $\gamma \delta$ Tc of $3.1 \%$ (among total lymphocytes), ranging from 0.2 to 14.0, and a median count of $70 \gamma \delta \mathrm{Tc} / \mu \mathrm{L}$, varying from 5 to 319 [63]. Grossly speaking, similar 
results were obtained by Michishita et al. in a series of 120 Asian Japanese healthy adults (53 males mean age of 40 years: $68 \pm 44 \gamma \delta \mathrm{Tc} / \mu \mathrm{L}$, ranging from 4 to 207) [55].

\subsection{Gamma-Delta $T$ subsets in the $P B$}

The development of mAbs specific for TCR $\mathrm{V} \gamma$ and $\mathrm{V} \delta$ families allowed for the characterization of the complete TCR- $\gamma \delta$ repertoire since the late 80 s, although most of the initial studies have analyzed Tc clones derived from PB instead of PB Tc [64-66]. Concerning to the $V \gamma$ chains, the first studies have identified $\mathrm{V} \gamma 9$ as the most frequently used $\mathrm{V} \gamma$ chain in the PB from healthy adult persons, followed by $\mathrm{V} \gamma 2 / \mathrm{V} \gamma 3$. In accordance, it was found that, on average, $80 \%$ of the circulating $\gamma \delta$ Tc expressed $\mathrm{V} \gamma 9,12 \% \mathrm{~V} \gamma 2 / \mathrm{V} \gamma 3,4 \% \mathrm{~V} \gamma 4$, and $8 \%$ of one of the remaining $\mathrm{V} \gamma$ regions $(\mathrm{V} \gamma 5, \mathrm{~V} \gamma 8, \mathrm{~V} \gamma 10$ or $\mathrm{V} \gamma 11)$; in addition, $83 \%$ of the $\mathrm{V} \gamma 9$ Tc used $\mathrm{V} \delta 2$ and only $13 \%$ used $\mathrm{V} \delta 1$, whereas the majority $(70 \%)$ of $\mathrm{V} \gamma 2 / \mathrm{V} \gamma 3 / \mathrm{V} \gamma 4$-bearing Tc co-expressed $\mathrm{V} \delta 1$ and only $18 \%$ co-expressed $\mathrm{V} \delta 2$. In overall, the majority $(50-90 \%)$ of $\gamma \delta$ Tc in the PB of healthy adults were shown to use $\mathrm{V} \gamma 9$ and $\mathrm{V} \delta 2$ as variable elements [65].

In studies where TCR-V $\gamma$ and $V \delta$ families were expressed as percentages, these were calculated as fractions of total lymphocytes [54,55], total Tc [53] or $\gamma \delta$ Tc [23,51,53]. Expressing the results as percentages of total Tc or total lymphocytes may introduce bias related to variations in the percentages of $\gamma \delta$ Tc among Tc and the percentages of Tc among lymphocytes, respectively. Thus, similarly to what happens in the studies of TCR-V $\beta$ Tc repertoire, in which the results are usually presented as percentages of cells expressing each of the TCR-V $\beta$ families among the corresponding $\alpha \beta$ Tc population (e.g., CD4+ or CD8+ Tc), we consider it to be more suitable to express the results of the $\mathrm{V} \gamma$ and $\mathrm{V} \delta \mathrm{T}$ cell repertoires relative to $\gamma \delta$ Tc.

In 2006, Sandberg et al. analyzed the expression of V $81, \mathrm{~V} \delta 2$ and $V \gamma 9$ in the PB from 15 healthy Danish adults, and they reported frequencies of $\gamma \delta$ Tc expressing the mentioned variable regions ranging from $10 \%$ to $15 \%$ for $\mathrm{V} \delta 1,80-85 \%$ for $\mathrm{V} \delta 2$ and $85-90 \%$ for $\mathrm{V} \gamma 9$ [23]. These ranges are narrower than those obtained in our study (4-66\%, 16-96\% and 26-97\%, respectively). However, in Sandberg's study, the age and gender of the study population were not mentioned, nor were the median, mean or SD values of the percentages obtained for the analyzed Tc populations.

In the Japanese study of Michishita et al. published in 2011, the average \pm SD and minimummaximum values of blood V $\delta 1$ and V $\delta 2$ Tc were $16 \pm 12(2-52)$ and $43 \pm 36(1-153)$ cells/ $\mu \mathrm{L}$ [55].

Other relevant papers published more recently-which included two small $[67,68]$ and two large $[69,70]$ studies where healthy individuals were divided in age groups and according to the CMV status-have mainly graphic presentations, and the descriptive summary statistics were not tabulated or presented in the text, impeding the possibility of those being used as reference values; besides, the supplementary material from one of the largest studies is available only for authorized users [69]. These studies will be discussed further below, regarding the effect of age and CMV status on $\gamma \delta$ Tc.

\subsection{Effect of Race/Ethnicity}

We found only three small studies reporting on the influence of race/ethnicity on the percentages of $\gamma \delta$ Tc and their subsets in the PB [51,54,71].

Esin et al. (1996) investigated the frequency of $\gamma \delta$ Tc in the PB of 26 Turkish, 24 Swedish, 35 Asian Japanese and 14 Asian non-Japanese, healthy volunteers, and they found that the median percentages of $\gamma \delta$ Tc (among Tc) in the Turkish and Asian non-Japanese were significantly higher than those observed in the Swedish and Asian Japanese groups, with Turkish and Asian non-Japanese having a higher incidence of cases with $>10 \% \gamma \delta$ Tc compared to Swedish and Asian Japanese [71].

Hviid et al. (2000) analyzed the percentages of total $\gamma \delta$ Tc and V $\delta 1$ Tc in the PB from 10 Caucasian Danish and eight (West African) Ghanaian healthy adults (age and gender not provided) [51]. They observed that the absolute numbers of total Tc did not differ between groups, but the frequencies of $\gamma \delta$ Tc (among total Tc) in West Africans were about twice those of Caucasian Europeans, mainly due to an increased representation of V $\delta 1$ Tc. However, data ware presented mainly graphically, and most descriptive statistic values were not provided [51]. 
Some years later, Cairo et al. (2010) obtained PB specimens from 32 African American (13 males median age of 47 years) and 33 Caucasian American (14 males median age of 41 years) blood donors [54], and they found significantly higher fractions of $\mathrm{V} \delta 2 \mathrm{Tc}$ in the first group, with mean \pm SD percentages of V $\delta 2$ cells in total lymphocytes of $3.7 \% \pm 4.4 \%$ and $1.2 \% \pm 2.1 \%$, respectively.

In the Michishita' series (2011) of Asian Japanese healthy adults mentioned above, the mean percentages of V $82 \mathrm{Tc}$ among total lymphocytes were 3.0\% $\pm 3.1 \%$ [55]; thus, they were between those observed by Cairo et al. for African American and Caucasian American adults [54]. In our series of Caucasian European adults, the correspondent percentages were $2.4 \% \pm 2.1 \%$.

With respect to absolute cell counts, the values obtained in the Japanese series were $43 \pm 36$ (1-153) V $\delta 2 \mathrm{Tc} / \mu \mathrm{L}$ and $16 \pm 12(2-52) \mathrm{V} \delta 1 \mathrm{Tc} / \mu \mathrm{L}$ [55]. The other series mentioned above did not provide the absolute cell numbers. However, some studies in which the $\gamma \delta$ Tc subsets were investigated in pathological conditions have provided the values obtained in healthy subjects used as controls. As an example, Re et al. (2005) evaluated 10 Caucasian, Italian, healthy volunteers (median age of 39 years; gender not available) as controls for patients with melanoma, and they found $83 \pm 34 \mathrm{~V} \delta 2 \mathrm{Tc} / \mu \mathrm{L}$ and $31 \pm 12$ V $\delta 1 \mathrm{Tc} / \mu \mathrm{L}$ [72]. In addition, Henriques et al. (2016) studied 20 Caucasian, Portuguese, healthy volunteers (mean age of 52 years; 4 males) as controls for patients with Scleroderma, and they found mean counts of $\mathrm{V} \gamma 9+\mathrm{V} \delta 2+$ and $\mathrm{V} \gamma 9-\mathrm{V} \delta 2+$ of $51 \pm 81$ and $2 \pm 3 \mathrm{Tc} / \mu \mathrm{L}$, respectively, and $10 \pm 8 \mathrm{~V} \gamma 9-\mathrm{V} \delta 2-$ $\mathrm{Tc} / \mu \mathrm{L}$, the later corresponding most probably to V $\delta 1 \mathrm{Tc}[73]$.

Generally speaking, the values obtained in our series of Caucasian, Portuguese, healthy adults, for V $\delta 2(63 \pm 62 ; 6-243 \mathrm{Tc} / \mu \mathrm{L})$, and for $\mathrm{V} \delta 1(23 \pm 19 ; 2-75 \mathrm{Tc} / \mu \mathrm{L}) \mathrm{Tc}$, were within the series of Caucasian, European, healthy individuals mentioned above, in which the median and range values were not provided.

Differences in $\gamma \delta$ Tc between racial and ethnic groups may result from environmental factors and/or genetic influences and needed to be further explored.

\subsection{Effect of Age}

The ontogeny of $\gamma \delta$ Tc precedes that of $\alpha \beta$ Tc, and $\gamma \delta$ TCR gene rearrangements can be detected by embryonic week 8 in humans [74-76].

Previous studies have shown that neonatal $\gamma \delta$ Tc express diverse $\mathrm{V} \gamma$ and $\mathrm{V} \delta$ regions paired in a variety of combinations rarely observed in the PB from adults, and that $\mathrm{V} \delta 1$ Tc predominate over $\mathrm{V} \delta 2$ Tc in the CB from neonates $[23,38,77,78]$. The absolute numbers of peripheral blood $\gamma \delta$ Tc were shown to increase from birth to about 10 years of age, due to the expansion of the $\mathrm{V} \gamma 9 \mathrm{~V} \delta 2$ Tc subset, going from a minor population in the CB to the majority of circulating $\gamma \delta$ Tc in adults $[23,38]$. V $\gamma 9 \mathrm{~V} \delta 2 \mathrm{Tc}$ expansion in the first decade of life presumably results from the exposure to environmental Ags, such as microbial phosphoantigens and alkylamines [6].

In accordance, in the early 90s, Parker et al. reported that proportion of Tc expressing TCR- $\gamma \delta$ in CB was quite similar in all cases tested (mean of $1.7 \%$ ) and threefold lower than the proportion of Tc expressing TCR- $\gamma \delta$ in adult PB (mean of $5.7 \%$ ); besides, they observed that in the CB from neonates, $\gamma \delta$ Tc use predominantly V $\delta 1$ ( $50 \%$ of $\gamma \delta \mathrm{Tc}$ ) and less frequently express $\mathrm{V} \delta 2$ ( $25 \%$ of $\gamma \delta \mathrm{Tc}$ ), as compared to values of $<30 \%$ and $>70 \%$ in the PB from adults, respectively [38]. They also showed that the proportion of Tc expressing TCR- $\gamma \delta$ gradually increased to an average of $10 \%$ at 6 years of age, after which it fell to a lower level in adulthood [38].

More recently, Sandberg et al. (2006) described a fivefold increase of absolute numbers of $\gamma \delta$ Tc during the first 2 years of life, followed by a gradual decrease to adult levels [23]. They also compared the expression of $\mathrm{V} \gamma 9, \mathrm{~V} \delta 1$ and $\mathrm{V} \delta 2$ on $\gamma \delta \mathrm{Tc}$ in the CB from neonates $(n=10)$ and in PB samples from healthy children $(n=15)$ and healthy adults $(n=15)$, and they found that in neonatal $\mathrm{CB}$, approximately half of the $\gamma \delta$ Tc expressed V $\delta 1$ (as compared to $10-15 \%$ in adults), while $30-40 \%$ used $\mathrm{V} \gamma 9$ and/or V $\delta 2$ (as compared to V $82: 80-85 \%$ and $\mathrm{V} \gamma 9: 85-90 \%$ in adults) [23].

Little was known about the relative representation of the $\gamma \delta$ Tc subsets in the human PB before birth until 2015, when Dimova et al. reported on the $V \gamma$ and $V \delta$ usage in the PB from human fetuses 
$(n=87)$ at different gestation times [56]. Unexpectedly, they observed that $\mathrm{V} \gamma 9 \mathrm{~V} \delta 2 \mathrm{Tc}$ were the predominant $\gamma \delta$ Tc subset in the PB of the second-trimester fetus ( $75-80 \%$ of the $\gamma \delta$ Tc), i.e., before postnatal microbial exposure, and that the second most abundant population was $\mathrm{V} \gamma 9 \mathrm{~V} \delta 2+(15-20 \%$ of $\gamma \delta \mathrm{Tc}$ ), whereas $\mathrm{V} \delta 1$ and $\mathrm{V} \delta 3 \mathrm{Tc}$ were present only at low frequencies [56]. At later gestational times, V $\delta 2$ Tc in fetal PB decreased significantly, while V $\delta 1$ Tc increased continuously, representing the major $\gamma \delta$ Tc subpopulation in the PB at term delivery (15-20\% of $\gamma \delta \mathrm{Tc}$ ). They also showed that fetal $\mathrm{V} \gamma 9 \mathrm{~V} \delta 2 \mathrm{Tc}$ were responsive to phosphoantigens and had limited diversity in the CDR3 of the V $\gamma 9$ chain gene, with a germline-encoded sequence accounting for $>50 \%$ of all sequences, in association with a prototypic complementary determining region 3 (CDR3) $\delta 2$; furthermore, fetal blood V $\gamma 9 \mathrm{~V} \delta 2 \mathrm{Tc}$ were preprogrammed for an effector T helper (Th) type 1 (Th1) phenotype, with properties of rapidly activatable Tc [56].

Major age-related changes in the $\gamma \delta$ Tc compartment have also been reported in healthy adults, and they were shown to be more accentuated in old people and centenarians. In line with that, Argentati et al. (2002), in a series of 104 Italian healthy volunteers, observed that the absolute numbers of circulating $\gamma \delta$ Tc were significantly less prevalent in centenarians (mean age: 100 years,) and old people (mean age: 80 years) compared to young adults (mean age: $34 \pm 6$ years), as a consequence of the age-related decrease in lymphocyte numbers [52]. They also observed that the decrease of $\gamma \delta$ Tc counts with aging resulted from a decrease of V $\delta 2$ Tc (mean counts of 77,31 and 23 cells/ $\mu \mathrm{L}$, for young and old adults and centenarians, respectively), whereas the absolute number of V $\delta 1 \mathrm{Tc}$ was unaffected by age (mean counts of 41,34 and 38 cells/ $\mu \mathrm{L}$, respectively); consequently, the V $\delta 2 / \mathrm{V} \delta 1$ ratio was inverted in the PB from old subjects and centenarians [52].

Subsequently, Re et al. (2005) also found that upon activation in vitro, the percentage of tumor necrosis factor-alpha (TNF- $\alpha$ ) producing $\gamma \delta$ Tc was higher in old in comparison with young/adult healthy subjects, whereas no significant differences were noted in the percentage of $\gamma \delta$ Tc producing interferon-gamma (IFN- $\gamma$ ) [79]. Thus, they demonstrated that $\gamma \delta$ Tc from older individuals were not only reduced in number, they were also functionally different. In the same year, Re et al. realized that the decreased absolute numbers of $\mathrm{V} \gamma 9 \mathrm{~V} \delta 2 \mathrm{Tc}$ in old individuals in comparison with young and middle aged adults resulted from a reduction of naïve $\left(\mathrm{T}_{\mathrm{N}}\right)$ and central memory $\left(\mathrm{T}_{\mathrm{CM}}\right) \mathrm{V} \delta 2 \mathrm{Tc}$, bearing CD27 and CCR7 receptors, whereas the proportion of effector memory ( $\left.\mathrm{T}_{\mathrm{EM}}\right) \mathrm{V} \delta 2 \mathrm{Tc}$, lacking CD27 and CCR7, was significantly increased [72]. Subsequent functional studies revealed that $\mathrm{T}_{\mathrm{EM}} \mathrm{V} \delta 2$ Tc were increased after in vitro culture in the presence of IPP and interleukin (IL)-2, in contrast to that observed in old subjects, thereby confirming a lack of $\mathrm{T}_{\mathrm{N}}$ and $\mathrm{T}_{\mathrm{CM}}$ responding to IL-2. Finally, they observed that perforin-containing, terminally differentiated effector $\left(\mathrm{T}_{\mathrm{EMRA}}\right) \mathrm{V} \delta 2 \mathrm{Tc}$ showed no age-related differences. These data demonstrated a shift of the circulating $\gamma \delta$ Tc towards $\mathrm{T}_{\mathrm{EM}}$ and $\mathrm{T}_{\mathrm{EMRA}}$ in the elderly, with reduction of $\mathrm{T}_{\mathrm{N}}$ and $\mathrm{T}_{\mathrm{CM}}$ cells [72].

One year later, Caccamo et al. (2006) studied 320 Italian healthy subjects aged from 2 to 70 years-old, and they observed that the percentage of peripheral blood $\mathrm{V} \gamma 9 \mathrm{~V} \delta 2 \mathrm{Tc}$ (in total $\mathrm{Tc}$ ) raised from birth to puberty, and gradually decreased beyond the age of 20-30 years [53]; they analyzed separately, three age groups (2-15, 20-30 and 30-60 years-old), and they found that the percentages of $\mathrm{V} \gamma 9 \mathrm{~V} \delta 2 \mathrm{Tc}$ (among total $\mathrm{Tc}$ ) decreased progressively in children, younger adults and older adults (mean values of $3.5 \%$, $3.0 \%$ and $1.5 \%$ ) [53]. Furthermore, they demonstrated that loss of peripheral $\mathrm{V} \gamma 9 \mathrm{~V} \delta 2 \mathrm{Tc}$ with aging was accompanied by changes in the distribution of functional Tc subsets. By splitting V $\gamma 9 \mathrm{~V} \delta 2$ Tc into $\mathrm{T}_{\mathrm{N}}(\mathrm{CD} 27+\mathrm{CD} 45 \mathrm{RA}+), \mathrm{T}_{\mathrm{CM}}(\mathrm{CD} 27+\mathrm{CD} 45 \mathrm{RA}-), \mathrm{T}_{\mathrm{EM}}$ (CD27-CD45RA-) and $\mathrm{T}_{\mathrm{EMRA}}$ (CD27-CD45RA+), they observed a progressive decrease in $\mathrm{T}_{\mathrm{EM}}$ and $\mathrm{T}_{\mathrm{EMRA}}$ in the $\mathrm{V} \gamma 9 \mathrm{~V} \delta 2 \mathrm{Tc}$ compartment with aging, with a concomitant enrichment in $\mathrm{T}_{\mathrm{CM}}$. The former proliferated more poorly than the later in response to stimulation with IPP in vitro but produced higher amounts of IFN- $\gamma$ [53]. Once again, most of the values were only represented graphically.

A few years later (2011), Michishita et al., when examining the $\gamma \delta$ Tc repertoire in the series of 120 Asian Japanese healthy volunteers mentioned above, also observed that the absolute numbers of $\gamma \delta$ Tc decrease with aging, as the result of reduction of V $\delta 2$, but not of V $\delta 1$ Tc [55]. To understand 
why V $\delta 2$ Tc had an age-dependent decrease, they studied the expansion capability of V $\delta 1$ and V $\delta 2 \mathrm{Tc}$ after culture with phytohemagglutinin (PHA), in the presence or absence of IL-2. They observed that, in contrast to V $\delta 1 \mathrm{Tc}, \mathrm{V} \delta 2$ Tc rapidly died after stimulation with PHA, and that this phenomenon was not rescued by adding IL-2. They also found that the fraction of apoptotic cells was higher among V $\delta 2$ Tc and that Bcl-2 expression was down-regulated in stimulated V $\delta 1 \mathrm{Tc}$, but not in stimulated V $\delta 2$ Tc. They concluded that age-related decrease of V $\delta 2$ Tc may be explained, at least in part, by a higher susceptibility to activation-induced cell death [55].

Cairo et al. (2010) also described that the percentages of V $\delta 2$ Tc (among total lymphocytes) declined as age increased, and that rates of decline were the same for Caucasian Americans and African Americans [54], and Hviid et al. (2000) confirmed that the frequencies of V $\delta 1$ Tc (among $\gamma \delta$ Tc) did not depend on age [51].

In a study published by Roux et al. in 2013, in which 70 healthy adults were divided into age groups and according to the CMV serological status, a decrease in the frequency of $\gamma \delta$ Tc was also observed with aging; however, the frequency of V $\delta 2$ Tc decreased substantially with aging regardless of CMV status, while the percentage of V82-negative Tc decreased mainly in CMV-seronegative subjects (please see below) [67].

In the same year, Wistuba-Hamprecht et al. reported on the percentage and immunophenotype of peripheral blood V $\delta 2$ Tc from 33 healthy donors (mean age: 52 years; 12 males) [68], and two years later, they published a large study that included 217 participants (23 to 85 years, gender not provided) of the Berlin Aging Study II (BASEII) study [69]. In both studies, the participants were aggrouped accordingly to age and CMV-serostatus, and V $\delta 1$ and V $\delta 2$ Tc were evaluated. In the first study, Wistuba-Hamprecht et al. observed a trend towards age-associated reduction in the frequency of V $\delta 2$ Tc when CMV-seropositive and seronegative subjects were poled together, and significant accumulation of V82-negative Tc with a late-differentiated (CD27-CD28-) phenotype with aging, the latter occurring only in CMV-seropositive subjects [68]. The second and largest study confirmed these observations, with older subjects having lower V 82 Tc counts regardless of the CMV serostatus; stratifying subjects according to age did not reveal any significant differences in $\mathrm{V} \delta 2 \mathrm{Tc}$, either for early (CD27+CD28+CD45RA+CD16-) or for late-differentiated (CD27-CD28-CD45RA+CD16-) $\gamma \delta$ Tc [69]. Changes observed in V $\delta 1$ depended mainly on the CMV serostatus and are described below.

More recently, other large study (157 healthy adults, 20-95 years-old, 58 males) published by Kallemeijn et al. in 2017, also aimed to evaluate the impact of aging and latent CMV infection on the immunophenotypic features of $\gamma \delta \mathrm{Tc}$, including those expressing the TCR-V $\gamma 9, \mathrm{~V} \gamma \delta 1$ and $\mathrm{V} \delta 2$ families [70]. They also found a significant decrease in total $\gamma \delta$ Tc numbers with aging, which was paralleled by a significant decrease of V $\delta 2$ Tc but not of V $\delta 1$ Tc [70]. In addition, they described a decrease in absolute numbers of effector memory (CD45RO+CD197-) and effector (CD45RO-CD197-) $\gamma \delta$ Tc, without significant differences in numbers of naïve (CD45RO-CD197+) and central memory $(C D 45 R O+C D 197+)$; expressing the results as percentages, there was a decrease in naïve and an increase in effector $\gamma \delta \mathrm{Tc}$, which were already visible from age 50 onwards-more pronounced in the oldest age group ( $>70$ years) [70]. These changes were accompanied by a shift from less differentiated (i.e., CD27-/+CD28+) to a more differentiated (i.e., CD27-CD28-) phenotype, especially in the oldest age group, although there was a decrease in absolute cell numbers of all these $\gamma \delta$ Tc populations [70].

In agreement to the studies mentioned above, we observed that in Caucasian, Portuguese, healthy adults aged from 20 to 70 years the peripheral blood $\gamma \delta$ Tc decreased with aging [52,55,67,80], and that the relative representation of the $\mathrm{V} \delta 1$ and $\mathrm{V} \delta 2$ subsets among $\gamma \delta$ Tc did not vary significantly. Additionally, in line with these studies [52,55], we found that the decrease of the absolute numbers of $\gamma \delta$ Tc with aging resulted mainly from a reduction of $\mathrm{V} \gamma 9 \mathrm{~V} \delta 2 \mathrm{Tc}$, with less relevant changes in the $\mathrm{V} \delta 1$ Tc compartment. It is worth noting that our series did not include the extremes of life, where major changes in the $\gamma \delta$ Tc repertoire are expected to occur. 


\subsection{Effect of Gender}

When studying the series of Italian blood donors mentioned above $(n=224,20-60$ years, 111 males), Caccamo et al. were the first to demonstrate gender bias in $\gamma \delta \mathrm{Tc}$ [53]. They realized that the percentage of V $\delta 2$ Tc (among Tc) did not differ between males and females under 15-year-old, but they were significantly less prevalent in males than in females aged from 20-30 years, and especially, in those aged from 30-60 years. They also found that the depletion of $\mathrm{T}_{\mathrm{EM}}$ and $\mathrm{T}_{\mathrm{EMRA}}$ was more pronounced in adult males than in adult females [53]. Thus, it seems that age-related differences in $\mathrm{V} \gamma 9 \mathrm{~V} \delta 2 \mathrm{Tc}$ between males and females only manifest after puberty, probably because of hormonal or other physiological factors.

In contrast, Cairo et al. did not find significant differences between Italian healthy males and females ( $n=65,19-64$ years, 38 males), concerning the percentage of V 22 Tc among total lymphocytes [54], and Michishita et al. realized that the numbers of $\gamma \delta$ Tc and V $\delta 2$ Tc were significantly higher in 42 Japanese healthy adult males, as compared to Japanese healthy adult age-matched females [55].

Concerning the impact of gender on the analyzed Tc populations, we feel that in our study, as in the Cairo's study [54], larger sample sizes could have revealed an influence of gender similar to that found by Caccamo et al., who reported higher V 82 Tc counts in women compared to age-matched men [53]. We have no obvious explanation for the opposite results obtained by Michishita et al. [55].

Similarly to Caccamo et al. [53], we observed that the percentage of V 22 Tc dropped later and more slowly in females than in males, and although we did not obtain significant differences when considering the overall study population, we found that middle aged females had significantly higher levels of V $\delta 2$ Tc than middle aged males. Thus, circulating $\gamma \delta$ Tc remain elevated for a longer period in life in women, dropping slowly than in men, an effect that is mostly observed in V $\gamma 9 \mathrm{~V} \delta 2 \mathrm{Tc}$ [53].

\subsection{Effect of Pregnancy}

Previous studies have revealed significant changes in circulating $\gamma \delta$ Tc during pregnancy, peri and postpartum, as part of the physiological changes of adjustment of the immune system, and that uterine decidua $\gamma \delta$ Tc play an important role in fetal-maternal relationship, a process that seems to be hormone-dependent [81-83].

In accordance, in the uterine decidua from pregnant women, $\gamma \delta$ Tc significantly increase in number, and most of them are activated V $\delta 1$ Tc, which recognize conserved sequences on the trophoblast [84]. In the late 90s, it was reported that the percentage of $\gamma \delta$ Tc in the PB from healthy pregnant women is significantly higher, with a lower fraction of $\mathrm{V} \gamma 9 \mathrm{~V} \delta 2$ and a higher fraction of $\mathrm{V} \gamma 1.4$ (now designated as $\mathrm{V} \gamma 4$ ) V $81 \mathrm{Tc}$, compared to women with recurrent miscarriages and healthy non-pregnant women $[85,86]$. Signaling via the $\mathrm{V} \gamma 4 \mathrm{~V} \delta 1$ was shown to induce Th2 type polarization, whereas Tc activation via $\mathrm{V} \gamma 9 \mathrm{~V} \delta 2$ resulted in a Th1 type response [86]. More recently, it was shown that the initiation of labor is characterized by changes in the V-chain usage of $\gamma \delta \mathrm{Tc}$, with increased percentages of $\mathrm{V} \gamma 9 \mathrm{~V} \delta 2$ and decreased percentages of $\mathrm{V} \gamma 4 \mathrm{~V} \delta 1 \mathrm{Tc}$ [87].

Further studies on the $\gamma \delta$ Tc repertoires in specific periods of women life, such as on the menarche and menstrual cycles, will probably contribute to elucidating the physiological role of $\gamma \delta$ Tc.

The results obtained in our study were not influenced by pregnancy, as women are deferred from blood donation during pregnancy, and for 6 months after delivery or abortion.

\subsection{Pathological Conditions Involving $\gamma \delta T$ Cells}

Increased relative and/or absolute numbers of $\gamma \delta$ Tc have been described in association with several pathological conditions. Granel et al. (2002) reviewed the clinical data of 55 patients with $\gamma \delta$ Tc lymphocytosis, defined by a proportion of $\gamma \delta$ Tc over $10 \%$ of the peripheral blood Tc, and they observed three groups of pathologies: infectious (e.g., viral infections and tuberculosis), inflammatory (e.g., sarcoidosis and autoimmune diseases) and hematological (e.g., monoclonal gammopathy) [2]. 
When investigating the diseases associated with an increase of $\gamma \delta \mathrm{Tc}$ in the $\mathrm{PB}$, in patients observed at the Mayo Clinic, Roden et al. (2008) considered arbitrarily $\gamma \delta$ Tc to be increased when they comprised more than 5\% of PB lymphocytes and/or when their absolute number exceeded 200 cells/ $\mu \mathrm{L}$ [3]. They noticed that $62(18 \%)$ of $352 \mathrm{~PB}$ samples analyzed consecutively had an increase in $\gamma \delta$ Tc. In 28 out of 36 cases $(78 \%)$ where clinical information was available, there were one or more associated conditions, consisting of infectious/inflammatory pathologies, autoimmune diseases, lymphoproliferative disorders and previous splenectomy [3].

Among the pathological conditions that have been associated with a $\gamma \delta$ Tc-mediated immune response, only infections by human herpes virus (HHV) will be discussed in detail, because of their ability to infect and to persist in the host without causing clinical manifestations. Detailed analysis of the role of $\gamma \delta$ Tc in other infections, and in autoimmune and neoplastic diseases, is outside the scope of this work, since all individuals examined were healthy.

\subsubsection{Viral Infections}

\section{Herpesviruses}

Most of the herpesviruses known to cause diseases in humans are ubiquitous viruses that share the ability to remain latent within the body, to interact with immune cells in order to create a permissive environment and to escape immune surveillance, reactivating in immunodepressed patients; some of them have also been implicated in the genesis of malignant neoplasms [88]. Of the HHVs, only cytomegalovirus (CMV, HHV-5) has been exhaustively investigated, concerning both the participation of $\gamma \delta$ Tc in the immune response against the virus, and its ability to influence the $\gamma \delta$ Tc repertoire.

\section{Cytomegalovirus/Human Herpes Virus Type 5}

Human CMV (HHV-5) usually infects the host during childhood, establishing life-long latency [89]. The CMV genome contains several accessory genes, most of which are involved in immune evasion, resulting in a symbiosis between virus and host [90]. However, the mechanisms by which CMV maintains latency and reactivates in immunocompromised subjects are not completely understood. In immunodepressed patients, CMV infection can be life-threatening, causing organ injury (e.g., hepatitis, pneumonitis, retinitis, meningitis and encephalitis), and systemic disease; intrauterine CMV infection may cause microcephaly, sensorineural hearing loss and mental retardation [91,92].

The first evidence of involvement of $\gamma \delta$ Tc in the immune response against CMV dates to 1999, when Déchanet et al. detected an expansion of $\gamma \delta$ Tc in 31 of 205 renal allograft recipients and identified CMV infection as the only independent variable associated with high levels of circulating $\gamma \delta$ Tc [93]. In the same year, they showed that V $\delta 1$ and V $\delta 3$ Tc were preferentially expanded in these patients, and they found a marked restriction of CDR3 size distribution in V $\delta 3$, and to a lesser extent, in V $\delta 1$ $\mathrm{Tc}$; furthermore, they observed that V 81 and V $83 \mathrm{Tc}$ from CMV-infected kidney recipients were able to proliferate in vitro in response to CMV [94]. Subsequent reports have confirmed that $\gamma \delta$ Tc are implicated in the control of CMV infection, which is mediated through V $\delta 2$-negative, mainly V $\delta 1+$ or $\mathrm{V} \delta 3+$, but also V85+ Tc $[95,96]$.

In healthy subjects, seropositivity for CMV has been related with higher frequencies and absolute numbers of V82-negative Tc in the PB with a restricted repertoire and a differentiated immunophenotype [67-70,97]. It seems that aging and CMV infection independently impact $\gamma \delta \mathrm{Tc}$, providing an explanation for different changes observed in V $\delta 2$-negative and V $\delta 2+\mathrm{Tc}$ in the elderly [67].

In conformity to what was said above, Pitard et al. (2008) observed that the percentages of V $\delta 2$-negative $\gamma \delta$ Tc were increased in CMV-seropositive compared with -seronegative healthy subjects [97]. Additionally, in seropositive subjects, V $\delta 2$-negative $\gamma \delta$ Tc exhibited a more differentiated cytotoxic effector/memory phenotype (CD45RA+CD27- CD28-CD62L-), which was also observed in transplanted patients challenged with CMV, whereas in seronegative people V $\delta 2$-negative $\gamma \delta$ Tc had mainly a naïve (CD45RA+ CD27+ CD28-/+ CD62L+) phenotype. Moreover, V81 Tc from 
CMV-seropositive donors showed a more restricted repertoire than those from seronegative ones, as revealed by CDR3 size distributions of the TCR V $\delta 1$ sequences. They concluded that increased effector-memory V $\delta 2$-negative $\gamma \delta \mathrm{Tc}$ in the PB traduces an adaptive immune response to CMV infection in both immunocompetent and immunosuppressed individuals [97].

Some years later, Roux et al. (2013) showed that the frequency of V82 Tc declines in with advanced age irrespective of the CMV status, whereas V $\delta 2$-negative $\gamma \delta$ Tc only decrease in CMV-seronegative individuals, being preserved overtime in CMV-seropositive subjects, probably because of persistent $\gamma \delta$ Tc stimulation [67]. The stimulatory effect of CMV on V $\delta 2$-negative $\gamma \delta$ Tc was documented by the expression of activation related markers (e.g., CD38 and HLA-DR) in patients with acute and chronic CMV infection, and using in vitro experiments [67].

In the same year, Wistuba-Hamprecht et al. reported that in CMV-seropositive healthy subjects there was a significantly lower ratio of $\mathrm{V} \delta 2+/ \mathrm{V} \delta 2$-negative $\gamma \delta \mathrm{Tc}$ in older individuals, and an age-associated trend towards a reduction of early-differentiated CD27+CD28+V $\delta 2$-negative Tc, with concomitant increase of terminally differentiated CD27-CD28-V82-negative Tc, whereas the phenotype of V82 Tc was not affected by a latent CMV infection [68]. These differences were, however, absent in CMV-seronegative donors, in whom they observed a significant reduction of V82-negative Tc.

When studying a large number of individuals from the Berlin Aging Study II, Wistuba-Hamprecht et al. (2015) also found higher percentages of V81 Tc and less abundance of V82 Tc in CMV-seropositive elderly people, resulting in the highest values of V81:V $\delta 2$ [69]. In addition, they observed higher frequencies of late-differentiated (CD27-CD28-) and lower frequencies of early-differentiated (CD27+CD28+) cells among $\mathrm{V} \delta 1+$ and $\mathrm{V} \delta 1 / \mathrm{V} \delta 2$ negative $\gamma \delta \mathrm{Tc}$, but not among V $\delta 2+\mathrm{Tc}$ from elderly CMV-seropositive individuals, confirming the association of V $\delta 2$-negative $\gamma \delta \mathrm{Tc}$ with CMV-immunosurveillance [69].

Finally, the large study performed by Kallemeijn et al. (2017) also revealed a major impact of past CMV infection on $\gamma \delta \mathrm{Tc}$, with a shift from naïve to more differentiated effector $\gamma \delta$ Tc phenotypes [70]. The main findings observed in V $\delta 1$ Tc were lower proportions of early differentiated (CD27+CD28+ $\mathrm{CD} 45 \mathrm{RA}+$ ) and higher proportions of late-differentiated (CD27-CD28-CD45RA+) cells in young and old CMV-seropositive individuals, when compared to CMV-seronegative individuals of the same age group. Similar findings were found in V $81 / \mathrm{V} \delta 2$ negative Tc, but not in V $\delta 2+\mathrm{Tc}$ [70].

Thus, CMV infection has been considered one of the most important factors for driving immune senescence, having impacts on both $\alpha \beta$ and $\gamma \delta$ Tc $[98,99]$. Taking into account that the rates of CMV infection are diverse in different parts of the world, it may also account for race/ethnicity related differences.

\section{Other Herpesviruses}

Gamma delta Tc have also been implicated in the immune response against other HHV, including herpes simplex viruses type 1 and 2 (HSV-1 and 2), varicella zoster virus (VZV, HHV-3), Epstein Barr virus (EBV, HHV-4), and Kaposi's sarcoma-associated herpes virus (KSHV, HHV-8), although the evidence is much lower than in CMV (HHV-5).

Herpes simplex viruses types 1 and 2: Only a few studies in animal models have implicated $\gamma \delta$ Tc in the immune response against HSV-1 [100,101] and HSV-2 [102-104], and studies in humans are even scarcer $[105,106]$. In humans, HSV-specific cytotoxic activity is mediated mainly by $\gamma \delta \mathrm{Tc}$ in some persons, whereas in other, $\alpha \beta$ Tc are primarily involved [105]. One study revealed that Tc recovered from the lesions of patients with genital herpes and expanded by mitogen stimulation, gave rise to $\gamma \delta$ Tc clones that were predominantly $\mathrm{V} \gamma 9 \mathrm{~V} \delta 2$, showed reactivity to IPP and were able to secrete IFN- $\gamma$, TNF- $\alpha$, IL-8, MIP- $1 \alpha$ (macrophage inflammatory protein-1 alpha) and RANTES (regulated on activation, normally T cell expressed or secreted), suggesting that IPP-reactive Th1-pollarized V $\gamma 9 \mathrm{~V} \delta 2$ Tc are involved in the immune response against HSV-2 [106].

Varicella zoster virus-human herpes virus type 3: Evidence for the implication of $\gamma \delta$ Tc in the immune response against VZV is also scarce. We found only one study indicating that patients with recurrent aphthous ulceration (RAU), presumably related to VZV reactivation [107], have increased 
percentages of $\gamma \delta$ Tc in the PB [107]. The study population consisted of 13 patients with active RAU, 14 patients with inactive RAU and 18 healthy volunteers without RAU. The mean percentage of circulating $\gamma \delta \mathrm{Tc}$ (among total Tc) was increased in patients with active RAU, as compared with patients with inactive RAU, and with controls [108].

Epstein Barr virus-human herpes virus type 4: Several studies have indicated that $\gamma \delta \mathrm{Tc}$, and particularly the V $\delta 1$ subset, are able to respond to ligands expressed in EBV-infected B cells [109-112]. Gamma delta Tc may be themselves infected by EBV and then expand clonally, such as occurring in patients with chronic active EBV disease $[113,114]$. In addition, EBV has been implicated in the genesis of $\gamma \delta$ Tc lymphomas, which are mainly extranodal cytotoxic lymphomas $[115,116]$. Some studies, however, have associated $\mathrm{V} \gamma 9 \mathrm{~V} \delta 2$ Tc to the immune response against EBV, particularly $\mathrm{V} \gamma 9-\mathrm{J} \gamma \mathrm{P} / \mathrm{V} \delta 2-\mathrm{J} \delta 3+\gamma \delta \mathrm{Tc}$, which were shown to be preferentially expanded in patients with nasal $\gamma \delta \mathrm{Tc}$ lymphoma and chronic active EBV infection [117]. Finally, targeted activation of human V $\gamma 9 \mathrm{~V} \delta 2 \mathrm{Tc}$ controls EBV-induced B cell LPD [118].

Human herpes viruses types 6 and 7: Some studies have revealed that when $\gamma \delta$ Tc purified from the PB of healthy adults and activated in vitro with PHA, were exposed to HHV-6, they became infected by the virus; in contrast, no signs of infection or were detected after exposure to HHV-7 [119]. Additionally, $\gamma \delta$ Tc displayed cytolytic activity against autologous and heterologous target cells infected with HHV-6 [119].

Kaposi's sarcoma-associated herpes virus-human herpes virus type 8: Barcy et al. found that HHV-8 infection was associated with significant expansion of $\gamma \delta$ Tc in the PB, consisting mainly of terminal effector V $\delta 1$ Tc [120]. They showed that in vitro stimulation of PB mononuclear cells from HHV-8-infected subjects with either HHV-8 or viral proteins resulted in V81 Tc activation; in addition, V81 Tc displayed a strong reactivity against HHV-8-infected cell lines and prevented the release of infectious viral particles following lytic replication, suggesting that $\gamma \delta$ Tc play a role in the immune response against HHV-8 [120].

The number of studies that have investigated the role of HHV other than CMV in modeling the $\gamma \delta$ Tc repertoire in healthy humans is even more limited, and we found only one study addressing this question [55]. In their study of 120 Japanese healthy individuals mentioned above, Michishita et al. investigated whether past viral infections with CMV, EBV, HSV, VZV and Human Parvovirus B19 (HPVB19), affected the $\gamma \delta$ Tc repertoire. Confirming previous observations, they found that the numbers V $\delta 1$ Tc (but not V $\delta 2 \mathrm{Tc}$ ) were significantly higher in CMV-seropositive than in CMV-seronegative subjects, and they realized that serological status for HSV and HPVB19 infection did not have impact in V $\delta 1$ and V $\delta 2$ Tc counts; however, they were not able to conclude about the effect of VZV and EVB, because most of the subjects examined had positive serological tests for these viruses [55].

Serological tests for HHV are not included in the recommended tests for blood donors in Portugal, and so, they were not performed in our study population; seroprevalence studies for most of these viruses in the general Portuguese population are also not available. However, it can be grossly estimated using studies performed in other countries with similar characteristics. Taking in account the available data, we estimate a seroprevalence (IgG+/IgM-) $>70-80 \%$ for HHV-1 (HSV-1), $>10-20 \%$ for HHV-2 (HSV-2), > $90-95 \%$ for HHV-3 (VZV), >80-90\% for HHV-4 (EBV), >70-80\% for HHV-5 (CMV) and $>80-90 \%$ for HHV-6 and HHV-7.

\section{Other Viruses}

Several studies have reported on the role of $\gamma \delta$ Tc in the immune response against the HIV $[9,10]$, and some studies have also implicated these cells in hepatitis caused by HBV and HCV [11,121]. In addition, HTLV-I was shown to infect $\gamma \delta$ Tc, but, to the best of our knowledge, the role of $\gamma \delta$ Tc in the immune response to HTLV has not been investigated [122]. All blood donors included in our study have been tested (and were negative) for HIV-1 and 2, HTLV-I and II, HBV and HCV. 


\subsubsection{Bacterial Infections}

Gamma delta Tc, as other "innate" Tc, are known to have an important role in bacterial infections, acting as a bridge between the innate and adaptive immune system [123]. Increased proportions and/or absolute numbers of circulating $\gamma \delta \mathrm{Tc}$, mostly of the $\mathrm{V} \gamma 9 \mathrm{~V} \delta 2 \mathrm{Tc}$ subset, have been observed in various human intracellular bacterial infections-most of the studies having been performed in the 90s [13]. These include tuberculosis [124,125], salmonellosis [126], brucellosis [127], legionellosis [128], listeriosis [129], tularemia [130] and ehrlichiosis [131]. None of the individuals analyzed in our study had clinical evidence of having bacterial infections.

\subsubsection{Parasitic Protozoan Infections}

Increased proportion and/or absolute numbers of $\gamma \delta$ Tc have also been described in parasitic protozoan infections, such as in malaria [132-134], toxoplasmosis [135,136] and leishmaniosis [137]. The healthy subjects that participated in our study had no clinical evidence of being infected by parasitic protozoan.

\subsubsection{Autoimmune/Inflammatory Diseases}

Gamma delta Tc have also been implicated in autoimmune/inflammatory disorders, especially in those that are organ-specific, such as rheumatoid arthritis, autoimmune thyroiditis, autoimmune hepatitis, autoimmune myositis, inflammatory bowel diseases and multiple sclerosis, but also in systemic lupus erythematosus, Sjögren Syndrome, Psoriasis and other systemic diseases [18,19]. None of the individuals analyzed in this study had autoimmune diseases.

\subsubsection{Neoplastic Diseases}

Alpha/beta and $\gamma \delta$ Tc make distinct contributions to anticancer surveillance, as they have distinct activation requirements [15-17]. Down-regulation of expression of MHC-class I molecules, and tumor-specific Ags, is observed frequently during tumor progression, resulting in an impairment of MHC-restricted, $\alpha \beta$ Tc-mediated tumor-specific immunity. Given the lack of requirement for classical MHC-presenting molecules, $\gamma \delta$ Tc may, therefore, represent a potent alternative in anti-cancer surveillance. In addition, subsets of human $\gamma \delta$ Tc can identify tumor-expressed ligands that are not seen by conventional $\alpha \beta$ Tc. For instance, $V \gamma 1$ Tc recognize MIC-A/B and ULBP expressed on epithelial tumors and some lymphoma cells and V $\delta 2$ Tc are activated by phosphoantigens overproduced by tumor cells [5,138]. In accordance, V $\delta 2$ Tc were shown to be capable of killing myeloma and lymphoma B cells by recognizing phosphoantigens produced by these cells [139]; the V $\delta 1$ Tc have been implied mainly in the defense against epithelial cancers, being able to recognize colorectal, renal and pancreatic cancer cells, releasing IFN- $\gamma$ and exhibiting cytolytic properties [140]. Nevertheless, this dichotomy is not absolute [141,142].

Altered percentages and/or absolute numbers of $\gamma \delta$ Tc have been described in the PB from patients with diverse types of hematological [143-145] and non-hematological tumors [79,146-150]. These alterations are difficult to systematize and to interpret due to the tumor diversity, disease stage, therapy-related effects and the complexity of the host-tumor interactions. People who had or who have had cancer are impeded of giving blood. Thus, although the possibility of clinical silent not yet identified neoplasm cannot be excluded, it is unlikely that the $\gamma \delta$ TCR repertoire described herein was influenced by the existence of malignant neoplasms.

The role of $\gamma \delta$ T-cells in the anticancer therapy, is being explored as a novel immunotherapy in many types of cancer [21]. However, recent studies have revealed that in certain conditions $\gamma \delta$ Tc may display tumor-promoting functions, and these properties have been linked to IL-17 production [151,152]. Moreover, regulatory $\gamma \delta$ Tc in the tumor microenvironment may exert suppressive effects, being that they are associated with poor prognosis [152-156]. 


\subsubsection{Food and Medications}

Human V $\gamma 9 \mathrm{~V} \delta 2$ Tc monitor isoprenoid metabolism by recognizing HMB-PP, an intermediate in non-mevalonate pathway used by microbes, and IPP, an intermediate in the mevalonate pathway used by humans. Bisphosphonates, especially nitrogen-containing bisphosphonates (NBP), such as pamidronate, alendronate and zoledronate, which are widely used to treat osteoporosis, and alkylamines, are derived from microbes and certain edible plants and fruits, such as tea, wine, apples and mushrooms, indirectly stimulate $\mathrm{V} \gamma 9 \mathrm{~V} \delta 2 \mathrm{Tc}$ by inhibiting farnesyl diphosphate synthase (FDPS) in the mevalonate pathway, thereby increasing the levels of IPP [157-159]. In contrast, pharmacological agents that block the mevalonate pathway upstream by inhibiting the enzyme 3-hydroxy-3-methylglutaryl-coenzyme A (HMG-CoA) reductase, such as statins, which are used as anti-lipemic drugs, lead to decreased IPP levels $[160,161]$. Taking in consideration the variety of bioactive food components and pharmacological agents that can influence $\gamma \delta$ Tc activation and function, the impact of the diet and medications on $\gamma \delta$ Tc are not simple to interpret. The possibility that the $\gamma \delta$ Tc may be altered by medications that do not contraindicate blood donation, such as statins as bisphosphonates, cannot be ruled out in the present study.

\subsection{Immunophenotypic and Functional Features of Peripheral Blood $\gamma \delta T$ Cells}

Gama delta Tc are a heterogeneous cell population that combines rapid innate-like with conventional adaptive properties, making essential contributions to the immune response [162].

As for $\alpha \beta$ Tc, there are many factors influencing the immunophenotypic features of $\gamma \delta$ Tc. Upon stimulation, naïve $\gamma \delta \mathrm{Tc}$ can sequentially differentiate into $\mathrm{T}_{\mathrm{CM}}, \mathrm{T}_{\mathrm{EM}}$ and $\mathrm{T}_{\mathrm{EMRA}}$ cells, thereby modifying the levels of CD45RA, CD45RO, CD27, CD28, CD197/CCR7 and other cell surface receptors [72,163,164]. In addition, once activated, $\gamma \delta$ Tc modulate a wide range of cell surface activation-related molecules (e.g., CD69, CD25, CD28, CD38, CD45RO and HLA-DR) [165,166]. Activated $\gamma \delta$ Tc were shown to have properties of Ag presenting cells (APC), thereby providing co-stimulatory signals enough for inducting naïve $\alpha \beta$ Tc proliferation and differentiation [167,168], and promoting dendritic cell maturation [169].

Depending on the microenvironment (i.e., cytokine milieu) human $\gamma \delta$ Tc polarize into Th1 (e.g., IFN- $\gamma$-producing), Th2 (e.g., IL-4-producing) and Th17 (e.g., IL-17-producing) cells, making different types of cytokines $[170,171]$, and eventually converting into cytotoxic T lymphocytes (CTL), so playing a role in anti-viral and anti-tumor immune responses. Cytotoxic $\gamma \delta$ Tc do express receptors involved in the recognition and/or adhesion to their targets (e.g., CD16, CD56 and different types of killer cell receptors) [172,173], and cytotoxic granules containing granzymes and perforin $[174,175]$. The chemokine receptor CXCR5 (CD185) identifies a unique subset of $\mathrm{V} \gamma 9 \mathrm{~V} \delta 2$ Tc that expresses the costimulatory molecules CD278 (ICOS, inducible T-cell costimulatory molecule), CD279 (programmed cell death 1, PD-1), and CD154 (CD40 ligand, CD40L); secretes IL-2, IL-4 and IL-10; and helps B cells with $\mathrm{Ab}$ production [176]. These properties portray CXCR5+ V $\gamma 9 \mathrm{~V} \delta 2 \mathrm{Tc}$ as a memory Tc subset with B cell helper functions, analogous to follicular helper Tc (Tfh) [177]. Regulatory $\gamma \delta$ Tc with immunosuppressive properties, able to produce transforming growth factor-beta (TGF- $\beta$ ) and IL-10, have also been described $[152,156,178,179]$.

All these changes impose a large variability to the expression of cell surface and intracellular molecules. Among them, we will discuss only those evaluated in this study.

\subsubsection{CD3/TCR Complex}

The human TCR- $\gamma \delta$ is a protein complex composed of three heterodimers (TCR- $\gamma /$ TCR- $\delta$, $\mathrm{CD} 3 \gamma / \mathrm{CD} 3 \varepsilon$ and $\mathrm{CD} 3 \delta / C D 3 \varepsilon$ ) and a $\zeta / \zeta$ homodimer; the TCR- $\gamma \delta$ heterodimer contains variable regions and lets for Ag recognition, while the other molecules are required for surface TCR expression and intracellular signaling $[4,180]$.

In accordance to previous studies, we observed that the levels of CD3 expression were higher in $\gamma \delta$ Tc as compared to $\alpha \beta$ Tc, being lower in V $\delta 1$ Tc than in V $\delta 2$ Tc $[181,182]$. This could explain 
why the neoplastic Tc from patients with hepatosplenic $\gamma \delta$ Tc lymphoma, which originate from the V81 Tc subset, have been reported as having abnormally low levels of CD3 expression, as compared to those found in $\gamma \delta$ Tc from "normal" and "reactive" PB samples (expressing mostly V 82 ) [183]. Differences in CD3 expression may influence Tc reactivity and the threshold for Tc activation after Ag recognition [182].

Concerning the phenotypic characterization of $\gamma \delta$ Tc for the expression of different types of TCR- $\gamma \delta$, it is an opportune place to mention that there are many clones of anti-human "pan" TCR- $\gamma \delta$ mAbs, and that some of them may not be able to identify every $\gamma \delta$ Tc. In accordance, it has been reported that some anti-TCR- $\gamma \delta$ clones may miss specific $\gamma \delta$ Tc subsets, as identified by anti-V $\delta 1$ (e.g., clones TS8.2 and R9.12) and anti-V82 (e.g., clones B6 and Immu389) mAbs, respectively [184]. For instance, among three "pan" TCR- $\gamma \delta$ mAbs tested by Wistuba-Hamprecht et al. (clone B1, APC; clone B1.1, PE; and clone 11F2A, PE-Cy7- and FITC), only one (clone 11F2A, unconjugated) was found to identify all V $\delta 1$ and V $\delta 2$ Tc [184]. We ourselves observed interferences when the "pan" anti-TCR- $\gamma \delta$ (clone Immu510; PC5.5; BC/IOT) and the anti-V81 (clone TS8.2; FITC; Endogen) were used in the same tube, although this interference did not prevent the quantification of V $\delta 1$ Tc (Figure 1). A possible explanation could be steric hindrance effects because the epitopes recognized by these clones might be in proximity $[184,185]$.

\subsubsection{CD5 Signaling Molecule}

CD5, a transmembrane protein that associates with the CD3/TCR complex, and is expressed in most mature Tc, has been shown to regulate negatively TCR-mediated signaling, and to protect against autoimmunity [186]; however, high levels of CD5 expression may render Tc less able to recognize and eliminate malignant or viral-infected cells [187].

Previous studies have showed that the levels of CD5 on $\gamma \delta$ Tc are lower than that observed in $\alpha \beta$ Tc, and that CD5 negative $\gamma \delta$ Tc are CTL [188]. In addition, it has been found that V $\delta 2$ Tc are mainly CD5+, CD28+ and CD57-, whereas V81 Tc tend to be CD5-/+low, CD28- and CD57+ [189]. In line with these observations, we found that the levels of CD5 expression were lower in $\gamma \delta$ Tc as compared to $\alpha \beta \mathrm{Tc}$, and lower in V $\delta 1$ than in V $\delta 2 \mathrm{Tc}$, a larger fraction of CD5- cells being observed in the V $\delta 1 \mathrm{Tc}$ compartment. Down regulation of CD5 may be a strategy adopted by tumor- or viral-specific CTL to optimize cytotoxicity and cytokine secretion [190].

Loss of CD5 expression has been considered an aberrant immunophenotypic feature, useful for identifying the neoplastic Tc, in the PB and in the involved tissues [191]. However, this characteristic may only traduce a terminal differentiation of the neoplastic Tc into CTL, as occurs in $\gamma \delta$ Tc LGL leukemia [23], cutaneous $\gamma \delta$ Tc lymphoma [192] and intestinal $\gamma \delta$ Tc lymphoma [193]; or a premature loss of CD5 expression in activated, functionally-immature, cytotoxic, neoplastic Tc, as happens in hepatosplenic $\gamma \delta$ Tc lymphoma [48].

\subsubsection{CD8 Accessory Molecule}

The CD8 molecule is expressed on most CD8+ $\alpha \beta$ Tc mainly as a CD8 $\alpha \beta$ heterodimer, and it acts as the co-receptor for MHC class I molecules.

Previous studies have reported that $20 \%-30 \%$ of peripheral blood $\gamma \delta$ Tc are CD8+low, $[188,194]$ expressing CD8 $\alpha$ and $C D 8 \beta$ polypeptides in all possible combinations, with the largest proportion of cells $(44 \% \pm 17 \%)$ exhibiting CD $8 \beta \beta$ homodimers and smaller fractions expressing CD $8 \alpha \alpha$ homodimers $(14 \% \pm 12 \%)$ or $C D 8 \alpha \beta$ heterodimers $(14 \% \pm 12 \%$, and that the mean fluorescence intensity of CD8 expression is much lower in $C D 8 \alpha \alpha$ and $C D 8 \beta \beta \gamma \delta$ Tc [181]. One study showed that $C D 8 \alpha \beta+\gamma \delta$ Tc were enriched within the gut mucosa comparatively to the $\mathrm{PB}$; they expressed cytotoxic cell-associated markers, such as the CD56 adhesion molecule; and cytotoxic granule proteins, such as granzyme $\mathrm{B}$ and perforin; they produced mainly IFN- $\gamma$ and TNF- $\alpha$, and, in the PB, they were mostly V $\delta 1$ [195]. This could explain why we observed that in nearly half of the normal PB samples analyzed, part of the V81, 
but not of V $82 \mathrm{Tc}$, had high and homogeneous CD8 expression, at levels that approximated to those observed in CD8+high $\alpha \beta$ Tc. The significance of this $\gamma \delta$ Tc population needs to be clarified.

The precise functional role of the CD8 $\alpha \alpha$ and $C D 8 \beta \beta$ co-receptors is not known. Interestingly, both $C D 8 \alpha \alpha$ and $C D 8 \alpha \beta$ have been reported to bind to MHC class I and class I-like molecules, but $\mathrm{CD} 8 \alpha \beta$ was found to be more effective in promoting TCR activation [196]. In addition, CD8 has been suggested to play a role in TCR-independent immune responses of $\gamma \delta$ Tc and NK cells [197].

During $\mathrm{Ag}$ recognition, both $\mathrm{CD} 8 \alpha \beta$ and $\mathrm{CD} 8 \alpha \alpha$ strengthen the $\mathrm{TCR} \alpha \beta$ binding to the MHC-peptide complex [198,199]. Nevertheless, efficient recruitment of CD8 molecules into lipid rafts, wherein they associate with CD3, TCR and p56(lck), seems to depend on CD8 $\beta$ chains [200,201]. Besides, CD8 $\alpha \alpha$ molecules have differential ability to bind distinct MHC (HLA in humans) class I molecules [202]. For instance, they bind normally to the non-classical MHC class I molecule HLA-G, but only weakly to HLA-E. Interestingly, HLA-G is mainly expressed in the placenta where it has been shown to inhibit trophoblast cells lysis by decidua NK cells [203], whereas HLA-E binds to the conserved leader peptides of a range of MHC class I molecules, and mediates protection from cytolysis by interacting with inhibitory CD94/NKG2 receptors expressed on NK cells and CTL, including $\gamma \delta$ Tc [204]. It has also been proposed that CD8 expressed on $\gamma \delta$ Tc might interact with MHC-like molecules (e.g., CD1, MICA, MICB) [181]. More recently, evidence has been provided that CD8 $\alpha \alpha$ homodimer suppresses Tc activation [205].

\subsubsection{CD28 Costimulatory Molecule}

Activation of $\alpha \beta$ Tc is induced primarily by signals generated by the specific interaction of a TCR with an Ag bound to the MHC molecules on APC. The major second signal needed for Tc activation is produced by the interaction of the CD28 molecule expressed in naïve and central memory Tc with their natural ligands, CD80 and CD86, located on APC, resulting in cell proliferation, cytokine production and effector functions [206,207]. CD28 is also constitutively expressed in naïve and central memory $\gamma \delta$ Tc, and CD80/CD86-CD28 costimulatory signals were shown to control the survival and proliferation of $\gamma \delta$ Tc via IL-2 production [208-210].

After Tc activation, some Tc lose CD28 expression, and chronic Ag stimulation leads to gradual accumulation of CD28 negative Tc [211,212]. CD28 negative Tc are Ag-experienced and Ag-specific, highly differentiated, effector Tc, with cytotoxic or immunosuppressive capacities; they are characterized by shortened telomeres and gain of CD57 expression, and they play significant roles in inflammatory conditions, infections and cancers [213].

Many age-associated changes have been described in $\alpha \beta$ Tc, including the accumulation of terminally differentiated CD28 negative $\alpha \beta$ Tc, and they have been attributed mainly to a latent infection with CMV [214]. Contrarily to what happens (and we observed) in $\alpha \beta$ Tc, we found no significant correlation between the fraction of CD28- $\gamma \delta$ Tc and age. This is agreement with that reported by Tan et al., who found that the proportion of terminally differentiated CD28-CD27- $\alpha / \beta$ Tc was significantly higher in the elderly compared to the young, but the fraction of CD28-CD27- V82 Tc did not differ significantly between these age groups [215].

\subsubsection{CD16 and CD56-Cytotoxic-Cell-Associated Molecules}

As NK cells, some $\gamma \delta$ Tc do express CD16 (Fc gamma receptor type III, Fc $\gamma$ RIII), which binds to the fragment of IgG with low affinity and leads to antibody-dependent cellular cytotoxicity (ADCC) [216]. Upon stimulation with non-peptide Ags (e.g., phosphoantigens), V $\gamma 9 \mathrm{~V} \delta 2 \mathrm{Tc}$ upregulate CD16 expression and produce large amounts of IFN- $\gamma$ and TNF- $\alpha$, and $V \gamma 9 \mathrm{~V} \delta 2$ Tc having high levels of CD16 are NKG2A/CD94+ perforin+ activated/memory cells $[217,218]$. Angenili et al. discriminated two populations of effector memory V82 Tc: CD16 negative V82 $\mathrm{T}_{\mathrm{EM}}$ cells, expressing high levels of chemokine receptors, but low levels of perforin and of natural killer cell receptors (NKR); and CD16 positive V $\delta 2 \mathrm{~T}_{\text {EMRA }}$ cells, expressing several NKR and having high amounts of perforin, but low levels of chemokine receptors [218]. Whereas the former produced large amounts of IFN- $\gamma$ and TNF- $\alpha$ in 
response to phosphoantigens, the later were refractory to phosphoantigen stimulation but reacted to activation via CD16 (Fc $\gamma$ RIII) and were highly cytotoxic against tumor cells $[217,218]$. In addition, it was demonstrated that late-differentiated $V \delta 2$ negative $\gamma \delta$ Tc from CMV-seropositive individuals are CD16+high, and have intrinsic ADCC potential; CD16 $+\gamma \delta$ Tc produced IFN $-\gamma$ when incubated with IgG-opsonized CMV viruses, and IFN- $\gamma$ production was enhanced by IL-12 and IFN- $\alpha$, two cytokines produced during CMV infection, and conferred to $\gamma \delta$ Tc the ability to inhibit CMV multiplication in vitro [219].

The neural cell adhesion molecule (NCAM, CD56), a cell adhesion molecule of the Ig-superfamily expressed on the surface of neurons and glial cells, has also been shown to be expressed on NK cells, and on Tc populations, including a fraction of $\gamma \delta$ Tc [66]. CD56 expression in Tc defines a commitment to a cytotoxic phenotype $[220,221]$, and CD56+V V $\delta 2$ Tc have been characterized as having potent cytotoxic activity, being capable of killing tumor cells [174].

\section{Take-Home Messages}

Message 1: Due to the high biological variation, caution should be taken when interpreting quantitative and qualitative changes in circulating $\gamma \delta$ Tc from individual subjects, which should always be read in the clinical context, to be considered, or not, pathological. Bearing in mind this variation and the difficulties in obtaining reference intervals for $\gamma \delta$ Tc, we propose to use the minimum and maximum values found in healthy individuals as mere indicators of a possible pathological condition that needs to be further investigated.

Message 2: To facilitate comparisons between studies and to avoid bias related to the representation of other cell populations, we recommend expressing the $\mathrm{V} \gamma$ and $\mathrm{V} \delta$ families and $\gamma \delta$ Tc subsets as percentages of $\gamma \delta \mathrm{Tc}$, and in absolute cell numbers, preferentially determined with single platform methods.

Message 3: Given the relatively scarce number of studies performed, the small size of the samples in most studies performed and/or missing or incomparable data, further investigations are needed to better evaluate the impacts of race, ethnicity and gender on $\gamma \delta$ Tc and their subsets. With the information available, in young and middle-aged Caucasian European adults, we propose considering an increase of absolute and relative frequencies of $\gamma \delta \mathrm{Tc}$ if they exceed $300 \mathrm{cells} / \mu \mathrm{L}$ or $15 \%$ of the circulating Tc, and an increase in the absolute counts of V $\delta 2$ and $V \delta 1 \gamma \delta$ Tc if they exceed 250 and 50 cells/ $\mu \mathrm{L}$, respectively.

Message 4: Age has a major impact on $\gamma \delta$ Tc and their subsets: V $\gamma 9 \mathrm{~V} \delta 2$ Tc expressing a semiinvariant TCR are the predominant $\gamma \delta$ Tc population in the PB from second-trimester fetuses, whereas $\mathrm{V} \delta 1 \mathrm{Tc}$ are overrepresented in the cord blood from neonates. V $\gamma 9 \mathrm{~V} \delta 2 \mathrm{Tc}$ increase from birth to about 10 years of age, accounting for the majority of circulating $\gamma \delta$ Tc in young and middle-aged adults. Then, a progressive decrease of $\mathrm{V} \gamma 9 \mathrm{~V} \delta 2$ occurs; these changes occur latterly and more slowly in females than in males, and are more evident in the elderly. Concomitantly, there is a shift from naive to more differentiated effector $\gamma \delta$ Tc phenotypes, which is more pronounced in $\mathrm{V} \delta 1 \mathrm{Tc}$.

Message 5: In addition to an increase in V $\delta 1$ Tc in the uterine decidua, changes occurring in peripheral blood $\gamma \delta$ Tc and their subsets during healthy pregnancy probably contribute to fetal-maternal tolerance. Some of the reported variations include a diminished representation of $\mathrm{V} \gamma 9 \mathrm{~V} \delta 2 \mathrm{Tc}$, with increased proportions of other $\gamma \delta$ Tc subsets, such as $\mathrm{V} \gamma 4 \mathrm{~V} \delta 1$. However, considering the limited number of studies performed, additional investigation is needed on this subject.

Message 6: CMV infection has a substantial impact on $\gamma \delta$ Tc and their subsets, affecting mainly $\mathrm{V} \delta 2$ negative $\gamma \delta \mathrm{Tc}$, and contributing to many of the changes observed with aging; it may also explain some of the differences observed between races and ethnicities. Other HHVs may also contribute to modeling the $\gamma \delta$ Tc repertoire, but their role needs further investigation.

Message 7: Among the medications influencing $\gamma \delta$ Tc are bisphosphonates, largely used to treat osteoporosis, and statins, commonly used as anti-lipemic drugs. The dietary content of alkylamines may also impact $\gamma \delta$ Tc. 
Message 8: Gamma delta and $\alpha \beta$ Tc share virtually all cell molecules, except the type of TCR. Upon antigen recognition, both Tc types express activation related markers, progress through sequential differentiation stages and may have diverse types of functional polarization, producing different sets of cytokines. As a consequence, and depending on the circumstances, both may exhibit different functions, acting as APC; helping B cells for antibody production; suppressing the immune responses or promoting the inflammatory responses; and eventually converting into cytotoxic Tc. The distinct immunophenotypes observed in $\gamma \delta$ and $\alpha \beta$ Tc, and in $\gamma \delta$ Tc subsets, may traduce diverse activation and differentiation stages and/or distinct functional polarization, rather than being lineage related.

\section{Conclusions}

In summary, $\gamma \delta$ Tc found in human PB are influenced by the race/ethnicity; age; gender; special periods of life, such as menarche, menstrual cycle, pregnancy and menopause; and by present and past immunological experiences, infections, diet, medications and previous and concomitant diseases; additionally, major immunophenotypic differences are observed between $\alpha \beta$ and $\gamma \delta$ Tc, and between $\gamma \delta$ Tc subsets, which may result from different maturation/differentiation/activation stages and may account for distinct functional properties.

Gamma/delta Tc and their subsets are frequently studied in the context of a wide range of pathological situations, and for the investigation of patients with cytopenias or suspected of having Tc LPD. However, due to the high variation observed, caution should be taken in interpreting the clinical significance of finding "abnormal levels" and/or "phenotypically abnormal" $\gamma \delta$ Tc populations in individual patients.

Population-based studies using optimized multicolor FCM panels are required to define the reference intervals for the $\gamma \delta$ Tc subsets and their differentiation and activation stages, accordingly to the demographic characteristics, and the influence of specific factors.

Supplementary Materials: Supplementary material is available online at http://www.mdpi.com/2073-4409/9/3/729/ s1. Table S1: Evaluation of the normality of distributions using the D'Agostino-Pearson and Kolmogorov-Smirnov tests and identification of outliers using the Tukey test. Table S2. Percentages of CD5, CD8, CD16, CD56 and $\mathrm{CD} 28+$ cells among peripheral blood $\gamma \delta \mathrm{Tc}, \mathrm{V} \delta 1+$ and $\mathrm{V} \delta 2+\gamma \delta \mathrm{Tc}$, in the study population of healthy adults. Table S3. Percentages and numbers of peripheral blood $\gamma \delta$ Tc and $\gamma \delta$ Tc subsets accordingly to the age in the study population of healthy adults. Table S4. Percentages and numbers of peripheral blood $\gamma \delta$ Tc and $\gamma \delta$ Tc subsets accordingly to the gender in the study population of healthy adults. Table S5: Spearman's rank correlations between the percentages and numbers of peripheral blood $\gamma \delta$ Tc and $\gamma \delta$ Tc subsets in the study population of normal healthy adults, by age and by gender. Table S6: Linear regression analysis between the percentages and numbers of peripheral blood $\gamma \delta$ Tc and $\gamma \delta$ Tc in the study population of normal healthy adults, by age and by gender. Table S7. Percentages and numbers of peripheral blood $\gamma \delta$ Tc and $\gamma \delta$ Tc subsets in the study population of healthy adults, accordingly to age and gender. Table S8. 95th reference intervals for the percentages and numbers of peripheral blood $\gamma \delta$ Tc and $\gamma \delta$ Tc subsets in the study population of healthy adults obtained with different statistic approaches. Figure S1: Relation between the logarithm of the percentages and numbers of peripheral blood $\gamma \delta$ Tc and $\gamma \delta$ Tc subsets in the study population of healthy adults, by ages and genders. Panel A: males + females; panel B: females; panel C: males. The Spearman's rank correlation coefficients (R) and $p$ values $(p)$ are indicated inside the graphics.

Author Contributions: S.F. and V.P. were involved in cell immunophenotyping, data acquisition and preliminary flow cytometry data analysis; C.L. and M.d.A.T. contributed to flow cytometry data analysis and interpretation; M.B.-A. was responsible for blood donor selection procedures; M.L. designed the experiments, performed flow cytometry data analysis and interpretation, collected and interpreted the data, analyzed statistics, reviewed the literature, and wrote the manuscript. All authors have approved the final version of the manuscript.

Funding: The Centro Hospitalar Universitário do Porto made available the necessary infrastructure and equipment and gave financial support to this study (grant 036/11-021-DEFI/036-CES).

Acknowledgments: The authors thank to the Blood Donors for agreeing to participate in the study, to nurses of the Blood Bank for blood collection, and to the other medical doctors and technicians of the Laboratory of Cytometry for support concerning the routine laboratory tests.

Conflicts of Interest: The authors declare no conflict of interest. The funders had no role in study design, data collection and analysis, decision to publish, or preparation of the manuscript.

Abbreviations: ADCC: Antibody-dependent cellular cytotoxicity; Ag: Antigen; AIDS: Acquired immunodeficiency syndrome; APC: Allophycocyanin cyanine (fluorochrome); APC: Antigen-presenting cells; 
APC-H7: Allophycocyanin cyanine 7 (fluorochrome); B3A1: Butyrophilin 3A1; BC: Beckman Coulter; BD: Becton Dickinson; CB: Cord blood; CD: Cluster of differentiation; CDR3, complementary determining region 3; CD40L: CD40 ligand (CD154); CLSI: Clinical and Laboratory Standards Institute; CMV: Cytomegalovirus (HHV-5); CNS: Central nervous system; CTL: Cytotoxic T lymphocytes; CXCR5: CX-chemokine receptor type 5 (CD185); D'A-PT: D'Agostino-Pearson test (for normality) (statistic); EBV: Epstein Barr Virus (HHV-4); FCM: Flow cytometry; Fc $\gamma$ RIII: Fc gamma receptor type III, low affinity Fc receptor for IgG; FDPS: Farnesyl diphosphate synthase; FITC: Fluorescein isothiocyanate (fluorochrome); FSC: Forward scatter; FT: F test (for variances) (statistics); HBV: Hepatitis B virus; HCV: Hepatitis C virus; HHV: Human herpes virus; HHV-1: Human herpes virus-1 (HSV-1); HHV-2: Human herpes virus-2 (HSV-2); HHV-3: Human herpes virus-3 (HZV); HHV-4: Human herpes virus-4 (EBV); HHV-5: Human herpes virus-5 (CMV); HHV-6: Human herpes virus-6; HHV-7: Human herpes virus-7; HHV-8: Human herpes virus-8 (KZHV); HIV: Human immunodeficiency virus; HMB-PP: (E)-4-hydroxy-3-methyl-but-2-enyl pyrophosphate; HMG-CoA: 3-hydroxy-3-methylglutaryl-coenzyme A; HPVB19: Human parvovirus B19; HSP: Heat shock proteins; HSV-1: Herpes simplex virus-1; HSV-2: Herpes simplex virus-2; HTLV: Human T cell lymphoma/leukemia virus; ICOS: Inducible T-cell costimulatory molecule (CD278); IFN- $\gamma$ : Interferon gamma; IL: Interleukin; IOT: Immunotech; IPP: Isopentenyl pyrophosphate; K3-EDTA: Tripotassium ethylenediaminetetraacetic acid; KO, Krome orange (fluorochrome); KST: Kolmogorov-Smirnov test (for normality); KZHV: Kaposi's sarcoma-associated herpes virus (HHV-8); LGL: Large granular lymphocyte; LPD: Lymphoproliferative disorders; mAb: Monoclonal antibody; MAIT: Mucosal associated invariant T cells; MedFI: Median fluorescence intensity; MHC: Major histocompatibility complex; MIC: MHC class I polypeptide-related chains; MIC-A: MHC class I polypeptide-related chain type A; MIC-B: MHC class I polypeptide-related chain type B; MIP-1 $\alpha$ : Macrophage inflammatory protein-1 alpha: MWUT: Mann-Whitney U test (statistic); NA: Not applicable; NAT: Nucleic acid tests; NBP: Nitrogen-containing bisphosphonates; NCAM: Neural cell adhesion molecule; NCCLS: National Committee for Clinical Laboratory Standards; NK, Natural killer; NKG2D: Natural killer group 2 member D (killer cell receptor); NKR: Natural killer cell receptors; PB: Peripheral blood; PC5.5: PE-Cyanine 5.5 (fluorochrome); PC7: PE-Cyanine 7 (fluorochrome); PD-1: Programmed cell death 1, PD-1 (CD279); PE: Phycoerythrin (fluorochrome); PHA: Phytohemagglutinin (mitogen); PMT: Photomultiplier tubes; PTLS: Post-transplant lymphoproliferative syndrome; RAET1: Retinoic acid early transcripts; RANTES: Regulated on activation, normally T cell expressed or secreted; RAU: Recurrent aphthous ulceration; SD: Standard deviation; SRCT: Spearman rank correlation test; SSC: Side scatter; Tc: T cells; TCM: Central memory T cells; TCR: T-cell receptor; $\mathrm{T}_{\mathrm{EM}}$ : Effector memory $\mathrm{T}$ cells; $\mathrm{T}_{\mathrm{EMRA}}$ : Terminally differentiated effector $\mathrm{T}$ cells; $\mathrm{Tfh}$ : Follicular helper $\mathrm{T}$ cells; TGF- $\beta$ : Transforming growth factor-beta; Th: T helper; Th1: T helper type 1; Th17: T helper type 17; Th2: T helper type 2; $\mathrm{T}_{\mathrm{N}}$ : Naïve T cells; TNF- $\alpha$ : Tumor necrosis factor alpha; Treg: Regulatory T cells; TT: Tukey test (statistic); ULBP: UL16 binding proteins; V450: Violet 450 (fluorochrome); VZV: Varicella Zoster Virus (HHV-3); WBC: White blood cells; WHO: World Health Organization; WSRT: Wilcoxon signed-rank (statistics).

\section{References}

1. Aljurf, M.; Ezzat, A.O.; Musa, M. Emerging role of gammadelta T-cells in health and disease. Blood Rev. 2002, 16, 203-206.

2. Granel, B.; Camoin, L.; Serratrice, J.; de Roux-Serratrice, C.; Brunet, C.; Pache, X.; Swiader, L.; Disdier, P.; Weiller, P.J. [Retrospective study of 55 patients with circulating blood T gama/delta lymphocytosis]. Rev. Med. Internet 2002, 23, 137-143. [CrossRef]

3. Roden, A.C.; Morice, W.G.; Hanson, C.A. Immunophenotypic attributes of benign peripheral blood gammadelta T cells and conditions associated with their increase. Arch. Pathol. Lab. Med. 2008, 132, 1774-1780. [PubMed]

4. Kalyan, S.; Kabelitz, D. Defining the nature of human $\gamma \delta \mathrm{T}$ cells: A biographical sketch of the highly empathetic. Cell. Mol. Immunol. 2013, 10, 21-29. [CrossRef] [PubMed]

5. Poggi, A.; Zocchi, M.R. $\gamma \delta$ T Lymphocytes as a First Line of Immune Defense: Old and New Ways of Antigen Recognition and Implications for Cancer Immunotherapy. Front. Immunol. 2014, 5, 575. [CrossRef]

6. Adams, E.J.; Gu, S.; Luoma, A.M. Human gamma delta T cells: Evolution and ligand recognition. Cell. Immunol. 2015, 296, 31-40. [CrossRef]

7. Chen, Z.W. Immune biology of Ag-specific $\gamma \delta$ T cells in infections. Cell. Mol. Life Sci. 2011, 68, $2409-2417$. [CrossRef]

8. Zheng, J.; Liu, Y.; Lau, Y.-L.; Tu, W. $\gamma \delta$-T cells: An unpolished sword in human anti-infection immunity. Cell. Mol. Immunol. 2013, 10, 50-57. [CrossRef]

9. Kabelitz, D.; Wesch, D. Role of gamma delta T-lymphocytes in HIV infection. Eur. J. Med. Res. 2001, 6, 169-174.

10. Pauza, C.D.; Poonia, B.; Li, H.; Cairo, C.; Chaudhry, S. $\gamma \delta$ T Cells in HIV Disease: Past, Present, and Future. Front. Immunol. 2014, 5, 687. 
11. Rajoriya, N.; Fergusson, J.R.; Leithead, J.A.; Klenerman, P. Gamma Delta T-lymphocytes in Hepatitis C and Chronic Liver Disease. Front. Immunol. 2014, 5, 400. [CrossRef] [PubMed]

12. Terrazzini, N.; Kern, F. Cell-mediated immunity to human CMV infection: A brief overview. F1000prime Rep. 2014, 6, 28. [CrossRef] [PubMed]

13. Chen, Z.W.; Letvin, N.L. Vgamma2Vdelta2+ T cells and anti-microbial immune responses. Microbes Infect. 2003, 5, 491-498. [CrossRef]

14. Meraviglia, S.; El Daker, S.; Dieli, F.; Martini, F.; Martino, A. $\gamma \delta$ T cells cross-link innate and adaptive immunity in Mycobacterium tuberculosis infection. Clin. Dev. Immunol. 2011, 2011, 587315. [CrossRef]

15. Ferrarini, M.; Ferrero, E.; Dagna, L.; Poggi, A.; Zocchi, M.R. Human gammadelta T cells: A nonredundant system in the immune-surveillance against cancer. Trends Immunol. 2002, 23, 14-18. [CrossRef]

16. Zocchi, M.R.; Poggi, A. Role of gammadelta T lymphocytes in tumor defense. Front. Biosci. J. Virtual Libr. 2004, 9, 2588-2604. [CrossRef]

17. Silva-Santos, B.; Serre, K.; Norell, H. $\gamma \delta$ T cells in cancer. Nat. Rev. Immunol. 2015, 15, 683-691. [CrossRef]

18. Su, D.; Shen, M.; Li, X.; Sun, L. Roles of $\gamma \delta \mathrm{T}$ cells in the pathogenesis of autoimmune diseases. Clin. Dev. Immunol. 2013, 2013, 985753. [CrossRef]

19. Paul, S.; Shilpi, N.; Lal, G. Role of gamma-delta $(\gamma \delta)$ T cells in autoimmunity. J. Leukoc. Biol. 2015, 97, $259-271$.

20. Gogoi, D.; Chiplunkar, S.V. Targeting gamma delta T cells for cancer immunotherapy: Bench to bedside. Indian J. Med. Res. 2013, 138, 755-761.

21. Deniger, D.C.; Moyes, J.S.; Cooper, L.J.N. Clinical applications of gamma delta T cells with multivalent immunity. Front. Immunol. 2014, 5, 636. [CrossRef] [PubMed]

22. Legut, M.; Cole, D.K.; Sewell, A.K. The promise of $\gamma \delta \mathrm{T}$ cells and the $\gamma \delta \mathrm{T}$ cell receptor for cancer immunotherapy. Cell. Mol. Immunol. 2015, 12, 656-668. [CrossRef] [PubMed]

23. Sandberg, Y.; Almeida, J.; Gonzalez, M.; Lima, M.; Bárcena, P.; Szczepañski, T.; van Gastel-Mol, E.J.; Wind, H.; Balanzategui, A.; van Dongen, J.J.M.; et al. TCRgammadelta+ large granular lymphocyte leukemias reflect the spectrum of normal antigen-selected TCRgammadelta+ T-cells. Leukemia 2006, 20, 505-513. [CrossRef] [PubMed]

24. Yabe, M.; Medeiros, L.J.; Wang, S.A.; Konoplev, S.; Ok, C.Y.; Loghavi, S.; Lu, G.; Flores, L.; Khoury, J.D.; Cason, R.C.; et al. Clinicopathologic, Immunophenotypic, Cytogenetic, and Molecular Features of $\gamma \delta$ T-Cell Large Granular Lymphocytic Leukemia: An Analysis of 14 Patients Suggests Biologic Differences With $\alpha \beta$ T-Cell Large Granular Lymphocytic Leukemia. [corrected]. Am. J. Clin. Pathol. 2015, 144, 607-619. [CrossRef]

25. Tripodo, C.; Iannitto, E.; Florena, A.M.; Pucillo, C.E.; Piccaluga, P.P.; Franco, V.; Pileri, S.A. Gamma-delta T-cell lymphomas. Nat. Rev. Clin. Oncol. 2009, 6, 707-717. [CrossRef]

26. Shi, Y.; Wang, E. Hepatosplenic T-Cell Lymphoma: A Clinicopathologic Review With an Emphasis on Diagnostic Differentiation From Other T-Cell/Natural Killer-Cell Neoplasms. Arch. Pathol. Lab. Med. 2015, 139, 1173-1180. [CrossRef]

27. Ferreri, A.J.M.; Govi, S.; Pileri, S.A. Hepatosplenic gamma-delta T-cell lymphoma. Crit. Rev. Oncol. Hematol. 2012, 83, 283-292. [CrossRef]

28. Go, R.S.; Wester, S.M. Immunophenotypic and molecular features, clinical outcomes, treatments, and prognostic factors associated with subcutaneous panniculitis-like T-cell lymphoma: A systematic analysis of 156 patients reported in the literature. Cancer 2004, 101, 1404-1413. [CrossRef]

29. Gu, S.; Nawrocka, W.; Adams, E.J. Sensing of Pyrophosphate Metabolites by V $\gamma 9 \mathrm{~V} \delta 2 \mathrm{~T}$ Cells. Front. Immunol. 2014, 5, 688 .

30. De Libero, G.; Lau, S.-Y.; Mori, L. Phosphoantigen Presentation to TCR $\gamma \delta$ Cells, a Conundrum Getting Less Gray Zones. Front. Immunol. 2014, 5, 679.

31. Raulet, D.H. Roles of the NKG2D immunoreceptor and its ligands. Nat. Rev. Immunol. 2003, 3, 781-790. [CrossRef] [PubMed]

32. Bahram, S.; Inoko, H.; Shiina, T.; Radosavljevic, M. MIC and other NKG2D ligands: From none to too many. Curr. Opin. Immunol. 2005, 17, 505-509. [CrossRef] [PubMed]

33. Spada, F.M.; Grant, E.P.; Peters, P.J.; Sugita, M.; Melián, A.; Leslie, D.S.; Lee, H.K.; van Donselaar, E.; Hanson, D.A.; Krensky, A.M.; et al. Self-recognition of CD1 by gamma/delta T cells: Implications for innate immunity. J. Exp. Med. 2000, 191, 937-948. [CrossRef] [PubMed]

34. Luoma, A.M.; Castro, C.D.; Adams, E.J. $\gamma \delta$ T cell surveillance via CD1 molecules. Trends Immunol. 2014, 35, 613-621. [CrossRef] [PubMed] 
35. de Jong, A. Activation of human T cells by CD1 and self-lipids. Immunol. Rev. 2015, 267, 16-29. [CrossRef] [PubMed]

36. Cao, W.; He, W. UL16 binding proteins. Immunobiology 2004, 209, 283-290. [CrossRef]

37. Hirsh, M.I.; Junger, W.G. Roles of heat shock proteins and gamma delta T cells in inflammation. Am. J. Respir. Cell Mol. Biol. 2008, 39, 509-513. [CrossRef]

38. Parker, C.M.; Groh, V.; Band, H.; Porcelli, S.A.; Morita, C.; Fabbi, M.; Glass, D.; Strominger, J.L.; Brenner, M.B. Evidence for extrathymic changes in the T cell receptor gamma/delta repertoire. J. Exp. Med. 1990, 171, 1597-1612. [CrossRef]

39. Wesch, D.; Hinz, T.; Kabelitz, D. Analysis of the TCR Vgamma repertoire in healthy donors and HIV-1-infected individuals. Int. Immunol. 1998, 10, 1067-1075. [CrossRef]

40. Przybylski, G.K.; Wu, H.; Macon, W.R.; Finan, J.; Leonard, D.G.; Felgar, R.E.; DiGiuseppe, J.A.; Nowell, P.C.; Swerdlow, S.H.; Kadin, M.E.; et al. Hepatosplenic and subcutaneous panniculitis-like gamma/delta T cell lymphomas are derived from different Vdelta subsets of gamma/delta T lymphocytes. J. Mol. Diagn. 2000, 2, 11-19. [CrossRef]

41. Lima, M.; Almeida, J.; Santos, A.H.; dos Anjos Teixeira, M.; Alguero, M.C.; Queirós, M.L.; Balanzategui, A.; Justiça, B.; Gonzalez, M.; San Miguel, J.F.; et al. Immunophenotypic analysis of the TCR-Vbeta repertoire in 98 persistent expansions of CD3(+)/TCR-alphabeta(+) large granular lymphocytes: Utility in assessing clonality and insights into the pathogenesis of the disease. Am. J. Pathol. 2001, 159, 1861-1868. [CrossRef]

42. Lima, M.; Almeida, J.; Dos Anjos Teixeira, M.; Alguero Md, M.; del, C.; Santos, A.H.; Balanzategui, A.; Queirós, M.L.; Bárcena, P.; Izarra, A.; et al. TCRalphabeta+/CD4+ large granular lymphocytosis: A new clonal T-cell lymphoproliferative disorder. Am. J. Pathol. 2003, 163, 763-771.

43. Lima, M.; Almeida, J.; dos Anjos Teixeira, M.; Queiros, M.L.; Santos, A.H.; Fonseca, S.; Balanzategui, A.; Justica, B.; Orfao, A.; Orfao, A. Utility of flow cytometry immunophenotyping and DNA ploidy studies for diagnosis and characterization of blood involvement in CD4+ Sézary's syndrome. Haematologica 2003, 88, 874-887.

44. Lima, M.; Teixeira, M.; dos, A.; Queirós, M.L.; Santos, A.H.; Gonçalves, C.; Correia, J.; Farinha, F.; Mendonça, F.; Soares, J.M.N.; et al. Immunophenotype and TCR-Vbeta repertoire of peripheral blood T-cells in acute infectious mononucleosis. Blood Cells. Mol. Dis. 2003, 30, 1-12.

45. Szereday, L.; Baliko, Z.; Szekeres-Bartho, J. Gamma/delta T cell subsets in patients with active Mycobacterium tuberculosis infection and tuberculin anergy. Clin. Exp. Immunol. 2003, 131, 287-291. [CrossRef] [PubMed]

46. Puig-Pey, I.; Bohne, F.; Benítez, C.; López, M.; Martínez-Llordella, M.; Oppenheimer, F.; Lozano, J.J.; GonzálezAbraldes, J.; Tisone, G.; Rimola, A.; et al. Characterization of $\gamma \delta \mathrm{T}$ cell subsets in organ transplantation. Transpl. Int. 2010, 23, 1045-1055. [CrossRef]

47. Moura, J.; Rodrigues, J.; Gonçalves, M.; Amaral, C.; Lima, M.; Carvalho, E. Impaired T-cell differentiation in diabetic foot ulceration. Cell. Mol. Immunol. 2016. [CrossRef]

48. Cooke, C.B.; Krenacs, L.; Stetler-Stevenson, M.; Greiner, T.C.; Raffeld, M.; Kingma, D.W.; Abruzzo, L.; Frantz, C.; Kaviani, M.; Jaffe, E.S. Hepatosplenic T-cell lymphoma: A distinct clinicopathologic entity of cytotoxic gamma delta T-cell origin. Blood 1996, 88, 4265-4274. [CrossRef]

49. van den Beemd, R.; Boor, P.P.; van Lochem, E.G.; Hop, W.C.; Langerak, A.W.; Wolvers-Tettero, I.L.; Hooijkaas, H.; van Dongen, J.J. Flow cytometric analysis of the Vbeta repertoire in healthy controls. Cytometry 2000, 40, 336-345. [CrossRef]

50. McLean-Tooke, A.; Barge, D.; Spickett, G.P.; Gennery, A.R. T cell receptor Vbeta repertoire of T lymphocytes and T regulatory cells by flow cytometric analysis in healthy children. Clin. Exp. Immunol. 2008, 151, 190-198. [CrossRef]

51. Hviid, L.; Akanmori, B.D.; Loizon, S.; Kurtzhals, J.A.; Ricke, C.H.; Lim, A.; Koram, K.A.; Nkrumah, F.K.; Mercereau-Puijalon, O.; Behr, C. High frequency of circulating gamma delta T cells with dominance of the $\mathrm{v}$ (delta) 1 subset in a healthy population. Int. Immunol. 2000, 12, 797-805. [CrossRef] [PubMed]

52. Argentati, K.; Re, F.; Donnini, A.; Tucci, M.G.; Franceschi, C.; Bartozzi, B.; Bernardini, G.; Provinciali, M. Numerical and functional alterations of circulating gammadelta $\mathrm{T}$ lymphocytes in aged people and centenarians. J. Leukoc. Biol. 2002, 72, 65-71. [PubMed]

53. Caccamo, N.; Dieli, F.; Wesch, D.; Jomaa, H.; Eberl, M. Sex-specific phenotypical and functional differences in peripheral human Vgamma9/Vdelta2 T cells. J. Leukoc. Biol. 2006, 79, 663-666. [CrossRef] [PubMed] 
54. Cairo, C.; Armstrong, C.L.; Cummings, J.S.; Deetz, C.O.; Tan, M.; Lu, C.; Davis, C.E.; Pauza, C.D. Impact of age, gender, and race on circulating $\gamma \delta$ T cells. Hum. Immunol. 2010, 71, 968-975. [CrossRef]

55. Michishita, Y.; Hirokawa, M.; Guo, Y.-M.; Abe, Y.; Liu, J.; Ubukawa, K.; Fujishima, N.; Fujishima, M.; Yoshioka, T.; Kameoka, Y.; et al. Age-associated alteration of $\gamma \delta$ T-cell repertoire and different profiles of activation-induced death of V $\delta 1$ and V $\delta 2$ T cells. Int. J. Hematol. 2011, 94, 230-240. [CrossRef]

56. Dimova, T.; Brouwer, M.; Gosselin, F.; Tassignon, J.; Leo, O.; Donner, C.; Marchant, A.; Vermijlen, D. Effector V $\gamma 9$ V 22 T cells dominate the human fetal $\gamma \delta$ T-cell repertoire. Proc. Natl. Acad. Sci. USA 2015, 112, E556-E565. [CrossRef]

57. Kalina, T.; Flores-Montero, J.; van der Velden, V.H.J.; Martin-Ayuso, M.; Böttcher, S.; Ritgen, M.; Almeida, J.; Lhermitte, L.; Asnafi, V.; Mendonça, A.; et al. EuroFlow standardization of flow cytometer instrument settings and immunophenotyping protocols. Leukemia 2012, 26, 1986-2010. [CrossRef]

58. Kalina, T.; Flores-Montero, J.; Lecrevisse, Q.; Pedreira, C.E.; van der Velden, V.H.J.; Novakova, M.; Mejstrikova, E.; Hrusak, O.; Böttcher, S.; Karsch, D.; et al. Quality assessment program for EuroFlow protocols: Summary results of four-year (2010-2013) quality assurance rounds. Cytom. Part J. 2015, 87, 145-156. [CrossRef]

59. Wayne, PA: NCCLS How to Define and Determine Reference Intervals in the Clinical Laboratory: Approved Guideline. NCCLS Document C28-A2. 2nd edition. 2000. Available online: http://www.zxyjhjy.com/upload/ attached/file/20170406/20170406120112_8797.pdf (accessed on 6 April 2017).

60. Wayne, PA: CLSI Defining, Establishing, and Verifying Reference Intervals in the Clinical Laboratory Approved Guideline. CLSI Document EP28-A3C. Third edition. Available online: http://shop.clsi.org/site/ Sample_pdf/EP28A3C_sample.pdf (accessed on 19 October 2010).

61. Gebo, K.A.; Gallant, J.E.; Keruly, J.C.; Moore, R.D. Absolute CD4 vs. CD4 percentage for predicting the risk of opportunistic illness in HIV infection. J. Acquir. Immune Defic. Syndr. 1999 2004, 36, 1028-1033.

62. Swerdlow, S.H.; Campo, E.; Harris, N.L.; Jaffe, E.S.; Pileri, S.A.; Stein, H.; Thiele, J. WHO Classification of Tumours of Haematopoietic and Lymphoid Tissues. Revised Fourth Edition.; IARC: Lyon, France, 2017.

63. Andreu-Ballester, J.C.; García-Ballesteros, C.; Benet-Campos, C.; Amigó, V.; Almela-Quilis, A.; Mayans, J.; Ballester, F. Values for $\alpha \beta$ and $\gamma \delta$ T-lymphocytes and CD4+, CD8+, and CD56+ subsets in healthy adult subjects: Assessment by age and gender. Cytometry B Clin. Cytom. 2012, 82, 238-244. [CrossRef]

64. Bottino, C.; Tambussi, G.; Ferrini, S.; Ciccone, E.; Varese, P.; Mingari, M.C.; Moretta, L.; Moretta, A. Two subsets of human $\mathrm{T}$ lymphocytes expressing gamma/delta antigen receptor are identifiable by monoclonal antibodies directed to two distinct molecular forms of the receptor. J. Exp. Med. 1988, 168, 491-505. [CrossRef]

65. Schondelmaier, S.; Wesch, D.; Pechhold, K.; Kabelitz, D. V gamma gene usage in peripheral blood gamma delta T cells. Immunol. Lett. 1993, 38, 121-126. [CrossRef]

66. Hinz, T.; Wesch, D.; Halary, F.; Marx, S.; Choudhary, A.; Arden, B.; Janssen, O.; Bonneville, M.; Kabelitz, D. Identification of the complete expressed human TCR V gamma repertoire by flow cytometry. Int. Immunol. 1997, 9, 1065-1072. [CrossRef] [PubMed]

67. Roux, A.; Mourin, G.; Larsen, M.; Fastenackels, S.; Urrutia, A.; Gorochov, G.; Autran, B.; Donner, C.; Sidi, D.; Sibony-Prat, J.; et al. Differential impact of age and cytomegalovirus infection on the $\gamma \delta \mathrm{T}$ cell compartment. J. Immunol. 2013, 191, 1300-1306. [CrossRef] [PubMed]

68. Wistuba-Hamprecht, K.; Frasca, D.; Blomberg, B.; Pawelec, G.; Derhovanessian, E. Age-associated alterations in $\gamma \delta$ T-cells are present predominantly in individuals infected with Cytomegalovirus. Immun. Ageing A 2013, 10, 26. [CrossRef]

69. Wistuba-Hamprecht, K.; Haehnel, K.; Janssen, N.; Demuth, I.; Pawelec, G. Peripheral blood T-cell signatures from high-resolution immune phenotyping of $\gamma \delta$ and $\alpha \beta$ T-cells in younger and older subjects in the Berlin Aging Study II. Immun. Ageing A 2015, 12, 25. [CrossRef]

70. Kallemeijn, M.J.; Boots, A.M.H.; van der Klift, M.Y.; Brouwer, E.; Abdulahad, W.H.; Verhaar, J.A.N.; van Dongen, J.J.M.; Langerak, A.W. Ageing and Latent CMV Infection Impact on Maturation, Differentiation and Exhaustion Profiles of T-cell Receptor Gammadelta T-cells. Sci Rep. 2017, 7, 5509. [CrossRef]

71. Esin, S.; Shigematsu, M.; Nagai, S.; Eklund, A.; Wigzell, H.; Grunewald, J. Different percentages of peripheral blood gamma delta $+\mathrm{T}$ cells in healthy individuals from different areas of the world. Scand. J. Immunol. 1996, 43, 593-596. [CrossRef]

72. Re, F.; Poccia, F.; Donnini, A.; Bartozzi, B.; Bernardini, G.; Provinciali, M. Skewed representation of functionally distinct populations of Vgamma9Vdelta2 T lymphocytes in aging. Exp. Gerontol. 2005, 40, 59-66. [CrossRef] 
73. Henriques, A.; Silva, C.; Santiago, M.; Henriques, M.J.; Martinho, A.; Trindade, H.; da Silva, J.A.P.; Silva-Santos, B.; Paiva, A. Subset-specific alterations in frequencies and functional signatures of $\gamma \delta \mathrm{T}$ cells in systemic sclerosis patients. Inflamm. Res. 2016, 65, 985-994. [CrossRef]

74. McVay, L.D.; Jaswal, S.S.; Kennedy, C.; Hayday, A.; Carding, S.R. The generation of human gammadelta T cell repertoires during fetal development. J. Immunol. 1998, 160, 5851-5860. [PubMed]

75. McVay, L.D.; Carding, S.R. Generation of human gammadelta T-cell repertoires. Crit. Rev. Immunol. 1999, 19, 431-460. [PubMed]

76. De Rosa, S.C.; Andrus, J.P.; Perfetto, S.P.; Mantovani, J.J.; Herzenberg, L.A.; Herzenberg, L.A.; Roederer, M. Ontogeny of gamma delta T cells in humans. J. Immunol. 2004, 172, 1637-1645. [CrossRef]

77. Smith, M.D.; Worman, C.; Yüksel, F.; Yüksel, B.; Moretta, L.; Ciccone, E.; Grossi, C.E.; MacKenzie, L.; Lydyard, P.M. T gamma delta-cell subsets in cord and adult blood. Scand. J. Immunol. 1990, 32, 491-495. [CrossRef] [PubMed]

78. Morita, C.T.; Parker, C.M.; Brenner, M.B.; Band, H. TCR usage and functional capabilities of human gamma delta T cells at birth. J. Immunol. 1994, 153, 3979-3988. [PubMed]

79. Re, F.; Donnini, A.; Bartozzi, B.; Bernardini, G.; Provinciali, M. Circulating gammadelta T cells in young/adult and old patients with cutaneous primary melanoma. Immun. Ageing A 2005, 2, 2. [CrossRef]

80. Vasudev, A.; Ying, C.T.T.; Ayyadhury, S.; Puan, K.J.; Andiappan, A.K.; Nyunt, M.S.Z.; Shadan, N.B.; Mustafa, S.; Low, I.; Rotzschke, O.; et al. $\gamma / \delta$ T cell subsets in human aging using the classical $\alpha / \beta$ T cell model. J. Leukoc. Biol. 2014, 96, 647-655. [CrossRef]

81. Szekeres-Bartho, J.; Barakonyi, A.; Polgar, B.; Par, G.; Faust, Z.; Palkovics, T.; Szereday, L. The role of gamma/delta $\mathrm{T}$ cells in progesterone-mediated immunomodulation during pregnancy: A review. Am. J. Reprod. Immunol. 1999, 42, 44-48. [CrossRef]

82. Szekeres-Bartho, J.; Barakonyi, A.; Miko, E.; Polgar, B.; Palkovics, T. The role of gamma/delta T cells in the feto-maternal relationship. Semin. Immunol. 2001, 13, 229-233. [CrossRef]

83. Chapman, J.C.; Chapman, F.M.; Michael, S.D. The production of alpha/beta and gamma/delta double negative (DN) T-cells and their role in the maintenance of pregnancy. Reprod. Biol. Endocrinol. 2015, 13, 73. [CrossRef]

84. Heyborne, K.; Fu, Y.X.; Nelson, A.; Farr, A.; O’Brien, R.; Born, W. Recognition of trophoblasts by gamma delta T cells. J. Immunol. 1994, 153, 2918-2926. [PubMed]

85. Polgar, B.; Barakonyi, A.; Xynos, I.; Szekeres-Bartho, J. The role of gamma/delta T cell receptor positive cells in pregnancy. Am. J. Reprod. Immunol. 1999, 41, 239-244. [CrossRef] [PubMed]

86. Barakonyi, A.; Polgar, B.; Szekeres-Bartho, J. The role of gamma/delta T-cell receptor-positive cells in pregnancy: Part II. Am. J. Reprod. Immunol. 1999, 42, 83-87. [PubMed]

87. Barakonyi, A.; Miko, E.; Varga, P.; Szekeres-Bartho, J. V-chain preference of gamma/delta T-cell receptors in peripheral blood during term labor. Am. J. Reprod. Immunol. 2008, 59, 201-205. [CrossRef]

88. Human Herpesviruses: Biology, Therapy, and Immunoprophylaxis; Arvin, A.; Campadelli-Fiume, G.; Mocarski, E.; Moore, P.S.; Roizman, B.; Whitley, R.; Yamanishi, K. (Eds.) Cambridge University Press: Cambridge, UK, 2007; ISBN 978-0-521-82714-0.

89. Goodrum, F.; Caviness, K.; Zagallo, P. Human cytomegalovirus persistence. Cell. Microbiol. 2012, 14, 644-655. [CrossRef] [PubMed]

90. Noriega, V.; Redmann, V.; Gardner, T.; Tortorella, D. Diverse immune evasion strategies by human cytomegalovirus. Immunol. Res. 2012, 54, 140-151. [CrossRef]

91. Griffiths, P.; Baraniak, I.; Reeves, M. The pathogenesis of human cytomegalovirus. J. Pathol. 2015, 235, 288-297. [CrossRef] [PubMed]

92. Navarro, D. Expanding role of cytomegalovirus as a human pathogen. J. Med. Virol. 2016, 88, 1103-1112. [CrossRef]

93. Déchanet, J.; Merville, P.; Bergé, F.; Bone-Mane, G.; Taupin, J.L.; Michel, P.; Joly, P.; Bonneville, M.; Potaux, L.; Moreau, J.F. Major expansion of gammadelta T lymphocytes following cytomegalovirus infection in kidney allograft recipients. J. Infect. Dis. 1999, 179, 1-8. [CrossRef]

94. Déchanet, J.; Merville, P.; Lim, A.; Retière, C.; Pitard, V.; Lafarge, X.; Michelson, S.; Méric, C.; Hallet, M.M.; Kourilsky, P.; et al. Implication of gammadelta $\mathrm{T}$ cells in the human immune response to cytomegalovirus. J. Clin. Investig. 1999, 103, 1437-1449. [CrossRef] 
95. Halary, F.; Pitard, V.; Dlubek, D.; Krzysiek, R.; de la Salle, H.; Merville, P.; Dromer, C.; Emilie, D.; Moreau, J.-F.; Déchanet-Merville, J. Shared reactivity of V\{delta\}2(neg) \{gamma\}\{delta\} T cells against cytomegalovirus-infected cells and tumor intestinal epithelial cells. J. Exp. Med. 2005, 201, 1567-1578. [CrossRef] [PubMed]

96. Knight, A.; Madrigal, A.J.; Grace, S.; Sivakumaran, J.; Kottaridis, P.; Mackinnon, S.; Travers, P.J.; Lowdell, M.W. The role of V $\delta 2$-negative $\gamma \delta$ T cells during cytomegalovirus reactivation in recipients of allogeneic stem cell transplantation. Blood 2010, 116, 2164-2172. [CrossRef] [PubMed]

97. Pitard, V.; Roumanes, D.; Lafarge, X.; Couzi, L.; Garrigue, I.; Lafon, M.-E.; Merville, P.; Moreau, J.-F.; Déchanet-Merville, J. Long-term expansion of effector/memory Vdelta2-gammadelta $\mathrm{T}$ cells is a specific blood signature of CMV infection. Blood 2008, 112, 1317-1324. [CrossRef] [PubMed]

98. Pawelec, G.; Derhovanessian, E. Role of CMV in immune senescence. Virus Res. 2011, 157, $175-179$. [CrossRef] [PubMed]

99. Pawelec, G. Immunosenenescence: Role of cytomegalovirus. Exp. Gerontol. 2014, 54, 1-5. [CrossRef] [PubMed]

100. Sciammas, R.; Kodukula, P.; Tang, Q.; Hendricks, R.L.; Bluestone, J.A. T cell receptor-gamma/delta cells protect mice from herpes simplex virus type 1-induced lethal encephalitis. J. Exp. Med. 1997, 185, 1969-1975. [CrossRef]

101. Puttur, F.K.; Fernandez, M.A.; White, R.; Roediger, B.; Cunningham, A.L.; Weninger, W.; Jones, C.A. Herpes simplex virus infects skin gamma delta $\mathrm{T}$ cells before Langerhans cells and impedes migration of infected Langerhans cells by inducing apoptosis and blocking E-cadherin downregulation. J. Immunol. Baltim. Md 1950 2010, 185, 477-487.

102. Rakasz, E.; Mueller, A.; Perlman, S.; Lynch, R.G. Gammadelta T cell response induced by vaginal Herpes simplex 2 infection. Immunol. Lett. 1999, 70, 89-93. [CrossRef]

103. Nishimura, H.; Yajima, T.; Kagimoto, Y.; Ohata, M.; Watase, T.; Kishihara, K.; Goshima, F.; Nishiyama, Y.; Yoshikai, Y. Intraepithelial gammadelta T cells may bridge a gap between innate immunity and acquired immunity to herpes simplex virus type 2. J. Virol. 2004, 78, 4927-4930. [CrossRef]

104. Kim, J.-O.; Cha, H.-R.; Kim, E.-D.; Kweon, M.-N. Pathological effect of IL-17A-producing TCR $\gamma \delta(+)$ T cells in mouse genital mucosa against HSV-2 infection. Immunol. Lett. 2012, 147, 34-40. [CrossRef]

105. Maccario, R.; Revello, M.G.; Comoli, P.; Montagna, D.; Locatelli, F.; Gerna, G. HLA-unrestricted killing of HSV-1-infected mononuclear cells. Involvement of either gamma/delta+ or alpha/beta+ human cytotoxic $T$ lymphocytes. J. Immunol. 1993, 150, 1437-1445. [PubMed]

106. Verjans, G.M.G.M.; Roest, R.W.; van der Kooi, A.; van Dijk, G.; van der Meijden, W.I.; Osterhaus, A. 'D M E Osterhaus, A. E. Isopentenyl pyrophosphate-reactive Vgamma9Vdelta $2 \mathrm{~T}$ helper 1-like cells are the major gammadelta $\mathrm{T}$ cell subset recovered from lesions of patients with genital herpes. J. Infect. Dis. 2004, 190, 489-493.

107. Pedersen, A.; Hornsleth, A. Recurrent aphthous ulceration: A possible clinical manifestation of reactivation of varicella zoster or cytomegalovirus infection. J. Oral Pathol. Med. Off. Publ. Int. Assoc. Oral Pathol. Am. Acad. Oral Pathol. 1993, 22, 64-68. [CrossRef]

108. Pedersen, A.; Ryder, L.P. Gamma delta T-cell fraction of peripheral blood is increased in recurrent aphthous ulceration. Clin. Immunol. Immunopathol. 1994, 72, 98-104. [CrossRef]

109. Lam, V.; DeMars, R.; Chen, B.P.; Hank, J.A.; Kovats, S.; Fisch, P.; Sondel, P.M. Human T cell receptor-gamma delta-expressing T-cell lines recognize MHC-controlled elements on autologous EBV-LCL that are not HLA-A, -B, -C, -DR, -DQ, or -DP. J. Immunol. 1990, 145, 36-45. [PubMed]

110. Häcker, G.; Kromer, S.; Falk, M.; Heeg, K.; Wagner, H.; Pfeffer, K. V delta 1+ subset of human gamma delta T cells responds to ligands expressed by EBV-infected Burkitt lymphoma cells and transformed B lymphocytes. J. Immunol. 1992, 149, 3984-3989. [PubMed]

111. Orsini, D.L.; Res, P.C.; Van Laar, J.M.; Muller, L.M.; Soprano, A.E.; Kooy, Y.M.; Tak, P.P.; Koning, F. A subset of $\mathrm{V}$ delta $1+\mathrm{T}$ cells proliferates in response to Epstein-Barr virus-transformed B cell lines in vitro. Scand. J. Immunol. 1993, 38, 335-340. [CrossRef] [PubMed]

112. Orsini, D.L.; van Gils, M.; Kooy, Y.M.; Struyk, L.; Klein, G.; van den Elsen, P.; Koning, F. Functional and molecular characterization of B cell-responsive V delta 1+ gamma delta T cells. Eur. J. Immunol. 1994, 24, 3199-3204. [CrossRef] [PubMed] 
113. Wada, T.; Toga, A.; Sakakibara, Y.; Toma, T.; Hasegawa, M.; Takehara, K.; Shigemura, T.; Agematsu, K.; Yachie, A. Clonal expansion of Epstein-Barr virus (EBV)-infected $\gamma \delta \mathrm{T}$ cells in patients with chronic active EBV disease and hydroa vacciniforme-like eruptions. Int. J. Hematol. 2012, 96, 443-449. [CrossRef]

114. Hirai, Y.; Yamamoto, T.; Kimura, H.; Ito, Y.; Tsuji, K.; Miyake, T.; Morizane, S.; Suzuki, D.; Fujii, K.; Iwatsuki, K. Hydroa vacciniforme is associated with increased numbers of Epstein-Barr virus-infected $\gamma \delta \mathrm{T}$ cells. J. Invest. Dermatol. 2012, 132, 1401-1408. [CrossRef]

115. Choe, J.-Y.; Bisig, B.; de Leval, L.; Jeon, Y.K. Primary $\gamma \delta$ T cell lymphoma of the lung: Report of a case with features suggesting derivation from intraepithelial $\gamma \delta \mathrm{T}$ lymphocytes. Virchows Arch. Int. J. Pathol. 2014, 465, 731-736. [CrossRef] [PubMed]

116. Kato, S.; Asano, N.; Miyata-Takata, T.; Takata, K.; Elsayed, A.A.; Satou, A.; Takahashi, E.; Kinoshita, T.; Nakamura, S. T-cell receptor (TCR) phenotype of nodal Epstein-Barr virus (EBV)-positive cytotoxic T-cell lymphoma (CTL): A clinicopathologic study of 39 cases. Am. J. Surg. Pathol. 2015, 39, 462-471. [CrossRef] [PubMed]

117. Oyoshi, M.K.; Nagata, H.; Kimura, N.; Zhang, Y.; Demachi, A.; Hara, T.; Kanegane, H.; Matsuo, Y.; Yamaguchi, T.; Morio, T.; et al. Preferential expansion of Vgamma9-JgammaP/Vdelta2-Jdelta3 gammadelta T cells in nasal T-cell lymphoma and chronic active Epstein-Barr virus infection. Am. J. Pathol. 2003, 162, 1629-1638. [CrossRef]

118. Xiang, Z.; Liu, Y.; Zheng, J.; Liu, M.; Lv, A.; Gao, Y.; Hu, H.; Lam, K.-T.; Chan, G.C.-F.; Yang, Y.; et al. Targeted activation of human $\mathrm{V} \gamma 9 \mathrm{~V} \delta 2-\mathrm{T}$ cells controls epstein-barr virus-induced B cell lymphoproliferative disease. Cancer Cell 2014, 26, 565-576. [CrossRef]

119. Lusso, P.; Garzino-Demo, A.; Crowley, R.W.; Malnati, M.S. Infection of gamma/delta T lymphocytes by human herpesvirus 6: Transcriptional induction of CD4 and susceptibility to HIV infection. J. Exp. Med. 1995, 181, 1303-1310. [CrossRef]

120. Barcy, S.; De Rosa, S.C.; Vieira, J.; Diem, K.; Ikoma, M.; Casper, C.; Corey, L. Gamma delta+ T cells involvement in viral immune control of chronic human herpesvirus 8 infection. J. Immunol. Baltim. Md 1950 2008, 180, 3417-3425.

121. Hammerich, L.; Tacke, F. Role of gamma-delta T cells in liver inflammation and fibrosis. World J. Gastrointest. Pathophysiol. 2014, 5, 107-113. [CrossRef]

122. Yasukawa, M.; Inatsuki, A.; Yakushijin, Y.; Kobayashi, Y. Human T-cell leukemia virus type I(HTLV-I) infection of T cells bearing T-cell receptor gamma delta: Effects of HTLV-I infection on cytotoxicity. Int. J. Cancer 1992, 50, 431-437. [CrossRef]

123. Gao, Y.; Williams, A.P. Role of Innate T Cells in Anti-Bacterial Immunity. Front. Immunol. 2015, 6, 302. [CrossRef]

124. Ito, M.; Kojiro, N.; Ikeda, T.; Ito, T.; Funada, J.; Kokubu, T. Increased proportions of peripheral blood gamma delta T cells in patients with pulmonary tuberculosis. Chest 1992, 102, 195-197. [CrossRef]

125. Balbi, B.; Valle, M.T.; Oddera, S.; Giunti, D.; Manca, F.; Rossi, G.A.; Allegra, L. T-lymphocytes with gamma delta $+\mathrm{V}$ delta $2+$ antigen receptors are present in increased proportions in a fraction of patients with tuberculosis or with sarcoidosis. Am. Rev. Respir. Dis. 1993, 148, 1685-1690. [CrossRef] [PubMed]

126. Hara, T.; Mizuno, Y.; Takaki, K.; Takada, H.; Akeda, H.; Aoki, T.; Nagata, M.; Ueda, K.; Matsuzaki, G.; Yoshikai, Y. Predominant activation and expansion of $\mathrm{V}$ gamma 9-bearing gamma delta $\mathrm{T}$ cells in vivo and in vitro in Salmonella infection. J. Clin. Investig. 1992, 90, 204-210. [CrossRef] [PubMed]

127. Ottones, F.; Dornand, J.; Naroeni, A.; Liautard, J.P.; Favero, J. V gamma 9V delta 2 T cells impair intracellular multiplication of Brucella suis in autologous monocytes through soluble factor release and contact-dependent cytotoxic effect. J. Immunol. Baltim. Md 1950 2000, 165, 7133-7139.

128. Kroca, M.; Johansson, A.; Sjöstedt, A.; Tärnvik, A. V gamma 9V delta $2 \mathrm{~T}$ cells in human legionellosis. Clin. Diagn. Lab. Immunol. 2001, 8, 949-954.

129. Jouen-Beades, F.; Paris, E.; Dieulois, C.; Lemeland, J.F.; Barre-Dezelus, V.; Marret, S.; Humbert, G.; Leroy, J.; Tron, F. In vivo and in vitro activation and expansion of gammadelta T cells during Listeria monocytogenes infection in humans. Infect. Immun. 1997, 65, 4267-4272. [CrossRef]

130. Kroca, M.; Tärnvik, A.; Sjöstedt, A. The proportion of circulating gammadelta T cells increases after the first week of onset of tularaemia and remains elevated for more than a year. Clin. Exp. Immunol. 2000, 120, 280-284. [CrossRef] 
131. Caldwell, C.W.; Everett, E.D.; McDonald, G.; Yesus, Y.W.; Roland, W.E. Lymphocytosis of gamma/delta T cells in human ehrlichiosis. Am. J. Clin. Pathol. 1995, 103, 761-766. [CrossRef]

132. Roussilhon, C.; Agrapart, M.; Ballet, J.J.; Bensussan, A. T lymphocytes bearing the gamma delta T cell receptor in patients with acute Plasmodium falciparum malaria. J. Infect. Dis. 1990, 162, 283-285. [CrossRef]

133. Perera, M.K.; Carter, R.; Goonewardene, R.; Mendis, K.N. Transient increase in circulating gamma/delta T cells during Plasmodium vivax malarial paroxysms. J. Exp. Med. 1994, 179, 311-315. [CrossRef]

134. Schwartz, E.; Shapiro, R.; Shina, S.; Bank, I. Delayed expansion of V delta 2+ and V delta 1+ gamma delta T cells after acute Plasmodium falciparum and Plasmodium vivax malaria. J. Allergy Clin. Immunol. 1996, 97, 1387-1392. [CrossRef]

135. Scalise, F.; Gerli, R.; Castellucci, G.; Spinozzi, F.; Fabietti, G.M.; Crupi, S.; Sensi, L.; Britta, R.; Vaccaro, R.; Bertotto, A. Lymphocytes bearing the gamma delta T-cell receptor in acute toxoplasmosis. Immunology 1992, 76, 668-670. [PubMed]

136. De Paoli, P.; Basaglia, G.; Gennari, D.; Crovatto, M.; Modolo, M.L.; Santini, G. Phenotypic profile and functional characteristics of human gamma and delta T cells during acute toxoplasmosis. J. Clin. Microbiol. 1992, 30, 729-731. [CrossRef] [PubMed]

137. Russo, D.M.; Armitage, R.J.; Barral-Netto, M.; Barral, A.; Grabstein, K.H.; Reed, S.G. Antigen-reactive gamma delta T cells in human leishmaniasis. J. Immunol. 1993, 151, 3712-3718. [PubMed]

138. Kabelitz, D.; Wesch, D.; He, W. Perspectives of gammadelta T cells in tumor immunology. Cancer Res. 2007, 67, 5-8. [CrossRef] [PubMed]

139. Uchida, R.; Ashihara, E.; Sato, K.; Kimura, S.; Kuroda, J.; Takeuchi, M.; Kawata, E.; Taniguchi, K.; Okamoto, M.; Shimura, K.; et al. Gamma delta T cells kill myeloma cells by sensing mevalonate metabolites and ICAM-1 molecules on cell surface. Biochem. Biophys. Res. Commun. 2007, 354, 613-618. [CrossRef]

140. Maeurer, M.J.; Martin, D.; Walter, W.; Liu, K.; Zitvogel, L.; Halusczcak, K.; Rabinowich, H.; Duquesnoy, R.; Storkus, W.; Lotze, M.T. Human intestinal Vdelta1+ lymphocytes recognize tumor cells of epithelial origin. J. Exp. Med. 1996, 183, 1681-1696. [CrossRef]

141. Knight, A.; Mackinnon, S.; Lowdell, M.W. Human Vdelta1 gamma-delta T cells exert potent specific cytotoxicity against primary multiple myeloma cells. Cytotherapy 2012, 14, 1110-1118. [CrossRef]

142. Lança, T.; Correia, D.V.; Moita, C.F.; Raquel, H.; Neves-Costa, A.; Ferreira, C.; Ramalho, J.S.; Barata, J.T.; Moita, L.F.; Gomes, A.Q.; et al. The MHC class Ib protein ULBP1 is a nonredundant determinant of leukemia/lymphoma susceptibility to gammadelta T-cell cytotoxicity. Blood 2010, 115, 2407-2411. [CrossRef]

143. McClanahan, J.; Fukushima, P.I.; Stetler-Stevenson, M. Increased peripheral blood gamma delta T-cells in patients with lymphoid neoplasia: A diagnostic dilemma in flow cytometry. Cytometry 1999, 38, 280-285. [CrossRef]

144. Wang, L.; Xu, M.; Wang, C.; Zhu, L.; Hu, J.; Chen, S.; Wu, X.; Li, B.; Li, Y. The feature of distribution and clonality of TCR $\gamma / \delta$ subfamilies T cells in patients with B-cell non-Hodgkin lymphoma. J. Immunol. Res. 2014, 2014, 241246. [CrossRef]

145. Ishida, M.; Iwai, M.; Yoshida, K.; Kagotani, A.; Okabe, H. Primary cutaneous B-cell lymphoma with abundant reactive gamma/delta T-cells within the skin lesion and peripheral blood. Int. J. Clin. Exp. Pathol. 2014, 7, 1193-1199. [PubMed]

146. Lee, A.-J.; Kim, S.-G.; Chae, H.-D.; Lee, G.H.; Shin, I.-H. $\gamma \delta$ T cells are increased in the peripheral blood of patients with gastric cancer. Clin. Chim. Acta Int. J. Clin. Chem. 2012, 413, 1495-1499. [CrossRef] [PubMed]

147. Bas, M.; Bier, H.; Schirlau, K.; Friebe-Hoffmann, U.; Scheckenbach, K.; Balz, V.; Whiteside, T.L.; Hoffmann, T.K. Gamma-delta T-cells in patients with squamous cell carcinoma of the head and neck. Oral Oncol. 2006, 42, 691-697. [CrossRef] [PubMed]

148. Kobayashi, H.; Tanaka, Y.; Yagi, J.; Toma, H.; Uchiyama, T. Gamma/delta T cells provide innate immunity against renal cell carcinoma. Cancer Immunol. Immunother. CII 2001, 50, 115-124. [CrossRef] [PubMed]

149. Gaafar, A.; Aljurf, M.D.; Al-Sulaiman, A.; Iqniebi, A.; Manogaran, P.S.; Mohamed, G.E.H.; Al-Sayed, A.; Alzahrani, H.; Alsharif, F.; Mohareb, F.; et al. Defective gammadelta T-cell function and granzyme B gene polymorphism in a cohort of newly diagnosed breast cancer patients. Exp. Hematol. 2009, 37, 838-848. [CrossRef] [PubMed]

150. Wistuba-Hamprecht, K.; Di Benedetto, S.; Schilling, B.; Sucker, A.; Schadendorf, D.; Garbe, C.; Weide, B.; Pawelec, G. Phenotypic characterization and prognostic impact of circulating $\gamma \delta$ and $\alpha \beta$ T-cells in metastatic malignant melanoma. Int. J. Cancer 2016, 138, 698-704. [CrossRef] 
151. Lafont, V.; Sanchez, F.; Laprevotte, E.; Michaud, H.-A.; Gros, L.; Eliaou, J.-F.; Bonnefoy, N. Plasticity of $\gamma \delta \mathrm{T}$ Cells: Impact on the Anti-Tumor Response. Front. Immunol. 2014, 5, 622. [CrossRef]

152. Wesch, D.; Peters, C.; Siegers, G.M. Human gamma delta T regulatory cells in cancer: Fact or fiction? Front. Immunol. 2014, 5, 598. [CrossRef]

153. Peng, G.; Wang, H.Y.; Peng, W.; Kiniwa, Y.; Seo, K.H.; Wang, R.-F. Tumor-infiltrating gammadelta T cells suppress $\mathrm{T}$ and dendritic cell function via mechanisms controlled by a unique toll-like receptor signaling pathway. Immunity 2007, 27, 334-348. [CrossRef]

154. Ma, C.; Zhang, Q.; Ye, J.; Wang, F.; Zhang, Y.; Wevers, E.; Schwartz, T.; Hunborg, P.; Varvares, M.A.; Hoft, D.F.; et al. Tumor-infiltrating $\gamma \delta \mathrm{T}$ lymphocytes predict clinical outcome in human breast cancer. J. Immunol. 2012, 189, 5029-5036. [CrossRef]

155. Ye, J.; Ma, C.; Wang, F.; Hsueh, E.C.; Toth, K.; Huang, Y.; Mo, W.; Liu, S.; Han, B.; Varvares, M.A.; et al. Specific recruitment of $\gamma \delta$ regulatory $\mathrm{T}$ cells in human breast cancer. Cancer Res. 2013, 73, 6137-6148. [CrossRef] [PubMed]

156. Ye, J.; Ma, C.; Hsueh, E.C.; Eickhoff, C.S.; Zhang, Y.; Varvares, M.A.; Hoft, D.F.; Peng, G. Tumor-derived $\gamma \delta$ regulatory $\mathrm{T}$ cells suppress innate and adaptive immunity through the induction of immunosenescence. J. Immunol. 2013, 190, 2403-2414. [CrossRef] [PubMed]

157. Bukowski, J.F.; Morita, C.T.; Brenner, M.B. Human gamma delta T cells recognize alkylamines derived from microbes, edible plants, and tea: Implications for innate immunity. Immunity 1999, 11, 57-65. [CrossRef]

158. Caccamo, N.; Meraviglia, S.; Cicero, G.; Gulotta, G.; Moschella, F.; Cordova, A.; Gulotta, E.; Salerno, A.; Dieli, F. Aminobisphosphonates as new weapons for gammadelta T Cell-based immunotherapy of cancer. Curr. Med. Chem. 2008, 15, 1147-1153. [CrossRef]

159. Wang, H.; Sarikonda, G.; Puan, K.-J.; Tanaka, Y.; Feng, J.; Giner, J.-L.; Cao, R.; Mönkkönen, J.; Oldfield, E.; Morita, C.T. Indirect stimulation of human $\mathrm{V} \gamma 2 \mathrm{~V} \delta 2 \mathrm{~T}$ cells through alterations in isoprenoid metabolism. J. Immunol. 2011, 187, 5099-5113. [CrossRef]

160. Thompson, K.; Rogers, M.J. Statins prevent bisphosphonate-induced gamma, delta-T-cell proliferation and activation in vitro. J. Bone Miner. Res. Off. J. Am. Soc. Bone Miner. Res. 2004, 19, 278-288. [CrossRef]

161. Lü, H.-Z.; Li, B.-Q. Effect of HMG-CoA reductase inhibitors on activation of human gammadeltaT cells induced by Mycobacterium tuberculosis antigens. Immunopharmacol. Immunotoxicol. 2009, 31, 485-491. [CrossRef]

162. Vantourout, P.; Hayday, A. Six-of-the-best: Unique contributions of $\gamma \delta \mathrm{T}$ cells to immunology. Nat. Rev. Immunol. 2013, 13, 88-100. [CrossRef]

163. Caccamo, N.; Meraviglia, S.; Ferlazzo, V.; Angelini, D.; Borsellino, G.; Poccia, F.; Battistini, L.; Dieli, F.; Salerno, A. Differential requirements for antigen or homeostatic cytokines for proliferation and differentiation of human Vgamma9Vdelta2 naive, memory and effector T cell subsets. Eur. J. Immunol. 2005, 35, 1764-1772. [CrossRef]

164. Toia, F.; Buccheri, S.; Anfosso, A.; Moschella, F.; Dieli, F.; Meraviglia, S.; Cordova, A. Skewed Differentiation of Circulating V $\gamma 9$ V82 T Lymphocytes in Melanoma and Impact on Clinical Outcome. PLoS ONE 2016, 11, e0149570. [CrossRef]

165. Jouen-Beades, F.; Gilbert, D.; Ramzaoui, S.; Borsa-Lebas, F.; Humbert, G.; Tron, F. Similarity of expression of activation markers and CD28 on gamma delta and alpha beta-receptor T cells in HIV infection. Clin. Immunol. Immunopathol. 1996, 79, 189-193. [CrossRef]

166. Ueda-Hayakawa, I.; Hasegawa, M.; Hamaguchi, Y.; Takehara, K.; Fujimoto, M. Circulating $\gamma / \delta$ T cells in systemic sclerosis exhibit activated phenotype and enhance gene expression of proalpha2(I) collagen of fibroblasts. J. Dermatol. Sci. 2013, 69, 54-60. [CrossRef]

167. Brandes, M.; Willimann, K.; Moser, B. Professional antigen-presentation function by human gammadelta T Cells. Science 2005, 309, 264-268. [CrossRef]

168. Moser, B.; Eberl, M. $\gamma \delta$ T-APCs: A novel tool for immunotherapy? Cell. Mol. Life Sci. CMLS 2011, 68, 2443-2452. [CrossRef] [PubMed]

169. Ismaili, J.; Olislagers, V.; Poupot, R.; Fournié, J.-J.; Goldman, M. Human gamma delta T cells induce dendritic cell maturation. Clin. Immunol. Orlando Fla 2002, 103, 296-302. [CrossRef] [PubMed]

170. Wesch, D.; Glatzel, A.; Kabelitz, D. Differentiation of resting human peripheral blood gamma delta T cells toward Th1- or Th2-phenotype. Cell. Immunol. 2001, 212, 110-117. [CrossRef] 
171. Mangan, B.A.; Dunne, M.R.; O’Reilly, V.P.; Dunne, P.J.; Exley, M.A.; O’Shea, D.; Scotet, E.; Hogan, A.E.; Doherty, D.G. Cutting edge: CD1d restriction and Th1/Th2/Th17 cytokine secretion by human V $83 \mathrm{~T}$ cells. J. Immunol. Baltim. Md 1950 2013, 191, 30-34. [CrossRef]

172. Wesch, D.; Kabelitz, D. Differential expression of natural killer receptors on Vdelta1 gammadelta T cells in HIV-1-infected individuals. J. Acquir. Immune Defic. Syndr. 1999 2003, 33, 420-425. [CrossRef] [PubMed]

173. D'Ombrain, M.C.; Hansen, D.S.; Simpson, K.M.; Schofield, L. gammadelta-T cells expressing NK receptors predominate over NK cells and conventional T cells in the innate IFN-gamma response to Plasmodium falciparum malaria. Eur. J. Immunol. 2007, 37, 1864-1873. [CrossRef] [PubMed]

174. Alexander, A.A.Z.; Maniar, A.; Cummings, J.-S.; Hebbeler, A.M.; Schulze, D.H.; Gastman, B.R.; Pauza, C.D.; Strome, S.E.; Chapoval, A.I. Isopentenyl pyrophosphate-activated CD56+ \{gamma\}\{delta\} T lymphocytes display potent antitumor activity toward human squamous cell carcinoma. Clin. Cancer Res. 2008, 14, 4232-4240. [CrossRef]

175. Moens, E.; Brouwer, M.; Dimova, T.; Goldman, M.; Willems, F.; Vermijlen, D. IL-23R and TCR signaling drives the generation of neonatal Vgamma9Vdelta2 $\mathrm{T}$ cells expressing high levels of cytotoxic mediators and producing IFN-gamma and IL-17. J. Leukoc. Biol. 2011, 89, 743-752. [CrossRef] [PubMed]

176. Caccamo, N.; Battistini, L.; Bonneville, M.; Poccia, F.; Fournié, J.J.; Meraviglia, S.; Borsellino, G.; Kroczek, R.A.; La Mendola, C.; Scotet, E.; et al. CXCR5 identifies a subset of Vgamma9Vdelta2 T cells which secrete IL-4 and IL-10 and help B cells for antibody production. J. Immunol. 2006, 177, 5290-5295. [CrossRef] [PubMed]

177. Vinuesa, C.G.; Tangye, S.G.; Moser, B.; Mackay, C.R. Follicular B helper T cells in antibody responses and autoimmunity. Nat. Rev. Immunol. 2005, 5, 853-865. [CrossRef]

178. Kühl, A.A.; Pawlowski, N.N.; Grollich, K.; Blessenohl, M.; Westermann, J.; Zeitz, M.; Loddenkemper, C.; Hoffmann, J.C. Human peripheral gammadelta T cells possess regulatory potential. Immunology 2009, 128, 580-588. [CrossRef]

179. Peters, C.; Oberg, H.-H.; Kabelitz, D.; Wesch, D. Phenotype and regulation of immunosuppressive

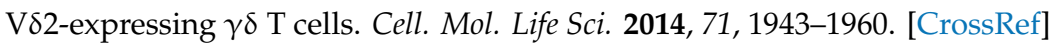

180. Call, M.E.; Wucherpfennig, K.W. Molecular mechanisms for the assembly of the T cell receptor-CD3 complex. Mol. Immunol. 2004, 40, 1295-1305. [CrossRef]

181. Lambert, C.; Genin, C. CD3 bright lymphocyte population reveal gammadelta T cells. Cytometry B Clin. Cytom. 2004, 61, 45-53. [CrossRef]

182. El Hentati, F.-Z.; Gruy, F.; Iobagiu, C.; Lambert, C. Variability of CD3 membrane expression and T cell activation capacity. Cytometry B Clin. Cytom. 2010, 78, 105-114. [CrossRef] [PubMed]

183. Baseggio, L.; Berger, F.; Monneret, G.; Magaud, J.-P.; Salles, G.; Felman, P. The expression of TCR-gamma delta/CD3 complex in neoplastic gamma delta T-cell. Haematologica 2006, 91, 1717-1719.

184. Wistuba-Hamprecht, K.; Pawelec, G.; Derhovanessian, E. OMIP-020: Phenotypic characterization of human $\gamma \delta$ T-cells by multicolor flow cytometry. Cytom. Part J. Int. Soc. Anal. Cytol. 2014, 85, 522-524. [CrossRef]

185. Wistuba-Hamprecht, K.; Pawelec, G. Characterization of $\gamma \delta$ T-cells via flow cytometry. Age Dordr. Neth. 2015, 37, 123. [CrossRef]

186. Raman, C. CD5, an important regulator of lymphocyte selection and immune tolerance. Immunol. Res. 2002, 26, 255-263. [CrossRef]

187. Dalloul, A. CD5: A safeguard against autoimmunity and a shield for cancer cells. Autoimmun. Rev. 2009, 8, 349-353. [CrossRef] [PubMed]

188. Spour, E.F.; Leemhuis, T.; Jenski, L.; Redmond, R.; Fillak, D.; Jansen, J. Characterization of normal human CD3+ CD5- and gamma delta T cell receptor positive T lymphocytes. Clin. Exp. Immunol. 1990, 80, 114-121. [PubMed]

189. De Rosa, S.C.; Mitra, D.K.; Watanabe, N.; Herzenberg, L.A.; Herzenberg, L.A.; Roederer, M. Vdelta1 and Vdelta2 gammadelta $\mathrm{T}$ cells express distinct surface markers and might be developmentally distinct lineages. J. Leukoc. Biol. 2001, 70, 518-526.

190. Tabbekh, M.; Mokrani-Hammani, M.; Bismuth, G.; Mami-Chouaib, F. T-cell modulatory properties of CD5 and its role in antitumor immune responses. Oncoimmunology 2013, 2, e22841.

191. Ahmad, E.; Kingma, D.W.; Jaffe, E.S.; Schrager, J.A.; Janik, J.; Wilson, W.; Stetler-Stevenson, M. Flow cytometric immunophenotypic profiles of mature gamma delta T-cell malignancies involving peripheral blood and bone marrow. Cytometry B Clin. Cytom. 2005, 67, 6-12. [CrossRef] 
192. Rodríguez-Pinilla, S.M.; Ortiz-Romero, P.L.; Monsalvez, V.; Tomás, I.E.; Almagro, M.; Sevilla, A.; Camacho, G.; Longo, M.I.; Pulpillo, Á.; Diaz-Pérez, J.A.; et al. TCR- $\gamma$ expression in primary cutaneous T-cell lymphomas. Am. J. Surg. Pathol. 2013, 37, 375-384. [CrossRef]

193. Wilson, A.L.; Swerdlow, S.H.; Przybylski, G.K.; Surti, U.; Choi, J.K.; Campo, E.; Trucco, M.M.; Van Oss, S.B.; Felgar, R.E. Intestinal $\gamma \delta \mathrm{T}$-cell lymphomas are most frequently of type II enteropathy-associated T-cell type. Hum. Pathol. 2013, 44, 1131-1145. [CrossRef]

194. Bucy, R.P.; Chen, C.L.; Cooper, M.D. Tissue localization and CD8 accessory molecule expression of T gamma delta cells in humans. J. Immunol. 1989, 142, 3045-3049.

195. Kadivar, M.; Petersson, J.; Svensson, L.; Marsal, J. CD $8 \alpha \beta+\gamma \delta$ T Cells: A Novel T Cell Subset with a Potential Role in Inflammatory Bowel Disease. J. Immunol. 2016, 197, 4584-4592. [CrossRef] [PubMed]

196. Chang, H.-C.; Tan, K.; Hsu, Y.-M. CD8alphabeta has two distinct binding modes of interaction with peptide-major histocompatibility complex class I. J. Biol. Chem. 2006, 281, 28090-28096. [CrossRef] [PubMed]

197. Gibbings, D.; Befus, A.D. CD4 and CD8: An inside-out coreceptor model for innate immune cells. J. Leukoc. Biol. 2009, 86, 251-259. [CrossRef]

198. Garcia, K.C.; Scott, C.A.; Brunmark, A.; Carbone, F.R.; Peterson, P.A.; Wilson, I.A.; Teyton, L. CD8 enhances formation of stable T-cell receptor/MHC class I molecule complexes. Nature 1996, 384, 577-581. [CrossRef] [PubMed]

199. Sun, J.; Kavathas, P.B. Comparison of the roles of CD8 alpha alpha and CD8 alpha beta in interaction with MHC class I. J. Immunol. Baltim. Md 1950 1997, 159, 6077-6082.

200. Arcaro, A.; Grégoire, C.; Bakker, T.R.; Baldi, L.; Jordan, M.; Goffin, L.; Boucheron, N.; Wurm, F.; van der Merwe, P.A.; Malissen, B.; et al. CD8beta endows CD8 with efficient coreceptor function by coupling T cell receptor/CD3 to raft-associated CD8/p56(lck) complexes. J. Exp. Med. 2001, 194, 1485-1495. [CrossRef]

201. Pang, D.J.; Hayday, A.C.; Bijlmakers, M.-J. CD8 Raft localization is induced by its assembly into CD8alpha beta heterodimers, Not CD8alpha alpha homodimers. J. Biol. Chem. 2007, 282, 13884-13894. [CrossRef]

202. Gao, G.F.; Willcox, B.E.; Wyer, J.R.; Boulter, J.M.; O'Callaghan, C.A.; Maenaka, K.; Stuart, D.I.; Jones, E.Y.; Van Der Merwe, P.A.; Bell, J.I.; et al. Classical and nonclassical class I major histocompatibility complex molecules exhibit subtle conformational differences that affect binding to CD8alphaalpha. J. Biol. Chem. 2000, 275, 15232-15238. [CrossRef]

203. Chumbley, G.; King, A.; Robertson, K.; Holmes, N.; Loke, Y.W. Resistance of HLA-G and HLA-A2 transfectants to lysis by decidual NK cells. Cell. Immunol. 1994, 155, 312-322. [CrossRef]

204. Braud, V.M.; Allan, D.S.; O'Callaghan, C.A.; Söderström, K.; D'Andrea, A.; Ogg, G.S.; Lazetic, S.; Young, N.T.; Bell, J.I.; Phillips, J.H.; et al. HLA-E binds to natural killer cell receptors CD94/NKG2A, B and C. Nature 1998, 391, 795-799. [CrossRef]

205. Cheroutre, H.; Lambolez, F. Doubting the TCR coreceptor function of CD8alphaalpha. Immunity 2008, 28, 149-159. [CrossRef] [PubMed]

206. Ward, S.G. CD28: A signalling perspective. Biochem. J. 1996, 318 Pt 2, 361-377. [CrossRef]

207. Boćko, D.; Kosmaczewska, A.; Ciszak, L.; Teodorowska, R.; Frydecka, I. CD28 costimulatory moleculeexpression, structure and function. Arch. Immunol. Ther. Exp. (Warsz.) 2002, 50, 169-177. [PubMed]

208. Ribot, J.C.; Debarros, A.; Mancio-Silva, L.; Pamplona, A.; Silva-Santos, B. B7-CD28 costimulatory signals control the survival and proliferation of murine and human $\gamma \delta$ T cells via IL-2 production. J. Immunol. 2012, 189, 1202-1208. [CrossRef] [PubMed]

209. Ribot, J.C.; Silva-Santos, B. Differentiation and activation of $\gamma \delta$ T Lymphocytes: Focus on CD27 and CD28 costimulatory receptors. Adv. Exp. Med. Biol. 2013, 785, 95-105.

210. Ribeiro, S.T.; Ribot, J.C.; Silva-Santos, B. Five Layers of Receptor Signaling in $\gamma \delta$ T-Cell Differentiation and Activation. Front. Immunol. 2015, 6, 15. [CrossRef]

211. Strioga, M.; Pasukoniene, V.; Characiejus, D. CD8+ CD28- and CD8+ CD57+ T cells and their role in health and disease. Immunology 2011, 134, 17-32. [CrossRef]

212. Maly, K.; Schirmer, M. The story of CD4+ CD28- T cells revisited: Solved or still ongoing? J. Immunol. Res. 2015, 2015, 348746.

213. Mou, D.; Espinosa, J.; Lo, D.J.; Kirk, A.D. CD28 negative T cells: Is their loss our gain? Am. J. Transplant. 2014, 14, 2460-2466. [CrossRef] 
214. Chidrawar, S.; Khan, N.; Wei, W.; McLarnon, A.; Smith, N.; Nayak, L.; Moss, P. Cytomegalovirus-seropositivity has a profound influence on the magnitude of major lymphoid subsets within healthy individuals. Clin. Exp. Immunol. 2009, 155, 423-432. [CrossRef]

215. Tan, C.T.Y.; Wistuba-Hamprecht, K.; Xu, W.; Nyunt, M.S.Z.; Vasudev, A.; Lee, B.T.K.; Pawelec, G.; Puan, K.J.; Rotzschke, O.; $\mathrm{Ng}$, T.P.; et al. $\mathrm{V} \delta 2+$ and $\alpha / \beta \mathrm{T}$ cells show divergent trajectories during human aging. Oncotarget 2016, 7, 44906-44918. [PubMed]

216. Trinchieri, G.; Valiante, N. Receptors for the Fc fragment of IgG on natural killer cells. Nat. Immun. 1993, 12, 218-234.

217. Lafont, V.; Liautard, J.; Liautard, J.P.; Favero, J. Production of TNF-alpha by human V gamma $9 \mathrm{~V}$ delta $2 \mathrm{~T}$ cells via engagement of Fc gamma RIIIA, the low affinity type 3 receptor for the Fc portion of IgG, expressed upon TCR activation by nonpeptidic antigen. J. Immunol. Baltim. Md 1950 2001, 166, 7190-7199.

218. Angelini, D.F.; Borsellino, G.; Poupot, M.; Diamantini, A.; Poupot, R.; Bernardi, G.; Poccia, F.; Fournié, J.-J.; Battistini, L. FcgammaRIII discriminates between 2 subsets of Vgamma9Vdelta2 effector cells with different responses and activation pathways. Blood 2004, 104, 1801-1807. [CrossRef] [PubMed]

219. Couzi, L.; Pitard, V.; Sicard, X.; Garrigue, I.; Hawchar, O.; Merville, P.; Moreau, J.-F.; Déchanet-Merville, J. Antibody-dependent anti-cytomegalovirus activity of human $\gamma \delta$ T cells expressing CD16 (Fc $\gamma$ RIIIa). Blood 2012, 119, 1418-1427. [CrossRef]

220. Urban, E.M.; Li, H.; Armstrong, C.; Focaccetti, C.; Cairo, C.; Pauza, C.D. Control of CD56 expression and tumor cell cytotoxicity in human Vgamma2Vdelta2 T cells. BMC Immunol. 2009, 10, 50. [CrossRef]

221. Urban, E.M.; Chapoval, A.I.; Pauza, C.D. Repertoire development and the control of cytotoxic/effector function in human gammadelta T cells. Clin. Dev. Immunol. 2010, 2010, 732893. [CrossRef]

(C) 2020 by the authors. Licensee MDPI, Basel, Switzerland. This article is an open access article distributed under the terms and conditions of the Creative Commons Attribution (CC BY) license (http://creativecommons.org/licenses/by/4.0/). 